\title{
ANAIS DO III CONGRESSO PIAUIENSE MULTIDISCIPLINAR DE ONCOLOGIA E I CONGRESSO MÉDICO DE ONCOLOGIA DO PIAUÍ - ONCOPIAUÍ 2019
}

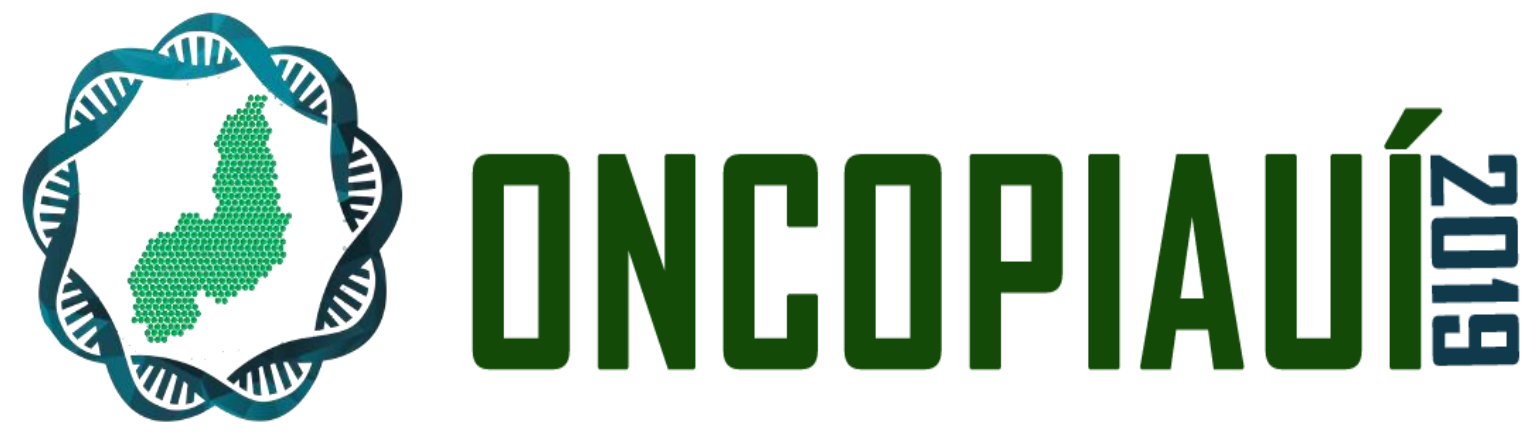

APOIO:

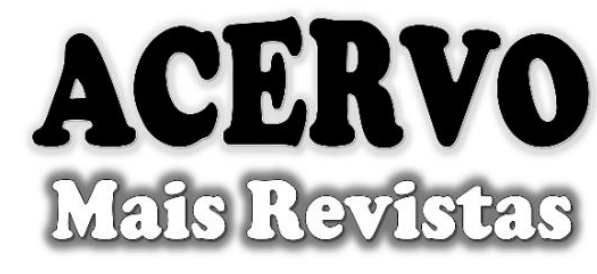

As publicações mais rápidas do país!

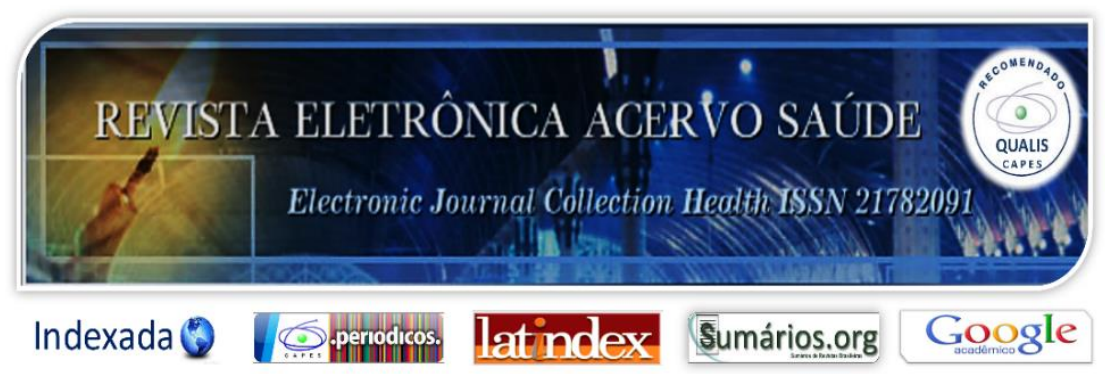




\section{COMISSÃO ORGANIZADORA DO III CONGRESSO PIAUIENSE MULTIDISCIPLINAR DE ONCOLOGIA E I CONGRESSO MÉDICO DE ONCOLOGIA DO PIAUÍ - ONCOPIAUÍ 2019}

\footnotetext{
Mariel Osório Silva (Presidente)

$>$ Danilo Rafael da Silva Fontinele

$>$ Emanuelle Pessoa Costa

$>$ Rebecca Lemos da Silva Lages

$>$ Francisco Dionne da Silva Carvalho

$>$ Lorena Thaís Fonseca Nunes

$>$ Mariana de Andrade Sousa

$>$ Mariana Fonseca Mendes Soares

$>$ Pedro Henrique Moraes Mendes

$>$ Allan Dellon da Silva

> Maria Gabriela Cavalcante Leal

> Verônica Lorranny Lima Araújo

$>$ Gabriel Ribeiro Costa

$>$ Marcos Vinicius de Souza

$>$ Thalia Pires do Nascimento

> Mayra Aparecida Santos Araújo

> Maria Clara Leal Cortez

$>$ Germano Soares Martins

$>$ Jocerone Emerson Nogueira Oliveira

$>$ Maynara de Carvalho Braga

> Leonara Maria Alves Coelho

$>$ Flanynmagna Costa Nunes Granja

$>$ Artur Moraes de Sousa Ribeiro

$>$ Carlos Eduardo Rocha Araújo

$>$ Isabelle Santos Palmeira

$>$ Ellem Silva Pestana

$>$ Clara Layse Freitas Florêncio

$>$ Matheus Abraão Cerqueira Guerra

$>$ Carlos Henrique da Silva Franco
} 


\section{APRESENTAÇÃO}

O ONCOPIAUÍ 2019, III Congresso Piauiense Multidisciplinar De Oncologia e I Congresso Médico De Oncologia Do Piauí, foi realizado em Teresina - Piauí, no auditório Fernando Bezerra, na Federação das Indústrias do Estado do Piauí (FIEPI).

O congresso foi organizado pela Liga Acadêmica de Oncologia do Piauí (LAO) e pelo restante da comissão organizadora, cujos membros foram selecionados pelos integrantes da Liga através de currículo e entrevista.

Esse evento traz anualmente nomes renomados das áreas da Medicina, Fisioterapia, Enfermagem, Psicologia, Educação Física, Nutrição e Serviço Social no que diz respeito ao tratamento de pacientes oncológicos. Dessa forma, além de trazer grandes debates, inovações e aprendizados na área da medicina oncológica, o congresso entende a multidisciplinaridade necessária no tratamento do câncer e a ressalta. 


\section{SUMÁRIO}

SERVIÇO SOCIAL E ONCOLOGIA: CONTRIBUIÇÕES DA/O ASSISTENTE SOCIAL NO ATENDIMENTO

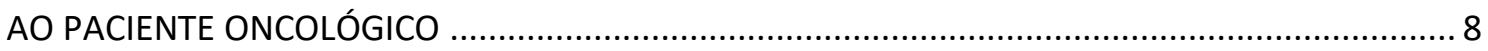

O BENEFÍCIO DA FISIOTERAPIA NAS COMPLICAÇÕES LOCAIS EM MASTECTOMIZADA PRÉ RADIOTERAPIA.

TAXA DE MORTALIDADE POR NEOPLASIAS MALIGNAS ÓSSEAS E DA CARTILAGEM ARTICULAR NO MUNICÍPIO DE TERESINA-PI: ESTUDO EPIDEMIOLÓGICO.

ESTUDO EPIDEMIOLÓGICO DE NEOPLASIAS MALIGNAS DE PELE NA MACRORREGIÃO

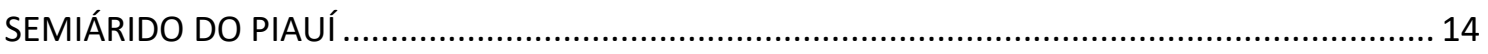

COMPOSTOS BIOATIVOS COMO ATIVADORES DA VIA NRF2 NO CÂNCER INTESTINAL............... 16

EFEITOS DO USO DE TERAPIA NUTRICIONAL IMUNOMODULADORA NO PÓS-OPERATÓRIO DE PACIENTES PORTADORES DE CÂNCER NO TRATO GASTROINTESTINAL ................................... 18

CUIDADOS PALIATIVOS A PACIENTES COM FERIDA NEOPLÁSICA: UM CUIDADO DE ENFERMAGEM 20

AVALIAÇÃO DA CAPACIDADE FUNCIONAL DE PACIENTES ONCOLÓGICOS EM UM HOSPITAL PÚBLICO DE TERESINA-PI ...

O CUIDADO VOLTADO AOS PROFISSIONAIS DE ENFERMAGEM ASSISTENTES AOS PACIENTES ONCOLÓGICOS: REVISÃO INTEGRATIVA

TERAPIA DE REPOSIÇÃO HORMONAL NO CLIMATÉRIO COMO FATOR DE RISCO PARA O CÂNCER DE MAMA

IMPORTÂNCIA DO PERFIL SOCIODEMOGRÁFICO, CLÍNICO E TERAPÊUTICO DE PACIENTES COM FERIDAS ONCOLÓGICAS

EFEITO TERAPÊUTICO DA Curcuma longa L. PARA O CÂNCER: UMA REVISÃO DE LITERATURA 30 ANÁLISE DA EFICIÊNCIA DO RASTREAMENTO PARA CÂNCER DE COLO DE ÚTERO EM PARNAÍBA ENTRE OS ANOS DE 2015 E 2018

A ESPIRITUALIDADE COMO FATOR PROTETIVO/CURATIVO SOBRE O CÂNCER: UM ENSAIO LITERÁRIO .34

RELATO DE CASO DE UM PACIENTE ACOMETIDO POR LEUCEMIA LINFÓIDE AGUDA: DO DIAGNÓSTICO AO TRATAMENTO... 36

MUSICOTERAPIA NA MELHORIA DA QUALIDADE DE VIDA PARA PACIENTES ONCOLÓGICOS: UMA REVISÃO DE LITERATURA.

A IMPORTÂNCIA DOS SUBTIPOS MOLECULARES NO DIAGNÓSTICO DO CÂNCER DE MAMA: UMA REVISÃO DE LITERATURA

INVESTIGAÇÃO DO EFEITO IMUNOMODULADOR DA L- CITRULINA NA TERAPIA ONCOLÓGICA: UMA REVISÃO DE LITERATURA

INFLUÊNCIA DO SELÊNIO NA REGULAÇÃO GÊNICA E TERAPIA ONCOLÓGICA: UMA REVISÃO DE LITERATURA. 
USO DE [10]-GINGEROL PARA O TRATAMENTO COMPLEMENTAR DE CÂNCER DE MAMA METASTÁTICO TRIPLO NEGATIVO (TNBC): UMA REVISÃO DE LITERATURA ....

INFLUÊNCIA DA MICROBIOTA INTESTINAL PARA O TRATAMENTO DO CÂNCER: UMA REVISÃO DE LITERATURA

PERFIL EPIDEMIOLÓGICO DO CÂNCER INFANTO-JUVENIL NO ESTADO DO PIAUÍ........................ 49

PROMOÇÃO A SAÚDE DE PACIENTES ONCOLOGICOS: RELATO DE EXPERIÊNCIA ......................... 51

APRESENTAÇÃO ATÍPICA DE CARCINOMA EPIDERMOIDE ESOFÁGICO DE BAIXO GRAU..............52

EXPOSIÇÃO A AGROTÓXICOS E OS RISCOS DE DESENVOLVIMENTO DO LINFOMA NÃOHODGKIN (LNH)

AVALIAÇÃO DA ATIVIDADE ANTITUMORAL E QUIMIOPROTETORA DO INDOL-3-CARBINOL, UM FITONUTRIENTE ENCONTRADO NO BRÓCOLIS

MEDIDAS NÃO FARMACOLÓGICAS QUE AJUDAM A MINIMIZAR OS ENJOOS CAUSADOS PELO

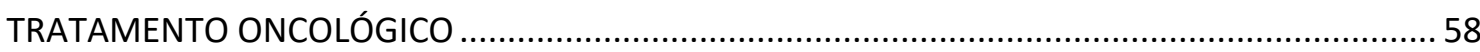

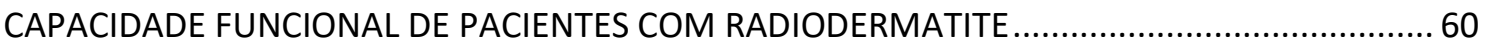

DIAGNÓSTICO E TRATAMENTO PRECOCE DA LEUCEMIA LINFOIDE AGUDA EM PACIENTES ONCOLÓGICOS PEDIÁTRICOS: REVISÃO DE LITERATURA

FATORES ASSOCIADOS À SÍNDROME DE BURNOUT EM PROFISSIONAIS DE ENFERMAGEM

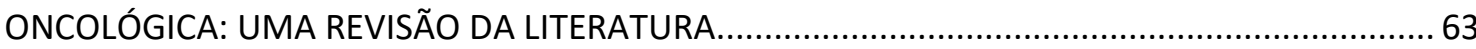

A IMPORTÂNCIA DA ATENÇÃO BÁSICA NO MANEJO DE PACIENTES ONCOLÓGICOS...................65 ÉTICA DA EQUIPE DE ENFERMAGEM NO CUIDADO À PACIENTES COM CÂNCER: UMA REVISÃO INTEGRATIVA.

INTERVENÇÕES NÃO INVASIVAS QUE INFLUENCIAM NA QUALIDADE DE VIDA DE PACIENTES

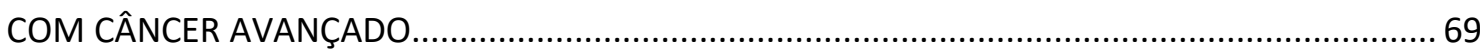

O CONSUMO ALIMENTAR DE PACIENTES ONCOLÓGICOS: UMA REVISÃO DE LITERATURA ....... 71 CURCUMINA: UM POTENTE POLIFENOL DA CÚRCUMA LONGA NA PREVENÇÃO DO CÂNCER GÁSTRICO

SUCCINATO DE ALFA-TOCOFERIL ( $\alpha$-TOS) E SEU PAPEL NA INDUÇÃO À APOPTOSE DE CÉLULAS CANCERÍGENAS

CÂNCER DE CABEÇA E PESCOÇO: POLIMORFISMOS GENÉTICOS E O METABOLISMO DO FOLATO

O USO DO RESVERATROL NO TRATAMENTO DO CÂNCER DE MAMA …...................................... 78

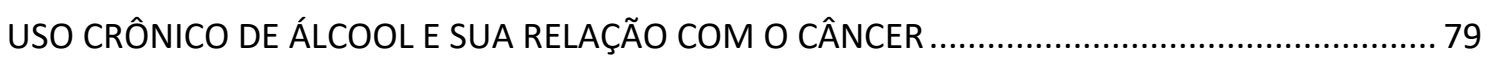

APLICAÇÃO DA BIÓPSIA LÍQUIDA EM ONCOLOGIA: UMA REVISÃO ACERCA DE SUAS

VANTAGENS E DESVANTAGENS NA DETECÇÃO DE BIOMARCADORES TUMORAIS ...................... 81

AUDITORIA DE PROCEDIMENTOS CLÍNICOS EM ONCOLOGIA CONFORME PRODUÇÃO

AMBULATORIAL DO SISTEMA ÚNICO DE SAÚDE EM TERESINA-PI.

MORTALIDADE FEMININA POR NEOPLASIA MALÍGNA DO OVÁRIO NO NORDESTE BRASILEIRO85 MORBIDADE HOSPITALAR POR NEOPLASIAS EM MULHERES PIAUIENSES: ANÁLISE DE UMA DÉCADA 
REFLEXO DAS NEOPLASIAS NO BRASIL: MORTALIDADE E MORBIDADE HOSPITALAR ENTRE 2010-2017

AVALIAÇÃO CITOPATOLÓGICA EM MULHERES NO CLIMATÉRIO EM CENTRO DE REFERÊNCIA DE OEIRAS-PIAUÍ... 90

INFLUÊNCIA DO ÍNDICE E CARGA GLICÊMICA DA DIETA SOBRE O CRESCIMENTO DO TUMOR MALIGNO DE MAMA

EFEITOS DA TERAPIA MEDICAMENTOSA COM TAMOXIFENO NO CÂNCER DE MAMA: UMA

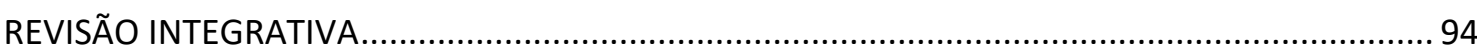

CARCINOMA OCULTO DE MAMA COM METÁSTASE CUTÂNEA: RELATO DE CASO ......................96 INTERRUPÇÃO DO CRESCIMENTO DE CÉLULAS CANCERÍGENEAS MEDIADA PELA VITAMINA D: UMA REVISÃO DE LITERATURA 98 MECANISMO DE AÇÃO DO ISOTIOCIANATO DE ALILA NA PREVENÇÃO DO CÂNCER DE BEXIGA:

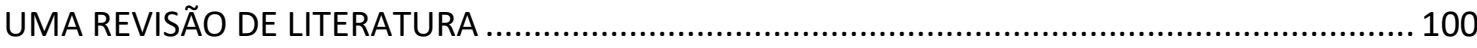

ANÁLISE DE PLANTAS MEDICINAIS COMO POTENTE AGENTE NEOPLÁSICO …......................... 102 $1^{\circ}$ CURSO MULTIPROFISSIONAL EM ONCOLOGIA: EDUCAÇÃO EM SAÚDE PARA CAPACITAÇÃO PROFISSIONAL 
RESUMOS 


\title{
SERVIÇO SOCIAL E ONCOLOGIA: CONTRIBUIÇÕES DA/O ASSISTENTE SOCIAL NO ATENDIMENTO AO PACIENTE ONCOLÓGICO
}

\author{
Edelyny Maria Leoncio Brito ; Ionara Barbosa Soares²; Ana Rosa Alves da Silvaª \\ ${ }^{1}$ Bacharela em Serviço Social pela Faculdade Cearense (FAC), Residente em \\ Cancerologia pela Escola de Saúde Pública do Ceará (ESP/CE); \\ ${ }^{2}$ Bacharela em Serviço Social pela Universidade Estadual do Ceará (UECE), Residente \\ em Cancerologia pela Escola de Saúde Pública do Ceará (ESP/CE). \\ ${ }^{3}$ Docente da Faculdade Metropolitana da Grande Fortaleza (FAMETRO), Bacharela em \\ Serviço Social pela Universidade Estadual do Ceará (UECE), Mestra em Psicologia \\ pela Universidade de Fortaleza (UNIFOR).
}

Autor para correspondência: Edelyny Maria Leoncio Brito / edelynyleoncio@gmail.com / 85996279820

INTRODUÇÃO: O Serviço Social tem como objeto de trabalho a questão social, definida como expressão das desigualdades sociais oriundas do modo de produção capitalista, atuando nas suas múltiplas expressões e formas concretas que assumem na dinâmica societária, podendo intervir no campo das políticas sociais e públicas, objetivando a viabilização dos direitos da população. Na saúde, tomando como base o olhar ampliado para a saúde promulgado na VIII Conferência Nacional de Saúde, de 1986, e instituído na Lei Orgânica de Saúde (LOS), de 1990, em que a saúde é determinada, além do estilo de vida, pelas condições sociais em que os sujeitos estão inseridos, a/o assistente social busca identificar as determinações sociais, econômicas e culturais que interferem no processo saúde/doença. $\mathrm{Na}$ oncologia, a/o profissional lida com as especificidades da doença, atendendo pessoas em sua maioria fragilizadas, com receio da doença e ansiosas por uma escuta, uma orientação, um olhar e um acolhimento mais humanizado. OBJETIVO: Demonstrar as contribuições das/os Assistentes Sociais no atendimento ao paciente oncológico. MÉTODOS: Trata-se de um estudo de natureza qualitativa, tendo sido aplicada a pesquisa bibliográfica, que é aquela baseada na literatura já existente, sendo utilizadas como categorias para análise: atuação do Serviço Social e oncologia. RESULTADOS: O resultado do estudo revelou que a/o Assistente Social contribui no cuidado integral ao paciente oncológico. Podemos destacar, dentre as atividades desenvolvidas por esta/e profissional, as orientações e esclarecimentos acerca dos direitos sociais da pessoa com câncer, a entrevista social para acompanhamento socioeconômico e cultural do paciente e os encaminhamentos às políticas sociais de acordo com a demanda, atribuições e competências da profissão de Serviço Social que auxiliam na identificação de fatores que possam afetar o tratamento da doença e a vida do paciente e de seus familiares. CONCLUSÃO: Concluímos que a inserção dos profissionais do Serviço Social torna-se cada vez mais necessária para o atendimento do paciente com câncer, tendo em vista a determinação social no processo saúde/doença. Sendo assim, orientada/o pelos princípios e direitos constitucionais e infraconstitucionais referentes às políticas sociais e aos direitos da população, a/o assistente social orienta suas 
ações com a finalidade de fortalecer o cuidado integral ao paciente oncológico, colaborando na melhoria da qualidade de vida do usuário.

Palavras-chave: Serviço Social, Câncer, Direitos.

\section{Referências}

IAMAMOTO, Marilda Vilela. O Serviço Social na contemporaneidade: trabalho e formação profissional.20.ed. São Paulo: Cortez,2011.

INCA. Diálogos em Saúde Pública e Serviço Social: a experiência do assistente social em oncologia. Instituto Nacional do Câncer José Alencar Gomes da Silva. Rio de Janeiro:INCA,2017.

Diálogos em Saúde Pública e Serviço Social: a residência multiprofissional em oncologia. Instituto Nacional do Câncer José Alencar Gomes da Silva. Rio de Janeiro:INCA,2018.

SANTOS, Josiane Soares. Questão social: particularidade no Brasil. Biblioteca Básica do Serviço Social. São Paulo:Cortez,2012. 


\title{
O BENEFÍCIO DA FISIOTERAPIA NAS COMPLICAÇÕES LOCAIS EM MASTECTOMIZADA PRÉ RADIOTERAPIA
}

\author{
Karen Ariele Ferreira da Costa ${ }^{1}$; Marília Vieira Farias ${ }^{1}$; Mara Dalila Vitor Vieira ${ }^{1}$; Erica \\ Vieira Nojosa²; Rafaela Pessoa Santana ${ }^{3}$; Lucimar Bóh Barbosa ${ }^{4}$. \\ ${ }^{1}$ Residente em Cancerologia pela Escola de Saúde Pública do Ceará; \\ ${ }^{2}$ Fisioterapeuta Especialista em Neurofuncional pelo Centro Universitário Estácio do \\ Ceará; \\ ${ }^{3}$ Docente do Centro Universitário Estácio do Ceará; \\ ${ }^{4}$ Preceptora do Centro Universitário Estácio do Ceará
}

Autor para correspondência: Karen Ariele Ferreira da Costa / karenarielec@ gmail.com / 85992572905

INTRODUÇÃO: As cirurgias por câncer de mama e as terapias adjuvantes como quimioterapia, radioterapia e hormonioterapia podem resultar em algumas complicações físicas, dentre elas: infecção, necrose de pele, seroma, aderência e deiscência cicatricial, limitação da amplitude de movimento (ADM) do ombro, cordões axilares, dor, lesão de nervos motor e/ou sensitivo, aderências na parede torácica, fraqueza muscular radiodermite e linfedema. Sendo fundamental a fisioterapia na reabilitação, prevenção e recuperação no pré e pós-operatório, favorecendo a uma melhora da conscientização corporal e oferecendo orientações necessárias para as atividades diárias. RELATO DE CASO: Paciente, sexo feminino, 47 anos, dona de casa. Nega diabetes, apresenta hipertensão fazendo uso de medicações, não pratica atividade física. Realizou mastectomia simples na mama esquerda, e cirurgia plástica na mama direita para simetria de tamanho. Há dois meses da cirurgia, já havia finalizado as sessões de quimioterapia e compareceu ao setor de fisioterapia trazendo como queixa principal dor intensa (EVA 8) fazendo uso de analgésicos e limitação de movimento, impedindo-a de realizar a radioterapia, por conta do posicionamento correto no aparelho. Segundo a avaliação com a goniometria, obteve-se os seguintes dados: abdução $70^{\circ}$ e flexão $110^{\circ}$ em membro superior esquerdo. O protocolo foi inicialmente com o objetivo de aumento da amplitude do movimento, consistindo de exercícios passivos, ativo-assistidos, e por fim para o fortalecimento muscular, exercícios resistidos. Realizada cinesioterapia E terapia manual. Os exercícios consistiam em movimentos de abdução, flexão e extensão. Foram dadas orientações dos exercícios realizados no ambulatório para a paciente realizar em domicílio. No decorrer dos atendimentos paciente foi reavaliada e alcançou $150^{\circ} \mathrm{de}$ abdução e $150^{\circ}$ flexão. CONSIDERAÇÕES FINAIS: Após 18 atendimentos, paciente aumentou sua amplitude na articulação glenoumeral. O plano terapêutico composto de técnicas de terapia manual e cinesioterapia com progressão da complexidade dos exercícios mostrou-se satisfatório no paciente em questão, pois o mesmo relatou alívio da dor, diminuindo a EVA para 5, e melhora da funcionalidade, estando apta a iniciar a radioterapia, no entanto concomitante ainda com a fisioterapia. A mesma foi encaminhada para continuar o exercício físico na academia após finalizar as vinte e seis sessões de radioterapia.

Palavras-chave: Câncer de mama, fisioterapia, radioterapia, mastectomia. 


\section{Referências}

VALE, C. C. S. O. et. al. Câncer de mama: a repercussão da mastectomiano psiquismo da mulher. Rev. Mental. V. 11, n. 21,p. 527545, 2017.

CHING, A.W. et. al. Influência das complicações pós-operatórias no insucesso da reconstrução de mama imediata com implante de silicone. Rev. Bras. Cir. Plást.V.30, n. 2, p. 182-189, 2015. 


\title{
TAXA DE MORTALIDADE POR NEOPLASIAS MALIGNAS ÓSSEAS E DA CARTILAGEM ARTICULAR NO MUNICÍPIO DE TERESINA-PI: ESTUDO EPIDEMIOLÓGICO
}

\author{
Leonardo Teixeira Alves ${ }^{1}$; Justijanio Cacio Leal Teixeira ${ }^{2}$. \\ ${ }^{1 .}$ Discente de Medicina, Centro Universitário Uninovafapi, Teresina, Piauí, Brasil; \\ ${ }^{2}$. Docente da disciplina de Ortopedia, Universidade Estadual do Piauí - Facime, \\ Teresina, Piauí, Brasil
}

Autor para correspondência: Leonardo Teixeira Alves / leonardoteixra@gmail.com / 86 999338423

INTRODUÇÃO: Neoplasias malignas podem apresentar maior agravo em relação às neoplasias de cunho benigno, visto sua capacidade de invadir tecidos vizinhos e atingir sítios distantes da lesão inicial. Quando no tecido ósseo, podem ser originárias de outros orgãos ou terem origem no próprio tecido. Os ossos comumente mais afetados são a coluna vertebral, os ossos da bacia, os arcos costais e o fêmur. Pacientes acometidos podem apresentar compressão medular, hipercalcemia, fraturas patológicas e dores severas. Já as neoplasias malignas articulares, são pouco frequientes e geralmente estão associadas a metástases de neoplasias ósseas ou de tecidos moles adjacentes. Em sua maioria, portadores de tais tumores, apresentam monoartrite crônica e alterações em ressonância magnética que podem sugerir o diagnóstico. OBJETIVOS: O presente trabalho, tem como objetivo, avaliar a mortalidade de pacientes portadores de neoplasias malignas ósseas e articulares no município de Teresina, considerando sexo e faixa etária, a partir da primeira semana epidemiológica de 2014 até a vigésima segunda de 2018. MÉTODOS: O estudo epidemiológico foi feito a partir da coleta de dados secundários do Sistema de Informações Hospitalares do SUS (SIH/SUS), sendo dispensada aprovação do Comitê de Ética. Para coleta e análise, foram considerados os dados referentes à primeira semana epidemiológica de 2014 até a vigésima segunda semana epidemiológica de 2018, segundo a taxa de mortalidade por neoplasias malignas do osso e da cartilagem articular, de acordo com sexo e faixa etária, no município de Teresina, Piauí. RESULTADOS: No período analisado, o ano de 2016 apresentou a maior taxa de mortalidade, com 9,05\% seguido por 2014, 2015, 2018 e 2017, com 5,26\%, 4,76\% , $3,56 \%$ e 3,47\% , respectivamente. Em relação ao sexo, o ano de 2016 também apresentou as maiores taxas de morte com $11,49 \%$ para o sexo feminino, e $7,14 \%$ para o sexo masculino. No que se refere à faixa etária, os pacientes a partir de 80 anos apresentaram maior mortalidade, com 42,86\%, já os pacientes de 1 a 4 anos, apresentaram a menor porcentagem, 1,69\%.CONCLUSÃO: Entre os anos analisados pode-se concluir que 2016 apresentou a maior taxa de mortalidade. Em relação ao sexo, predominam maiores porcentagens no feminino, sendo destaque o ano de 2016. Ainda, quanto à faixa etária, os casos são prevalentes em pacientes com idade maior ou igual à 80 anos.

\section{Referências}


ANDRADE NETO, Francisco et al. Knee bone tumors: findings on conventional radiology. Radiologia brasileira, v.49, n.3, p.182-189,2016.

BORTOLLI, Juliane de Quadros de. Entendendo o osteocondroma e a hiperplasia condilarna articulação temporomandibular: Ênfase no diagnóstico diferencial. 2014.

KIM, Leandro Duil et al. Metástase óssea como primeira manifestação de tumores: contribuição do estudo imuno-histoquímico para o estabelecimento do tumor primário. RevistaBrasileiradeOrtopedia,v.53,n.4,p.467-471,2018.

PEREIRA, Ariane Stephanie Silva; DE OLIVEIRA TAVARES, Renata; KOCHLA, Kátia Renata Antunes. INTRODUÇÃO: Condrossarcoma é um tipo de câncer do osso, baseado em cartilagem classificado na categoria dos sarcomas, apresentam uma variada aparênciar a diológica, o que torna frequentemente impossível sua distinção dos osteossarcomas (THOMPSON; POOL, 2002). É uma neoplasia maligna na qual, células cartilaginosas tumorais produzem quantidades variáveis de matriz.7

CONCLAVE DOS ACADÊMICOS DE ENFERMAGEM DA UNIVERSIDADE POSITIVO (CONAENF),p.66,2015.

ZANGHELINI, Fernando et al. Perfil de pacientes com artrite reumatoide em uso de inibidores do Fator de Necrose Tumoral alfa (TNF- $\alpha$ ), cadastrados no Componente Especializado da Assistência Farmacêutica de Pernambuco, Brasil. Revista de Ciências Farmacêuticas Básica e Aplicada,v.35, n.2, p.251-256,2015. 


\title{
ESTUDO EPIDEMIOLÓGICO DE NEOPLASIAS MALIGNAS DE PELE NA MACRORREGIÃO SEMIÁRIDO DO PIAUÍ
}

\author{
Alves, Leonardo Teixeira ${ }^{1}$; De Melo, Caroline Baima² \\ 1. Discente de Medicina, Centro Universitário Uninovafapi, Teresina, Piauí, Brasil; \\ 2. Docente da Disciplina de Dermatologia, Centro Universitário Uninovafapi, Teresina, \\ Piauí, Brasil.
}

Autor para correspondência: Leonardo Teixeira Alves leonardoteixra@gmail.com / 86 999338423

INTRODUÇÃO: A pele é o maior órgão do corpo humano e constitui fator de barreira e proteção contra agentes externos, como os raios UV. Indivíduos de pele clara, que negligenciam o uso de protetores solar e que, principalmente, têm casos de câncer de pele na família, são os mais afetados. Entretanto, indivíduos de pele escura também podem ser afetados. As neoplasias malignas da pele mais comuns são os carcinomas basocelulares (CBC) e os espinocelulares (CEC), sendo o primeiro mais prevalente e menos letal. Já o tipo melanoma é o menos prevalente mas de pior prognóstico. Desse modo, por receber uma intensa exposição solar, principalmente, no semiárido, o Estado do Piauí pode apresentar uma população vulnerável. OBJETIVOS: O presente estudo avalia a prevalência de neoplasias malignas no semiárido do Piauí, considerando casos notificados, de acordo com o número de internações e com a média de permanência de internação, a partir da primeira semana epidemiológica de 2014 à vigésima segunda semana de 2018. MÉTODOS: O estudo epidemiológico foi feito a partir da coleta de dados secundários do Sistema de Informações Hospitalares do SUS (SIH/SUS), sendo dispensada aprovação do Comitê de Ética. Foram considerados dados referentes à primeira semana epidemiológica de 2014 até a vigésima segunda semana epidemiológica de 2018, segundo o número de internações por neoplasias malignas de pele e a média de dias de permanência, na Macrorregião de Saúde Semiárido do Estado do Piauí. RESULTADOS: No período analisado, o município de Massape do Piauí, apresentou o maior número de internações, com 16, seguido por Picos, Queimada Nova, Elesbão Veloso, Paulistana, Pimenteiras e Santo Antônio de Lisboa, com 3, 3, 2, 2, 2, e 2 casos, respectivamente. Os demais municípios do semiário notificaram 1 único caso ou não pontuaram. Em relação à média de permanência de internação, destaca-se o município de Picos com 5,7, seguido por Santo Antonio de Lisboa, Marcolandia , Queimada Nova, Elesbão Veloso, Pimenteiras e Massape do Piauí, com 5,5 , 5 , 4,7 , 4,5 , 3,5 e 3,2 , respectivamente. CONCLUSÃO: Entre os municípios analisados, pode-se perceber que Massape do Piauí apresentou o maior número de internações por neoplasias malignas de pele. Contudo, o mesmo município apresentou média de permanência de internação inferior aos outros municípios do semiárido do Piauí, sendo o município de Picos o de maior média. 


\section{Referências}

COUTO, Luciana et al. Índice diagnóstico de neoplasia cutânea em campanha de combate ao câncer da pele em serviço dermatológico no interior do estado de São Paulo.Surgical\& Cosmetic Dermatology, v. 9, n. 4, p. 314-315, 2017.

DE BRITO, Raquel Carlos et al. ÓBITOS HOSPITALARES POR NEOPLASIAS DE PELE NO NORDESTE BRASILEIRO (2011 a 2015).ID ON LINE REVISTA MULTIDISCIPLINAR E DE PSICOLOGIA, v. 12, n. 40, p. 41, 2018.

DIAS, Ernandes Gonçalves et al. A experiência da elaboração de um material didático sobre câncer de pele para trabalhadores rurais. Saúde em Redes, v. 4, n. 3, p. 143-152, 2018 .

IMANICHI, Danielle et al. Fatores de risco do câncer de pele não melanoma em idosos no Brasil. Diagn. tratamento, v. 22, n. 1, p. 3-7, 2017.

SANTOS, Sandra Oliveira; SOBRINHO, Raimaria Rodrigues;

DE OLIVEIRA, Thainara Alves. Importância do uso de protetor solar na prevenção do câncer de pele e análise das informações desses produtos destinados a seus usuários. Journal of Health\& Biological Sciences, v. 6, n. 3, p. 279-285, 2018. 


\section{COMPOSTOS BIOATIVOS COMO ATIVADORES DA VIA NRF2 NO CÂNCER INTESTINAL}

Fernanda do Nascimento Araújo'; Maria Clara Leite Guimarães Serra ${ }^{2}$; Profa. Me. Camila Guedes Borges de Araujo ${ }^{3}$

1. Graduanda do Curso de Nutrição, Universidade Federal do Piauí - UFPI, Teresina, Piauí, Brasil,

${ }^{2}$.Graduanda do Curso de Nutrição, Universidade Federal do Piauí - UFPI, Teresina, Piauí, Brasil,

${ }^{3}$. Professora Mestre, Universidade Federal do Piauí - UFPI, Teresina, Piauí, Brasil

Autor para correspondência: Fernanda do Nascimento Araújo / Fernanda151927@hotmail.com / (86) 994803179

INTRODUÇÃO: O Câncer Colorretal é o terceiro câncer mais comum no mundo e o segundo tipo mais comum nos países ocidentais. É a segunda principal causa de morte por câncer nos Estados Unidos, e no Brasil, o número de mortes em 2013 foi de 15.415 e foram estimados 34.280 novos casos no ano de 2016. Estima - se que no período de 2018 a 2019 o câncer de intestino em mulheres alcançará 19 mil casos, e nos homens, 17 mil. No entanto, é um câncer tratável e, na maioria dos casos, curável, ao ser detectado precocemente. OBJETIVO: Avaliar o efeito dos compostos bioativos, via NRF2, no câncer intestinal. MÉTODOS: Trata-se de uma revisão literária, através da busca de artigos nas bases de dados Pubmed e Google acadêmico, sobre os assuntos, resultando em amostra com 10 artigos. RESULTADOS: Foi observado que o fator de transcrição nuclear Nrf2 se encontra inativo no citoplasma ligado à proteína Keap1(Kelch - like ECH - associatedprotein1), e essa ligação é ativada na presença de radicais livres. Contudo, os compostos bioativos vem sendo promotores de sua resposta transcricional no elemento de resposta antioxidante (ARE), o que faz a NRF2 se desligar da Keap1 e se translocar para o núcleo celular, possibilitando a codificação de enzimas detoxificantes e antioxidantes (superóxido dismutase, catalase, glutationa peroxidase), os quais são fundamentais na defesa celular, e consequentemente desfavorece a ocorrência de danos, que tem se associado à etiologia do câncer. CONCLUSÃO: Conclui- se que o câncer intestinal é um problema de saúde pública, mas que os estudos demonstram que os compostos bioativos, presentes nos alimentos, podem proteger contra esta patologia, ao ativar a via NRF2, aumentando assim a expressão de enzimas antioxidantes que atuam na defesa do organismo.

Palavras-chave: Câncer Colorretal, Proteína NRF2, Nutrição, Antioxidantes

\section{Referências}


AGLAGO, E.K; et. al. Consumption of Fish and Long-chain n-3 Poly unsaturated Fatty Acids Is Associated With Reduced Risk of Colorectal Cancerin a Large European Cohort. Clin Gastro enterol Hepatol. 25 jun. 2019.

AKHDAR, $\mathrm{H}$; et. al. Involvement of $\mathrm{Nrf2}$ activation in resistance to 5-fluorouracil in human colon cancer HT-29 cells. European Journal of Cancer, v. 45, n. 12, p.22192227, 2009.

ZHANG, C. X; et. al. Higher intake of carotenoidis associated with a lower risk of colorectal cancer in Chinese adults: a case-control study. Eur J Nutr. v. 54, n. 4, p. 619628, jun. 2015. 


\section{EFEITOS DO USO DE TERAPIA NUTRICIONAL IMUNOMODULADORA NO PÓS-OPERATÓRIO DE PACIENTES PORTADORES DE CÂNCER NO TRATO GASTROINTESTINAL}

Fernanda do Nascimento Araújo ${ }^{1}$; Lyandra Dias da Silva ${ }^{1}$; Nilmara Cunha da Silva ${ }^{1}$; Letycia Sousa Lima ${ }^{1}$; Maria Clara Leite Guimarães Serra ${ }^{1}$; Camila Guedes Borges de Araújo $^{2}$

1Discente em Nutrição na Universidade Federal do Piauí

2Docente do Departamento de Nutrição na Universidade Federal do Piauí

Autor para correspondência: Fernanda do Nascimento Araújo / Fernanda151927@hotmail.com / 86994803179

INTRODUÇÃO: Os tumores podem ser caracterizados como massas de tecidos produzidos por meio do crescimento descontrolado e disseminação de células anormais. A presença de tumor provoca uma resposta inflamatória sistêmica, resultando em alterações metabólicas e neuroendócrinas. E em pacientes submetidos a cirurgias de caráter oncológico no trato gastrointestinal, as taxas de morbidade e as complicações pósoperatórias são significativas. OBJETIVO: Avaliar o papel da terapia nutricional imunomoduladora no pós-operatório de pacientes com câncer gastrointestinal, em especial da glutamina, arginina e ácidos graxos poli-insaturados ômega 3. MÉTODOS: Trata-se de uma revisão integrativa de literatura. Foram consultadas as bases de dados: SciELO, Pubmed e Science Direct, entre os anos de 2010 a 2019, sendo utilizados para essa revisão o total de 12 artigos de acordo com os critérios de inclusão e exclusão, e os descritores foram Neoplasia gastrointestinal; Pós-operatório e Imunonutrição. RESULTADOS: A suplementação de nutrientes imunomoduladores no pós-operatório de pacientes com câncer gastrintestinais promove efeitos benéficos, por meio da redução de citocinas pró-inflamatórias e melhora da resposta imunológica, contribuindo para a melhora do estado nutricional e melhor prognóstico. Nessa perspectiva, a suplementação isolada de glutamina foi eficaz na redução de IL-6 e TNF- $\alpha$, bem como o ômega-3 que, além de reduzir marcadores inflamatórios, foi capaz de aumentar a razão CD4 $4^{+} / \mathrm{CD}^{+}$. Já a suplementação isolada de L-arginina apresentou-se capaz de aumentar a expressão de células TCD4 ${ }^{+}$e natural killer, bem como de IgG e IgA, melhorando a resposta imune. Além disso, a literatura aponta que a suplementação combinada de dois ou mais imunonutrientes também é benéfica na redução de marcadores de inflamação e na melhora da resposta imune. CONCLUSÃO: Apesar dos benefícios da nutrição imunomoduladora já evidenciada pela literatura, há necessidade de mais estudos para padronização de doses, via de administração e duração da suplementação. 
Palavras-chave: Neoplasia gastrointestinal; Pós-operatório; Imunonutrição.

\section{Referências}

CARMO, S. G., FORTES, R. C. Efeitos do uso de fórmulas imuno moduladoras em pacientes cirúrgicos portadores de câncer do trato gastrointestinal. Revista Cientifica Sena Aires,v.8,n.1,p.87-102,2019.

MA, C. J., et al. Prospective double-blind randomized study on the efficacy and safety of ann -3 fatty acid enriched intravenous fat emulsion in postsurgical gastric and colorectal câncer patients. Nutrition Journal, v. 14, n. 9, 2015.

SHINSUKE, K. et al. Efficacy of perioperative immuno nutrition in esophageal câncer patients undergoing esophagectomy. Nutrition, v. 59, n. 1, p. 96-102, 2019.

ULIAN, D. de M. F. et al. Uso de imuno moduladores e antioxidantes na terapia nutricional em câncer. Revista Funec Científica -Nutrição, Santa Fé do Sul (SP), v. 2, n. 3, p. 68-81, 2014. 


\title{
CUIDADOS PALIATIVOS A PACIENTES COM FERIDA NEOPLÁSICA: UM CUIDADO DE ENFERMAGEM
}

\author{
Francisco Alves de Sousa ${ }^{1}$; Jaqueline Castilho de Oliveira ${ }^{2}$ \\ 1. Especialista em Enfermagem Oncologica, Faculdade Unyleya, Teresina, Piauí, Brasil; \\ 2. Especialista em Sistema de Saúde , Universidade Candido Mendes, Teresina, Piauí, \\ Brasil
}

Autor para correspondência: Francisco Alves de Sousa / franciscoenfsousa@gmail.com / 86999226411

INTRODUÇÃO: O cuidado paliativo não tem característica curativa, portanto é de extrema relevância minimizar ou sancionar os sinais e sintomas apresentados. As feridas oncológicas constituem-se como uma das preocupações na assistência à saúde de pacientes com câncer, já que os efeitos da doença, como dor e aparência, interferem na qualidade de vida dessas pessoas e de suas famílias. O enfermeiro assume um papel fundamental no cuidado dessas feridas, através da orientação e da promoção à saúde. OBJETIVO: Analisar as evidências cientificas sobre cuidados paliativos de enfermagem em pacientes com ferida neoplásica. MÉTODOS: O estudo foi norteado pelo método da revisão integrativa. Para selecionar os artigos, foram utilizadas três bases de dados: SCIELO, LILACS e MEDLINE, e foram selecionados os seguintes descritores: "Cuidados paliativos", "Assistência de Enfermagem", Ferimentos e lesões e "Neoplasias. A fim de estabelecer a amostra dos estudos selecionados para a presente revisão integrativa, foram estabelecidos os seguintes critérios de inclusão: artigos nos idiomas português, inglês e espanhol, publicados entre os períodos de 2013 a 2018, associados ao objeto de estudo, em periódicos nacionais e internacionais, disponibilizados na íntegra (texto completo e de livre acesso). Conforme os critérios de inclusão pré-estabelecidos, foi obtida uma amostra de 13 artigos. RESULTADOS: Após a análise do material obtido, os resultados apontaram que, entre as ações de enfermagem direcionadas à pacientes com ferida neoplásica sob cuidados paliativos, destacam-se o alívio dos sintomas, a promoção de conforto e de bem-estar e a melhoria dos aspectos físicos, psicológicos, sociais e espirituais, desta forma, o enfermeiro assume um papel fundamental no cuidado dessas feridas, através da orientação e da promoção à saúde. CONCLUSÃO: No contexto dos cuidados paliativos, a enfermagem deve proporcionar uma assistência humanizada e singular, a fim de minimizar desconfortos e problemas diversos gerados pela doença oncológica, promovendo melhoria da qualidade de vida desses pacientes.

Palavras-chave: Cuidados paliativos, Assistência de Enfermagem, Ferimentos e lesões, Neoplasias Cutâneas.

\section{Referências}

CASTRO, Maria Cristina Freitas de et al. Sub conjunto terminológico CIPE® para pacientes em cuidados paliativos com feridas tumorais malignas.Actapaul.enferm,v.29,n.3,p.340-46,2016. 
FREITAS, Tayssa da Silva. A Importância do Enfermeiro na avaliação e tratamento de feridas.(Trabalho de Conclusão de Curso), Fundação Universitária Vida Cristã, Pindamonhangaba-SP, 2017.

GOMES, Roseane Ferreira et al. Knowledge of nursing student as boutth e care provided to people with neoplastic wounds. International Archives of Medicine,v.10,n.138,p.1$15,2017$.

LISBOA, Isabel Neves Duarte; VALENÇA, Marilia Perrelli. Caracterização de pacientes com feridas neoplásicas. Revista Estima,v.14,n.1,2016. 


\section{AVALIAÇÃO DA CAPACIDADE FUNCIONAL DE PACIENTES ONCOLÓGICOS EM UM HOSPITAL PÚBLICO DE TERESINA-PI}

Thyara Maria Stanley Vieira Lima ${ }^{1}$; Igor Almeida Silva²; Erika da Fonseca Reis Silva ${ }^{3}$; Lígia Carvalho de Figueiredo ${ }^{4}$

${ }^{1}$ Especialista, Uninovafapi, Teresina, Piauí, Brasil;

${ }^{2}$ Especialista, UFPI, Teresina, Piauí, Brasil;

${ }^{3}$ Mestre, Universidade Católica de Brasília, Brasília, Distrito Federal, Brasil;

${ }^{4}$ Mestre, Univap, São José dos Campos, São Paulo, Brasil.

Autor para correspondência: Thyara Maria Stanley Vieira Lima / thyaravlima@hotmail.com / 86999530917

INTRODUÇÃO: O câncer é um processo mórbido, onde uma célula transforma-se por alterações genéticas do DNA, gerando assim uma célula anormal que adquire características diferentes. O tratamento apresenta diversos efeitos colaterais, que por si só incapacitam a pessoa, apresentando uma série de consequências físicas, emocionais e sociais. As alterações físicas acarretam uma diminuição das atividades de vida diária, que por sua vez leva a diminuição da capacidade funcional. OBJETIVO: Avaliar a capacidade funcional de pacientes com diagnóstico de câncer atendidos em um hospital universitário; correlacionar as atividades de vida diária com a capacidade funcional. MÉTODOS: Trata-se de um estudo analítico, descritivo, observacional e transversal, com estratégia metodológica quantitativa. Esta pesquisa foi aprovada pelo Comitê de Ética em Pesquisa com Parecer $n^{\circ}$ 2.568.880. Para avaliação da capacidade funcional foram utilizadas a escala de Status de Desempenho do Grupo de Oncologia Cooperativa Oriental (PS-ECOG) e a escala de Karnofsky, e para avaliação das atividades da vida diária foi utilizado o Índice de Barthel. RESULTADOS: Participaram da pesquisa 10 pacientes, sendo $70 \%$ do sexo feminino com média de idade 57,2 $\pm 12,8$ anos, $50 \%$ com ensino fundamental completo. Quanto ao tipo de câncer, $40 \%$ corresponderam ao câncer de mama e ovário. Quanto aos fatores de risco, destacaram-se 30\% hipertensos, 60\% fumantes, $80 \%$ etilistas; $60 \%$ faziam atividade física. Quanto ao índice de desempenho de Karnofsky com mediana de 75 (mín=20; máx=90), 60\% apresentaram escore entre 9070 (independente), ou seja, equivalente aos índices 0 (completamente ativo) e 1 (ativo com restrição apenas para atividades físicas rigorosas) na escala PS-ECOG. Na avaliação de atividade de vida diária com base no Índice de Barthel observou-se uma mediana de 70 (mín=0; máx=90), indicativo de independência funcional. Destaca-se que as medidas obtidas pelas duas escalas de funcionalidade apresentaram correlação forte significativa ( $r s=0,885, p=0,01)$. CONCLUSÃO: Conclui-se então que nessa amostra os pacientes analisados são independentes funcionais, observados em pessoas que praticam atividade física e preservam as funções fisiológicas e metabólicas.

Palavras-chave: Hospitalização, Dependência, Oncologia.

\section{Referências}

GOMES,R.H.S.;SANTOS, R. S. Avaliação da capacidade e comprometimento funcional em pacientes traqueotomizados de um hospital público de Curitiba. Rev. CEFAC, v.18,n.1,p.120-8,2016. 
LEITE, F.M.C. et al. Diagnóstico de enfermagem relacionado aos efeitos adversos da radioterapia, Revista Mineira de Enfermagem, v.17,n.4,p.940-5,2013.

SILVA, P. L. N. ;et al. o significado do câncer: percepção de pacientes. Ver enferm UFPE on line,v.7,n.12,p.6828-33,dez.,2013. 


\section{O CUIDADO VOLTADO AOS PROFISSIONAIS DE ENFERMAGEM ASSISTENTES AOS PACIENTES ONCOLÓGICOS: REVISÃO INTEGRATIVA}

CRUZ, Francileuza Ciríaco ${ }^{1}$;SILVA, Fábio Soares Lima²; CAMPELO, Eduardo Melo; PINHEIRO, Daniella Mendes ${ }^{4}$; SOUSA, Marques Maryanne ${ }^{5}$; ARAÚJO, Olivia Dias ${ }^{6}$

${ }^{1}$ Enfermeira da UNACON Hospital Universitário do Piauí, Especialista em Oncologia, Teresina-PI

${ }^{2}$ Enfermeira e Chefe da UNACON Hospital Universitário do Piauí, Mestranda em Políticas Públicas, Teresina-PI

${ }^{3}$ Enfermeira da UNACON Hospital Universitário do Piauí, Especialista em Saúde da Família, Teresina-PI

4 Enfermeira da UNACON Hospital Universitário do Piauí, Mestranda em Terapia Intensiva, Teresina-PI

${ }^{5}$ Enfermeira da UNACON Hospital Universitário do Piauí, Especialista em Oncologia, Saúde do Trabalho, Saúde da Família e Saúde Pública, Teresina-PI

6. Profa. Pós Doutora da Universidade Federal do Piauí-Campus Ministro Petrônio Portella CCS/Depto de Enfermagem, Teresina-PI

Autor para correspondência: FRANCILEUZA CIRÍACO DA CRUZ / francileuzaciriaco@ hotmail.com / 86 9928-0403

INTRODUÇÃO: O cuidado ao paciente oncológico exige uma articulação entre as extensões gerencial e assistencial, visando atender as necessidades de cuidado dos pacientes, assim como também, das suas respectivas famílias e dos profissionais envolvidos no cuidado. OBJETIVO: analisar nas produções científicas acerca dos principais sentimentos desenvolvido pela enfermagem cuidadora de pacientes oncológicos. MÉTODO: Se trata de uma revisão integrativa da literatura. Foram incluídos 10 artigos no estudo, os quais foram analisados e discutidos. RESULTADOS: apontaram que os principais sentimentos foram referidos como tristeza, impotência, medo e depressão. Assim como realização e gratificação para a enfermagem em assistir o paciente oncológico. Também foi possível compreender que os enfermeiros utilizam estratégias individuais diante do contexto oncológico, como: negação, afastamento, desvinculação da prática laboral da vida pessoal, a busca por qualificação profissional, atividades de lazer e espirituais. Como também atividades coletivas por meio de movimentos de fala e escuta entre os colegas de trabalho, ações estas assumidas cotidianamente para enfrentar o sofrimento no trabalho. CONCLUSÃO: Esses achados podem corroborar com a construção de estratégias por meio da gestão de cuidados para aliviar os fatores estressores vivenciados pela enfermagem oncológica, como atualização contínua dos profissionais, o estímulo a comunicação e o trabalho em equipe multidisciplinar.

Palavras-chaves: "Oncologia”, "Enfermagem Oncológica”, "Gestão de cuidados", "Saúde Laboral"

\section{Referências}


INCA-

Câncer,2018.Disponívelem:<http://www1.inca.gov.br/conteudo_view.asp?id=322>Aces soem:25.mai.2018.

DESÁ MORORÓ, Deborah Dinorah et al. Análise conceitual da gestão do cuidado em enfermagem no âmbito. 


\title{
TERAPIA DE REPOSIÇÃO HORMONAL NO CLIMATÉRIO COMO FATOR DE RISCO PARA O CÂNCER DE MAMA
}

\author{
Marcos Vinicius de Souza; Denise Conceição Costa ${ }^{2}$; João Marcelo de Castro e Sousa ${ }^{3}$. \\ ${ }^{1}$ Acadêmico de Enfermagem da Universidade Federal do Piauí-UFPI/CSHNB. E-mail: \\ marcos91697247@hotmail.com \\ ${ }^{2}$ Acadêmico de Enfermagem da Universidade Federal do Piauí-UFPI/CSHNB. E-mail: \\ denisecconceicao4@gmail.com \\ ${ }^{3}$ Docente do Curso de Bacharelado em Enfermagem-UFPI/CSHNB Graduado em \\ Ciências Biológicas-UFPI. Mestre na área de Genética e Biologia Molecular-UFPA. \\ Doutor em Ciências Ambientais-UEM. E-mail: j.marcelo@ufpi.edu.br
}

Autor para correspondência: Marcos Vinicius de Souza / marcos91697247@ hotmail.com / 87 99169-7247

INTRODUÇÃO: O climatério é a passagem do período reprodutivo para o não reprodutivo que geralmente ocorrente entre a quarta e sexta década de vida da mulher, caracterizando-se pelos baixos níveis de hormônios sexuais. Dessa maneira, a utilização da terapia de reposição hormonal (TRH) tem papel fundamental para o alívio dos sintomas da menopausa, toda via essa conduta pode se tornar um fator de risco para o câncer de mama que está entre os principais tipos de doenças que acometem às mulheres, possuindo elevada incidência, bem como mortalidade. OBJETIVOS: Avaliar a terapia de reposição hormonal (TRH) no climatério como fator de risco para o surgimento do câncer de mama, bem como suas consequências. METODOLOGIA: Trata-se de uma revisão integrativa da literatura, de natureza quantitativa realizada nas bases de dados: SCIELO (Scientific Electronic Library Online), MEDLINE (Medical Literature Analysis and Retrieval System Online), BVS (Biblioteca Virtual em Saúde) e LILACS (Literatura Latino-Americana e do Caribe em Ciências da Saúde). A pesquisa foi realizada entre abril e julho de 2019, utilizando-se como descritores em saúde: Neoplasias da mama, Terapia de reposição hormonal e climatério. Os critérios de inclusão foram artigos publicados na integra com texto completo disponível, entre 2009 a 2019 em português, espanhol e inglês. Foram encontrados 436 artigos, sendo utilizado 51. Os critérios de exclusão foram aplicados aqueles que não se enquadraram na temática. RESULTADOS: Observou-se que o uso da terapia de reposição hormonal para diminuir os efeitos da menopausa está sendo utilizado cada vez mais na saúde da mulher, entretanto relata-se muito sobre suas consequências, principalmente nos que contém progesterona e estrógeno, pois o seu uso está intimamente ligado à proliferação celular do tecido da mama, por meio da ligação com os receptores das células MCF-7 e multiplicação dessas células, bem como seus efeitos clonogênicos e progressão do ciclo celular, podendo ser fator de risco para carcinogênese. CONCLUSÃO: Conclui-se que, apesar de ser um tema ainda não elucidado e complexo, o uso da hormonioterapia contra os efeitos da menopausa deve-se ser utilizado de forma racional, obedecendo todos os aspectos de predisposição da paciente e, também, observando os benefícios, bem como o risco de efeitos adversos, sendo essencial para o menor risco de neoplasias da mama.

Palavras chave: Terapia de reposição hormonal (TRH), câncer de mama, climatério.

\section{Referências}


PARDINI, D. TERAPIA DE REPOSIÇÃO HORMONAL NA MENOPAUSA. ARQ BRAS ENDOCRINOL METAB. 2014;58/2. SÃO PAULO, SP, BRASIL.

SCHUNEMANN JUNIOR E, SOUZA RT, DÓRIA MT. ANTICONCEPÇÃO HORMONAL E CÂNCER DE MAMA. FEMINA | ABRIL 2011 | VOL 39 | No 4.

SOUTO NF, MOREIRA CB, BARROS PAS, ET AL. J. TERAPIA DE REPOSIÇÃO HORMONAL NO CLIMATÉRIO COMO FATOR DE RISCO PARA O DESENVOLVIMENTO DO CÂNCER DE MAMA. RES.: FUNDAM. CARE. ONLINE, 2014. JUL./SET. 6(3):1302-1312. 


\title{
IMPORTÂNCIA DO PERFIL SOCIODEMOGRÁFICO, CLÍNICO E TERAPÊUTICO DE PACIENTES COM FERIDAS ONCOLÓGICAS
}

\author{
Marcos Vinicius de Souza ${ }^{1}$; Denise Conceição Costa $^{2}$; João Marcelo de Castro e Sousa ${ }^{3}$. \\ ${ }^{1}$ Acadêmico de Enfermagem da Universidade Federal do Piauí-UFPI/CSHNB. E-mail: \\ marcos91697247@hotmail.com
}

${ }^{2}$ Acadêmico de Enfermagem da Universidade Federal do Piauí-UFPI/CSHNB. E-mail: denisecconceicao4@gmail.com

${ }^{3}$ Docente do Curso de Bacharelado em Enfermagem-UFPI/CSHNB Graduado em Ciências Biológicas-UFPI. Mestre na área de Genética e Biologia Molecular-UFPA. Doutor em Ciências Ambientais-UEM. E-mail: j.marcelo@ufpi.edu.br

Autor para correspondência: Marcos Vinicius de Souza / marcos91697247@hotmail.com / 87 99169-7247

INTRODUÇÃO: Feridas neoplásicas são lesões decorrentes de células malignas que se infiltram no epitélio, sendo ocasionadas por câncer primário ou metastático. Essa patologia requer que os profissionais possuam competências técnicas com bases científicas bem constituídas, para que o mesmo obtenha uma visão holística e descentralizada de métodos tecnicistas que podem revelar dificuldades no tratamento de pacientes com o perfil clínico e terapêutico de feridas oncológicas. OBJETIVO: Demonstrar a importância da compreensão do perfil sociodemográfico, clínico e terapêutico de pacientes com feridas oncológicas, enfatizando benefícios que essas informações fornecem para o tratamento. METODOLOGIA: trata-se de uma revisão integrativa da literatura, de natureza quantitativa realizada nas bases de dados: Scielo (Scientific Eletronic Library Online); LILAC (Literatura Latino-americana e do Caribe em Ciências da Saúde) e BVS (Biblioteca Virtual em Saúde). A pesquisa foi realizada entre abril a junho de 2019, utilizando os descritores em saúde: feridas oncológicas, cuidados paliativos e cuidados em feridas oncológicas. Os critérios de inclusão foram artigos publicados em revistas científicas com texto completo disponível, entre 2009 e 2019 nos idiomas inglês, espanhol e português. Foram encontrados 366 artigos, destes, utilizou-se 68. Os critérios de exclusão foram aplicados aqueles que não se adequaram a temática. RESULTADOS: As feridas oncológicas são patologias de alta complexidade, que podem acometer pacientes os quais já estão em estado paliativo, devido ao longo processo de metástase que o organismo possui. Geralmente os tratamentos fornecidos por profissionais centralizam-se em cuidados técnicos com bases científicas, para fornecerem um melhor alento no que se refere aos pacientes que sofrem isolamento social desenvolvido pelos empecilhos de sua patologia, ocasionando em dificuldades dos mesmos para a melhoria que o tratamento deveria fornecer. No entanto, a obtenção de informações sobre as características sociodemográficas, clínicas e terapêuticas direcionam e caracterizam perfis, demonstrando ser intrinsecamente importantes para resultados eficazes. Dessa forma, os profissionais poderão realizar as devidas medidas nos cuidados fornecidos, por obterem informações próprias dos pacientes que caracterizam seu comportamento e interação social, em conjunto a isso, unificar seus aspectos clínicos para uma abordagem terapêutica eficaz, alcançando as metas paliativas e/ou prognósticas eficazes para os portadores das lesões. CONCLUSÃO: Conclui-se que o conhecimento das informações e características sociodemográficas, clínicas e terapêuticas dos pacientes com feridas oncológicas pelos profissionais são essenciais para um prognóstico melhor ou cuidados paliativos satisfatórios. 
Palavras-chave: Feridas oncológicas, cuidados paliativos, cuidados de feridas oncológicas.

\section{Referências}

BRITTO et al. Revista Enfermagem Atual.p.89-97,2017.

AZEVEDO et al. Revista Brasileira de Cancerologia.p.119-127,2014.

CASTRO et al. Biblioteca J Baeta Vianna.p.841-844,2014. 


\section{EFEITO TERAPÊUTICO DA Curcuma longa L. PARA O CÂNCER: UMA REVISÃO DE LITERATURA}

Erica Isabel de Abreu Freire ${ }^{1}$; Heverson Dias de Araújo ${ }^{2}$; Raniella Borges da Silva ${ }^{1}$; Ellienai Erika Pereira de Sousa ${ }^{1}$; Arielly Jesus Leitão ${ }^{1}$; Lidiane Pereira de Albuquerque ${ }^{1}$

${ }^{1}$ Universidade Federal do Piauí, campus Ministro Petrônio Portela, Teresina, Piauí, Brasil

${ }^{2}$ Faculdade Integral Diferencial - FACID Wyden

Autor para correspondência: Érica Isabel de Abreu Freire / isabelerica48@ gmail.com / 86 99438-6350

INTRODUÇÃO: O composto mais estudado do rizoma da Curcuma longa L. (curcumina, açafrão) é o polifenol, devido às suas propriedades antinflamatória, antioxidante e antitumoral. Tem sido identificada em diversos tipos de câncer a alteração de metilação do DNA, através de vários mecanismos, que resultam em padrão invertido de metilação. A metilação consiste na natural modificação covalente do DNA, pela ação de DNA metiltransferases (DNMTs). Em tumores, alterações epigenéticas do tipo hipermetilação ocorrem em regiões específicas do genoma, principalmente onde há promotores de genes que regulam a divisão celular, enquanto outras regiões (principalmente não codificadora) são hipometiladas, que estão associadas à instabilidade cromossómica. OBJETIVO: Investigar o efeito da $C$. longa no padrão alterado de metilação do DNA em células cancerígenas. MÉTODOS: Trata-se de uma revisão de literatura. A seleção dos artigos (em inglês e português) incluiu a busca no banco de dados Scielo, Lilacs e PubMed. Priorizaram-se estudos que abordavam a ação da curcumina na metilação do DNA de células cancerígenas, bem como a sua resposta na indução da apoptose celular e redução da proliferação do tumor. Entre os artigos analisados, dez atenderam aos critérios de inclusão (publicação entre 2010 e 2018, textos completos e estreita relação com o tema). RESULTADOS: Abordagens farmacológicas mostraram que extratos do rizoma da curcumina pode alterar o padrão de metilação. Suas propriedades antitumorais também têm sido investigadas acreditando-se que seu mecanismo de ação seja através da indução à morte da célula e ao desaparecimento do tumor. O potencial da curcumina em modular a DNMT1 implica em aumentar a sensibilidade das células tumorais a drogas ou agentes convencionais, potencializando seu efeito antiproliferativo. CONCLUSÃO: A curcumina apresenta propriedades terapêuticas promissoras para o prognóstico do câncer, pois sua seletividade às células cancerígenas é de grande relevância para redução dos efeitos colaterais em pacientes oncológicos, podendo ser uma alternativa de tratamento. Porém, são necessários mais estudos que elucidem o mecanismo de modulação da DNMT pela curcumina, uma vez que a alteração na metilação do DNA pode predispor ao câncer.

Palavras-chave: Câncer, $C$. longa, DNA metiltransferases.

\section{Referências}

Echeverry, A. H. C; et al. Actividad antitumoral de la curcumina asociada a la regulación de mecanismos epigenéticos: implicaciones en la vía Wnt/-catenina. Revista Cubana de Plantas Medicinales2016;21(4). 
Oliveira, N.F.P; Planello, A.C; Andia, D.C; Pardo, A. P. S. Metilação de DNA e Câncer. Revista Brasileira de Cancerologia2010; 56(4): 493-499 


\section{ANÁLISE DA EFICIÊNCIA DO RASTREAMENTO PARA CÂNCER DE COLO DE ÚTERO EM PARNAÍBA ENTRE OS ANOS DE 2015 E 2018}

Igor dos Santos Cavalcante'; Jocerone Emerson Nogueira Oliveira ${ }^{2}$; João Pedro Sousa Mendes 2; Gabriel Phelipe Dantas do Nascimento ${ }^{2}$; Julianna Pereira da Costa Maia ${ }^{2}$; Thiago Santos Lima Almendra ${ }^{3}$.

${ }^{1}$ Acadêmico de Medicina, Universidade Federal do Piauí (UFPI);

${ }^{2}$ Acadêmico de Medicina, Universidade Federal do Piauí (UFPI);

${ }^{3}$ Mastologista, Docente do Curso de Medicina da universidade Federal do Piauí (UFPI).

Autor para correspondência: Igor dos Santos Cavalcante / 86994590037 / igorsc@live.com

INTRODUÇÃO: O câncer de colo do útero é o tipo neoplásico que ocupa o terceiro lugar dentre os tipos de neoplasias mais incidentes na população feminina brasileira, de acordo com o Instituto Nacional de Câncer. Devido a uma ampla diversidade de fatores associados ao desenvolvimento de câncer cervical, tais como: multiparidade, tabagismo, início precoce de atividade sexual, além do uso prolongado de contraceptivos orais, tornase muito importante a realização do rastreamento como forma de prevenção dessa patologia, haja vista o grande impacto que esta exerce na saúde da mulher. OBJETIVOS: Avaliar a evolução do rastreamento do câncer de colo de útero no município de ParnaíbaPI. MÉTODOS: Trata-se de um estudo de caráter descritivo, retrospectivo, quantitativo e exploratório, com enfoque na saúde da mulher. A pesquisa foi realizada a partir de dados coletados na plataforma DATASUS, através do programa TABNET, analisando-se o recorte temporal de 2015 a 2018, por faixa etária. RESULTADOS: No ano de 2015, houve um total incidente de 1.629 pessoas com câncer de colo de útero. Em 2016, o total de mulheres que foram rastreadas dentro da mesma faixa etária subiu para 1.852. No ano seguinte, houve um salto para 7.122 mulheres. Em 2018, o número de mulheres que realizaram o Papanicolau passou para 64.125. CONCLUSÃO: Os dados apreendidos sugerem um significativo aumento no número de rastreamentos durante o período analisado, expresso na ordem de 40.000 vezes. Esse acréscimo pode estar associado à abertura dos cursos de Medicina no Campus de Parnaíba da Universidade Federal do Piauí e da Faculdade de Ciências Humanas, Exatas e da Saúde do Piauí - FAHESP/IESVAP, nos respectivos anos de 2014 e 2015, os quais contribuíram para o fortalecimento da rede de Atenção Primária na cidade, possibilitando a expansão dos recursos ofertados e, ainda, uma maior abrangência dos atendimentos realizados. Dessa forma, destaca-se a importância das ações de educação em saúde, em conjunto com a intensificação de campanhas de prevenção, na melhoria do sistema de rastreamento para as neoplasias cervicais. É importante ressaltar ainda, que por se tratar de um crescimento altamente expressivo, há a possibilidade da ocorrência da subnotificação nos anos anteriores a 2018, com uma consequente ocorrência de rastreamentos desnecessários, o que pode ter tornado o contraste tão pronunciado ao longo dos anos.

\section{Referências}


Barroso MF ,Gomes KRO, Andrade JX. Frequência da colpocitologia oncótica em jovens com antecedentes obstétricos em Teresina, Piauí, Brasil. Rev Panam Salud Publica.2011mar;29(3):162-8.

Brasil, Ministério da Saúde. Instituto Nacional de Câncer. Coordenação Geral de Ações Estratégicas. Divisão de Apoio à Rede de Atenção Oncológica. Diretrizes brasileiras para o rastreamento do câncer do colo do útero. Rio de Janeiro: Instituto Nacional de Câncer;2011.

Ministério da Saúde (BR).Instituto Nacional de Câncer José de Alencar Gomes da Silva. Coordenação de Prevenção e Vigilância. Monitoramento das ações de controle dos cânceres do colo do útero e de mama. Inf Detecção Precoce.2014jan-abr;5(1):1-8.

Brasil, Ministério da Saúde. Instituto Nacional do Câncer José de Alencar Gomes da Silva. Estimativa 2018: incidência de câncer no Brasil. Rio de Janeiro: Instituto Nacional do Câncer;2017. 


\section{A ESPIRITUALIDADE COMO FATOR PROTETIVO/CURATIVO SOBRE O CÂNCER: UM ENSAIO LITERÁRIO}

Igor dos Santos Cavalcante'; Jocerone Emerson Nogueira Oliveira ${ }^{2}$; João Pedro Sousa Mendes 2; Danilo Andrade Lima ${ }^{2}$; Nickolas Souza Silva ${ }^{3}$; Thiago Santos Lima Almendra 4

${ }^{1}$ Acadêmico de Medicina, Universidade Federal do Piauí (UFPI);

2 Acadêmico de Medicina, Universidade Federal do Piauí (UFPI);

${ }^{3}$ Acadêmico de Medicina, Universidade Federal do Ceará (UFC);

${ }^{4}$ Mastologista, Docente do Curso de Medicina da universidade Federal do Piauí (UFPI).

Autor para correspondência: Igor dos Santos Cavalcante / 86994590037 / igorsc@live.com

INTRODUÇÃO: Câncer é o nome genérico dado a um grupo de mais de cem doenças que envolvem o crescimento celular anormal e descontrolado, com potencial para a invasão sistêmica. A oncologia é a ciência médica que estuda o desenvolvimento dessas patologias, suas causas e consequências. De acordo com o Instituto Nacional de Câncer (INCA), há uma estimativa de incidência de 634.88 novos casos de neoplasias malignas no ano de 2018. Com isso, faz-se necessário analisar o impacto que o diagnóstico de câncer exerce na individualidade dos pacientes. Tendo em vista a importância que a religiosidade exerce como representação simbólica subjetiva, ela constitui-se como fator primordial na resistência durante o tratamento do câncer. Assim, a religiosidade pode ser associada ao bem-estar físico e mental dos pacientes, contribuindo de forma significativa na sua recuperação, reduzindo óbitos ou eventuais impactos na saúde dos mesmos. $\mathrm{O}$ objetivo deste trabalho é estudar a influência que a religiosidade exerce no processo de cura do câncer. MATERIAL E MÉTODOS: Ensaio bibliográfico, de caráter exploratório-descritivo, qualitativo. A plataforma de buscas utilizadas foi o SciELO, utilizando-se os descritores "religiosidade", "neoplasia" e "cura'. Os critérios de inclusão foram os artigos que trabalharam noções espiritualistas de cura do câncer, bem como, a ideia de melhora da qualidade de vida em pacientes oncológicos. RESULTADOS E DISCUSSÃO: A religiosidade, por apresentar-se como importante ferramenta de auxílio no cuidado, desempenha um importante papel no enfrentamento do câncer, desde a descoberta e durante todo o tratamento, por tanto a identificação, por parte da equipe de saúde, dos pacientes que utilizam desse enfrentamento espiritual auxilia na escolha de adequadas condutas e intervenções. Além disso, cabe ressaltar a necessidade de um olhar empático não apenas com o paciente, mas com toda a sua família, sendo necessário um cuidado singular para cada membro. Tal cuidado pode ainda ser útil para amparar de forma humanizada pacientes que se encontram em fase terminal. Ademais, é de extrema importância a capacitação de profissionais que aliem a gerência do cuidado com ferramentas espirituais. CONCLUSÃO: A religiosidade tem desempenhado um importante papel no tratamento e na cura do câncer não só para o paciente, mas também para os familiares que o acompanham no seu tratamento. Ainda há uma deficiência de 
profissionais que atuem com os cuidados que são geridos por protocolos e ao mesmo tempo associe o cuidado espiritual.

\section{Referências}

Batista S, Mendonça A R A. Espiritualidade e qualidade de vida nos pacientes oncológicos em tratamento quimioterápico. Ver Bioética. 2012; 20(1):175-88

Brasil. Instituto Nacional de Câncer José Alencar Gomes da Silva. Estimativa 2018: incidência de câncer no Brasil. Rio de Janeiro: INCA; 2017.

Brasil. Ministério da Saúde. Portaria nº874, de16 de maio de 2013-Institui a Política Nacional para a Prevenção e Controle do Câncer na Rede de Atenção à Saúde das Pessoas com Doenças Crônicas no âmbito do Sistema Único de Saúde (SUS), 2013.

Costa P, Leite R d C B d O. Estratégias de enfrentamento utilizadas pelos pacientes oncológicos submetidos a cirurgias mutiladoras. Ver Brás câncer ol.2009;55(4):355. 


\title{
RELATO DE CASO DE UM PACIENTE ACOMETIDO POR LEUCEMIA LINFÓIDE AGUDA: DO DIAGNÓSTICO AO TRATAMENTO
}

\author{
João Manoel Almeida Santos ${ }^{1}$; Maria Vitória Cunha de Azevedo1; Yandra Ariane Gomes \\ Lima $^{1}$; Anna Clara Cavalcante de Moura ${ }^{1}$; Paulo Gabriel Leal Gonçalves ${ }^{1}$; Eliamara Barroso \\ Sabino Nogueira ${ }^{2}$ \\ ${ }^{1}$ Acadêmico(a), Centro Universitário Uninovafapi, Teresina, Piauí, Brasil; \\ ${ }^{2}$ Docente, Centro Universitário Uninovafapi, Teresina, Piauí, Brasil. \\ Autor para correspondência: João Manoel Almeida Santos / \\ joaomanoelalmeidasantos98@gmail.com / 86981581150
}

INTRODUÇÃO: A leucemia linfóide aguda (LLA) é uma doença maligna derivada das células linfóides indiferenciadas (linfoblastos) que estão presentes em grande número na medula óssea, no timo e nos gânglios linfáticos. Acumula-se grande quantidade de linfoblastos em diferentes etapas da maturação, pois os mesmos mantêm capacidade de multiplicação, mas não de diferenciação até formas maduras e normais. Embora a LLA possa ocorrer em qualquer idade, sua incidência é maior entre crianças de 2 a 5 anos, numa porcentagem de cerca de $70 \%$, diminuindo entre adolescentes e adultos jovens. $\mathrm{O}$ diagnóstico da LLA fundamenta-se na demonstração de mais de $25 \%$ de linfoblastos na medula óssea. O hemograma pode revelar anemias normocítica e normocrômica e trombocitopenia. A diferenciação entre linfoblastos e blastos da leucemia mieloide aguda (mieloblastos) é feita por critérios morfológicos, citoquímicos e imunofenotipagem. $\mathrm{O}$ tratamento é baseado em esquema de quimioterapia, levando-se em consideração as características clínicas, imunológicas, citogenéticas e o envolvimento ou não de outros órgãos para a escolha do protocolo mais adequado, visando a remissão da doença. Por vezes não é possível diminuir a sobrevida livre de doença, sendo o transplante de célulastronco hematopoiéticas (TCTH) uma boa opção terapêutica na consolidação da remissão nas leucemias. RELATO DE CASO: J.V.O.S, Médico Ultrassonografista. Em janeiro de 2014, iniciou um quadro de tosse com cansaço progressivo. Cerca de 5 dias após o aparecimento dos primeiros sintomas, constatou trombose da veia jugular interna direita. Foi submetido a tomografia de tórax que mostrou massa mediastinal. Foi realizado mielograma com biópsia óssea por punção aspirativa. O diagnóstico inicial foi de LLA/ linfoma linfoblástico de células T. Foi submetido a 6 ciclos de quimioterapia do protocolo Hyper-CVAD. Após o $2^{\circ}$ ciclo de quimioterapia houve remissão da massa mediastinal e normalização do mielograma. Em 5 de Agosto de 2014, foi submetido a TCTH sendo a irmã doadora HLA (Human Leukocyte Antigen) compatível e de mesma tipagem sanguínea $(\mathrm{A}+)$. Paciente vem evoluindo com doença enxerto contra hospedeiro (DECH) crônica de fígado pele e pulmões. Encontra-se em uso de Micofenolato de Mofetila (MMF). CONSIDERAÇÕEES FINAIS: Conclui-se que a LLA apresenta uma evolução rápida com sintomatologia inespecífica. O diagnóstico é suspeitado a partir do hemograma e há uma associação de exames, fundamentais para a diferenciação da linhagem acometida, tratamento e prognóstico do paciente. O tratamento é direcionado de acordo do quadro clínico de cada paciente, o TCTH é uma alternativa, porém pode ocasionar sérios problemas, como DECH.

Palavras-chave: Diagnóstico, Evolução, Câncer, Leucemia Linfoblástica Aguda, Tratamento. 


\section{Referências}

Farias Mariel a Granero, Castro Simone Martins de. Diagnóstico laboratorial das leucemias linfoides agudas. J. Bras. Patol. Med. Lab. [Internet]. 2004 Abr [citado2019Ago09];40(2):9198.Disponívelem:http://www.scielo.br/scielo.php?script=sc i_arttext\&pid=S1676-24442004000200008\&lng=pt.http://dx.doi.org/10.1590/S167624442004000200008.

Zanichelli Maria Aparecida, Colturato Vergilio R., Sobrinho Jairo. Indicações em transplante de células-tronco hematopoéticas em pacientes adultos com leucemia linfoide aguda. Rev. Bras. Hematol. Hemoter .[Internet]. 2010 maio [citado 2019 Ago 09];32(Suppl1):54-60.Disponível

em: http://www.scielo.br/scielo.php?script=sci_arttext\&pid=S151684842010000700010\&ln $\mathrm{g}=$ pt.Epub30-Abr-2010.http://dx.doi.org/10.1590/S1516-84842010005000030. 


\title{
MUSICOTERAPIA NA MELHORIA DA QUALIDADE DE VIDA PARA PACIENTES ONCOLÓGICOS: UMA REVISÃO DE LITERATURA
}

\author{
Heverson Dias de Araújo $^{2}$; Erica Isabel de Abreu Freire ${ }^{1}$; Raniella Borges da Silva ${ }^{1}$;

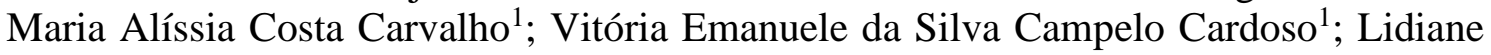 \\ Pereira de Albuquerque ${ }^{1}$

\footnotetext{
${ }^{1}$ Universidade Federal do Piauí, campus Ministro Petrônio Portela, Teresina, Piauí, Brasil

${ }^{2}$ Faculdade Integral Diferencial - FACID Wyden
}

Autor para contato: Heverson Dias de Araújo / heversondias7@gmail.com / 86 981772575

INTRODUÇÃO: O câncer atinge os pacientes física e mentalmente e tem seu poder no ápice quando o diagnostico não tem cura. Devido à esta capacidade de alcance da doença, surge a busca por cuidados paliativos e humanizados, dando assim um tratamento mais especifico para cada paciente, proporcionando maior conforto, bem estar e alívio da dor. Na musicoterapia, o profissional auxilia na promoção da saúde do paciente utilizando experiências musicais e as relações que se desenvolvem através delas como forças dinâmicas de mudança. OBJETIVO: Analisar os efeitos da musicoterapia na melhora da qualidade de vida de pacientes oncológicos. MÉTODOS: Trata-se de uma revisão narrativa de literatura. $\mathrm{O}$ processo de seleção dos artigos (em inglês e português) incluiu a busca no banco de dados Scielo e Google Acadêmico. Priorizaram-se trabalhos que abordavam os efeitos da musicoterapia em pacientes oncológicos. Entre os artigos pesquisados, dez atenderam aos critérios de inclusão (publicação entre 2010 e 2018, textos completos e estreita relação com o tema). RESULTADOS: A dor, em oncologia, se apresenta de modo agudo ou crônico e com características peculiares. Não apenas como dor física, provocada pelo tumor, mas também como reflexo da situação que o paciente vive, incluindo os aspectos físicos, mentais e espirituais. Foi demonstrando que a musicoterapia reduz a ansiedade e o estresse dos pacientes. Também foi mostrado que pacientes utilizando musicoterapia têm uma significativa redução da pressão arterial (PA) e da frequência cardíaca (FC) bem como do nível de dor. A redução do nível de dor pode ser explicada pelo fato de haver uma ação da música na função autônoma que causa uma estimulação da pituitária, resultando na liberação de endorfina, diminuindo a dor e levando os pacientes a reduzirem potencialmente a necessidade de analgésicos. CONCLUSÃO: A musicoterapia tem se mostrado um cuidado alternativo que, ao ser utilizado concomitantemente com o tratamento medicamentoso, pode melhorar não só o nível de dor do paciente, mas também outros aspectos como a ansiedade, incapacidade e irritabilidade. A importância desse tratamento está em olhar para o paciente em toda sua completude (psicológico, social e sentimentos) diferindo dos tratamentos convencionais em que a doença é tratada apenas no âmbito orgânico/fisiológico.

Palavras-chave: Oncologia, cuidados paliativos, musicoterapia.

\section{Referências}

Waterkemper, R; Reibnitz, K. S. Cuidados paliativos: a avaliação da dor na percepção de enfermeiras. Rev Gaúcha Enferm., Porto Alegre(RS)2010mar;31(1):84-91.

Bittencourt, W. S.et al. O efeito da música clássica no alívio da dor de crianças com câncer. UNI Ciências,v.14,n.1,2010. 


\title{
A IMPORTÂNCIA DOS SUBTIPOS MOLECULARES NO DIAGNÓSTICO DO CÂNCER DE MAMA: UMA REVISÃO DE LITERATURA
}

\author{
${ }^{1}$ Leonara Maria Alves Coelho; ${ }^{1}$ Iarly Santos Lima; ${ }^{2}$ Weslley Amorim de Macedo; \\ ${ }^{3}$ Msc. Aldenora Maria Ximenes Rodrigues. \\ ${ }^{1}$ Graduanda em Biomedicina pela Universidade Federal do Piauí (UFPI/CMRV) \\ ${ }^{2}$ Graduando em Medicina pela Universidade Federal do Piauí (UFPI/CMPP) \\ ${ }^{3}$ Mestre e Docente da Universidade Federal do Piauí (UFPI/CMRV)
}

Autor para correspondência: Leonara Maria Alves Coelho / leonaram.coelho@gmail.com / 89994207305

INTRODUÇÃO: Segundo o Instituto Nacional do Câncer (INCA), estima-se 59.700 casos novos de câncer de mama no território brasileiro, para o biênio 2018-2019, com um risco estimado de 56,33 casos a cada 100 mil mulheres. Nesse sentido, o conhecimento sobre subtipos moleculares de câncer de mama é relativamente recente quando comparado aos parâmetros tradicionais, como: tamanho, grau do tumor e status linfonodal. Além disso, pode ser útil no planejamento terapêutico e determinação de prognóstico dos pacientes acometidos. OBJETIVO: Descrever os principais subtipos moleculares do câncer de mama e suas principais características, destacando os marcadores imuno-histoquímicos utilizados para sua caracterização. MÉTODOS: Tratase de uma revisão de literatura nas bases eletrônicas PubMed e Medline a partir dos descritores "câncer de mama", "diagnóstico" e "imuno-histoquímica". O estudo foi baseado em artigos publicados entre junho de 2015 e junho de 2019. RESULTADOS: Os estudos relataram que o curso clínico de cada subtipo molecular de câncer de mama é diferente e define o tratamento juntamente com outras características clínico-patológicas, de modo que o luminal caracteriza-se pela expressão de receptores hormonais (RH) e apresenta-se com um comportamento menos agressivo que pode ser beneficiado através da terapia hormonal com ou sem quimioterapia. Aqueles que superexpressam HER2 têm comportamento mais agressivo e precisam de terapias mais específicas e elaboradas. Foi possível classificá-los em quatro principais: Luminal A, Luminal B, triplo-negativo e HER2+. Neto e colaboradores (2015) demonstraram que o subtipo mais comum é o Luminal B com 59,3\% e o menos comum é o HER2+ com 11,9\% dos casos. Os tumores luminais apresentam receptor de estrógeno (RE) positivo, padrões de expressão gênica das células epiteliais luminais mamárias, fenótipo de baixa proliferação celular, expressão elevada de genes relacionados ao RE e bom prognóstico. Já os tumores luminais tipo B apresentam altas taxas de proliferação, tipo histológico agressivo e prognóstico pior que os luminais A. O subtipo basal, também conhecido como 'triplo negativo', apresenta RE, receptor de progesterona (RP) HER2 negativos, comportamento agressivo de pior prognóstico e alvo terapêutico não definido. CONCLUSÃO: Portanto, a abordagem diagnóstica baseada nos subtipos moleculares representa um futuro promissor para as modalidades de tratamento. Porém, é necessário mais estudos aprofundados da correlação entre os seus aspectos gerais e sua utilização no diagnóstico do câncer de mama.

Palavras-chave: câncer de mama; diagnóstico; imuno-histoquímica

\section{Referências:}


NETO, N. J. S. B. et al. Perfil epidemiológico dos subtipos moleculares de carcinoma ductal da mama em população de pacientes em Salvador, Bahia. Rev Bras Mastologia, v. 24 n. 4 p. $98-102,2015$.

PROVENZANO, E.; ULANER, G. A.; CHIN, S. F. Molecular classification of breast câncer. PET Clin, v. 13, n. 3, p. 325-338, 2018.

SOLIS, A. E. V. et al. Supervivencia em câncer de mama por subtipo mediante imunohistoquímica: um estúdio retrospectivo. Gac Med Mex, v. 155, p. 50-55, 2019. 


\title{
INVESTIGAÇÃO DO EFEITO IMUNOMODULADOR DA L- CITRULINA NA TERAPIA ONCOLÓGICA: UMA REVISÃO DE LITERATURA
}

\author{
Raniella Borges da Silva ${ }^{1}$; Ellienai Erika Pereira de Sousa ${ }^{1}$; Arielly Jesus Leitão ${ }^{1}$; \\ Thaylla; Nara Hipólito Carvalho ${ }^{1}$; Heverson dias de Araújo²; Lidiane Pereira de \\ Albuquerque $^{3}$ \\ ${ }^{1}$ Graduanda em Nutrição, Universidade Federal do Piauí, Teresina, Piauí, Brasil \\ ${ }^{2}$ Graduando em Enfermagem, Faculdade integral diferencial - FACID Wyden, Teresina, \\ Piauí, Brasil \\ ${ }^{3}$ Docente, Depto de Bioquímica e Farmacologia, Universidade Federal do Piauí, \\ Teresina, Piauí, Brasil
}

Autor para correspondência: Raniella Borges da Silva / raniellaborges35gmail.com / 89 981460028

INTRODUÇÃO: Existe uma relação dinâmica entre câncer, nutrição e imunidade. A perda de peso e a desnutrição observadas em pacientes oncológicos comprometem significativamente a defesa imunológica, que depende de uma adequada oferta de aminoácidos para a síntese de proteínas e de outras biomoléculas. Nesse contexto, estudos indicam que a suplementação do aminoácido L-citrulina, no suporte de terapia nutricional, melhora eficientemente os níveis sanguíneos da arginina, um aminoácido condicionalmente essencial, avaliado como substrato para o implemento do sistema imunológico e para a redução da caquexia associada ao paciente com câncer. OBJETIVO: Analisar o efeito imunomodulador da suplementação de L-citrulina na terapia de suporte de nutricional para pacientes oncológicos. METODOLOGIA: Tratase de uma revisão narrativa de literatura. O processo de seleção dos artigos (em inglês e português) incluiu a busca no banco de dados Scielo, Lilacs e PubMed. Priorizaram-se os trabalhos que abordavam a ação da citrulina no sistema imunológico do paciente portador de câncer, bem como a sua resposta na redução da desnutrição energético-proteica. Entre os artigos pesquisados e analisados, quinze atenderam aos critérios de inclusão (publicação entre 2010 e 2018, textos completos e estreita relação com o tema). RESULTADOS: A L-citrulina é convertida em arginina pelos rins, melhorando a função de células $T$, a resposta imune mediada por células, a produção de anticorpos e o aceleramento da cicatrização. Estudos apontam que a suplementação de citrulina (em contraste com a depleção de L-arginina) durante o estresse e a infecção no câncer pode promover o incremento das vias específica e não-específica de ação tumoral, retardar o crescimento do tumor, diminuir a desnutrição energético-proteica e a taxa de mortalidade, conforme observado em condições experimentais. Adicionalmente, citrulina e arginina contribuem para produção de óxido nítrico, um gás solúvel lipofílico que promove a inibição do crescimento do tumor e do processo de metástase. CONCLUSÃO: A Lcitrulina demonstra efeitos imunomoduladores positivos para o prognostico do câncer e sua suplementação mostra-se como uma alternativa de uso atraente em pacientes oncológicos tanto por suas ações diretas (inibição da progressão e biologia do tumor) como por mecanismos indiretos de atuação (manutenção da massa muscular esquelética). Portanto, considerando a importância desse fármaco-nutriente, bem como a magnitude que o câncer vem ocupando no perfil epidemiológico mundial, justifica-se aprofundar os estudos que elucidem a sua relação imunomoduladora nas neoplasias malignas.

Palavras-chave: Oncologia, L-citrulina, Imunonutrição. 


\section{Referências}

CHANG, Ching Fang; DIERS, Anne R.; HOGG, Neil. Cancer cell metabolis mand the modulating effects of nitricoxide. FreeRadicalBiologyandMedicine,v.79,p.324-336, 2015 .

LIRA, Fabio Santos et al. Estratégias nutricionais no tratamento da síndrome da caquexia associada ao câncer. Inova Saúde,v.1,n.1,2012.

PRIETO, Isabel et al. The role of immuno nutritional support in câncer treatment: Current evidence. Clinical Nutrition,v.36,n.6,p.1457-1464,2017. 


\title{
INFLUÊNCIA DO SELÊNIO NA REGULAÇÃO GÊNICA E TERAPIA ONCOLÓGICA: UMA REVISÃO DE LITERATURA
}

\author{
Raniella Borges da Silva ${ }^{1}$; Erica Isabel de Abreu Freire ${ }^{1}$; Maria Alíssia Costa Carvalho ${ }^{1}$; \\ Osita da Costa Britto Sousa ${ }^{1}$; Heverson Dias de Araújo ${ }^{2}$; Lidiane Pereira de Albuquerque ${ }^{3}$ \\ ${ }^{1}$ Graduanda em Nutrição, Universidade Federal do Piauí, Teresina, Piauí, Brasil \\ ${ }^{2}$ Graduando em Enfermagem, Faculdade Integral Diferencial - FACID Wyden, Teresina, \\ Piauí, Brasil \\ ${ }^{3}$ Docente, Depto. Bioquímica e Farmacologia, Universidade Federal do Piauí, Teresina, \\ Piauí, Brasil
}

Autor para correspondência: Raniella Borges da Silva / raniellaborges35gmail.com / 89 981460028

INTRODUÇÃO: O controle da morbidade e da mortalidade do câncer tem direcionado a atenção da comunidade científica para o estudo de nutrientes ou componentes bioativos que atuam na manutenção da estabilidade do genoma. Durante o desenvolvimento do câncer, a metilação do DNA e a modificação das caudas das histonas caracterizam as alterações epigenéticas, nas quais os nutrientes exibem papéis bastante relevantes. Sobre este aspecto, há relatos de que o micronutriente selênio, de ação antioxidante, pode promover reparos de danos ao DNA, trazendo, desta forma, futuras perspectivas à terapia oncológica. OBJETIVO: Investigar a influência do selênio na regulação da expressão gênica e no aumento da resposta celular ao tratamento oncológico. METODOLOGIA: $O$ presente estudo trata-se de uma revisão narrativa de literatura. O processo de seleção dos artigos (em inglês e português) incluiu a busca no banco de dados Scielo, Lilacs e PubMed. Priorizaram-se os estudos que abordavam a ação do selênio na regulação da expressão gênica, bem como a sua resposta ao tratamento do câncer. Entre os artigos pesquisados e analisados, vinte atenderam aos critérios de inclusão (publicação entre 2010 e 2018, textos completos e estreita relação com o tema). RESULTADOS: O selênio é um micronutriente de grande importância para a manutenção da homeostase celular. É componente essencial do sítio ativo de enzimas, apresenta propriedades antioxidantes, participa da transdução de sinais e, em particular, da expressão gênica da apoptose. Estudos têm demonstrado que a suplementação com selênio pode ser capaz de prevenir, reduzir ou inibir o processo de carcinogênese experimental em diferentes tipos de câncer. Adicionalmente, pesquisas relatam o papel deste micronutriente na diminuição da atividade de histonas deacetilases (HDAC), proteínas relacionadas com a patogênese do câncer e de várias outras doenças. Sendo assim, uma vez que os inibidores de HDAC podem restringir e bloquear a inibição da expressão gênica, o maior efeito biológico provém da indução da diferenciação em células tumorais, prisão do ciclo celular em G0/G1, ativação da apoptose celular e aumento da sensibilidade celular para quimioterapia e radioterapia. CONCLUSÃO: O selênio demonstra efeitos positivos para o tratamento do câncer e a sua suplementação pode se apresentar como um novo alvo na terapia oncológica. Logo, considerando a importância desse micronutriente, bem como a magnitude que o câncer vem ocupando no perfil epidemiológico mundial, justifica-se aprofundar os estudos que elucidem a sua relação na redução da progressão do câncer. Palavras-chave: Oncologia, Selênio, Terapia. 


\section{Referências}

ALMONDES, K. G.S. et al . The role of seleno proteins in cancer. Revista da Associação Médica Brasileira,v.56,n.4,p.484-488,2010.

FERNANDES, A. P.; GANDIN, V. Selenium compo undsas therapeutica gents in cancer. Biochimica et Biophysica Acta (BBA)-General Subjects,v.1850,n.8,p.16421660,2015 .

MURDOLO, G. et al. Selenium and câncer stem cells. In: Advances in câncer research. Academic Press,2017.p.235-257.

VIARO, R.S.; VIARO, M.S.; FLECK, J.A importância bioquímica do selênio para o organismo humano. Disciplinarum Scientia Saúde 


\section{USO DE [10]-GINGEROL PARA O TRATAMENTO COMPLEMENTAR DE CÂNCER DE MAMA METASTÁTICO TRIPLO NEGATIVO (TNBC): UMA REVISÃO DE LITERATURA}

Ellienai Erika Pereira de Sousa ${ }^{1}$; Erica Isabel de Abreu Freire ${ }^{1}$; Raniella Borges da Silva ${ }^{1}$; Maria Alíssia Costa Carvalho ${ }^{1}$; Lidiane Pereira de Albuquerque ${ }^{1}$

${ }^{1}$ Universidade Federal do Piauí, campus Ministro Petrônio Portela, Teresina, Piauí, Brasil Autor para correspondência: Ellienai Erika Pereira de Sousa / ellienaierikah15@gmail.com / 86988171630

INTRODUÇÃO: O câncer de mama metastático triplo negativo (TNBC) é caracterizado pela rápida progressão à metástase e, embora inicialmente responda à quimioterapia, a recidiva é comum, com o surgimento de metástases quimio-resistentes, resultando em morte. Tais fatores motivam a busca por produtos naturais com menos efeitos colaterais para quimioterapias alternativas ou complementares. O rizoma de gengibre é rico em compostos bioativos como os gingeróis. Evidências crescentes indicam que os gingeróis medeiam as atividades antitumoral e anti-metastática in vitro em vários tipos de tumor, incluindo câncer de mama. OBJETIVO: Realizar uma revisão de literatura acerca de publicações que abordassem a ação terapêutica do [10]-gingerol no tratamento do TNBC. MÉTODOS: A seleção dos artigos incluiu a busca nos bancos de dados da Scielo, Lilacs e PubMed entre o período de 2010 e 2019. O critério de busca integrou as seguintes palavras-chave: [10]-gingerol; [10]-gingerol e câncer de mama; [10]-gingerol e ação antitumoral. RESULTADOS: Poucos estudos investigaram as propriedades antitumorais do [10] -gingerol e pouco se sabe sobre seu mecanismo de ação. Foi observado que o [10] -gingerol induz a apoptose em células TNBC. Estudos relataram que este composto inibe a proliferação e invasão de células de câncer de mama. Além disso, foi demonstrado que o [10] -gingerol é capaz de reverter o fenótipo maligno de células de câncer de mama em cultura tridimensional, promovendo a potente atividade anti-neuroinflamatória e, assim, contribuindo para o tratamento de metástases cerebrais. CONCLUSÃO: [10] -gingerol pode beneficiar pacientes com câncer de mama com metástase cerebral, através de suas propriedades diretas antitumorais e/ou neuro-protetoras.

Palavras-chave: [10] -gingerol; Câncer de mama metastático triplo negativo, Atividade antitumoral.

\section{Referências}

BERNARD,M.M;MCCONNERYJ;HOSKIN,D.W.[10]-Gingerol, ama jor phenolic constituent of gingerroot, induces cellcy clear restanda poptosis in triple-negative breast câncer cells. 2017. Disponível em: <https://www.ncbi.nlm.nih.gov/pubmed/28315687>. Acesso em: 15 jun. 2019. 
FUZER, A.M. et al.[10]-Gingerol Affects Multiple Metastatic Processes and Induces Apoptosis in MDAMB-231 Breast Tumor Cells. 2019. Disponível em: <https://www.ncbi.nlm.nih.gov/pubmed/30370858>.Acessoem:16jun.2019.

MARTIN, A.C.B.M. et al.[10] gingerol induces apoptosis and inhibits metastatic dissemination of triple negative breast câncer in vivo. 2017. Disponívelem:<https://www.ncbi.nlm.nih.gov/pubmed/29069785>.Acessoem:16jun.20 19. 


\section{INFLUÊNCIA DA MICROBIOTA INTESTINAL PARA O TRATAMENTO DO CÂNCER: UMA REVISÃO DE LITERATURA}

Arielly Jesus Leitão ${ }^{1}$; Erica Isabel de Abreu Freire ${ }^{1}$; Raniella Borges da Silva ${ }^{1 ;}$ Letícia Gabriely Madeira de Anchieta Silva ${ }^{1 ;}$ Heverson Dias de Araújo ${ }^{2}$; Lidiane Pereira de Albuquerque $^{1}$

Autor para correspondência: Arielly Jesus Leitão / arielly2110@gmail.com / 98 981583746

${ }^{1}$ Universidade Federal do Piauí, campus Ministro Petrônio Portela, Teresina, Piauí, Brasil.

${ }^{2}$ Faculdade Integral Diferencial - FACID Wyden

INTRODUÇÃO: A resistência aos ciclos quimioterápicos, a imunossupressão e os efeitos colaterais ainda são aspectos que dificultam o sucesso do tratamento do câncer. Nesse cenário, novas descobertas científicas sobre o comportamento da microbiota intestinal surgem como apostas promissoras para otimizar a resposta da intervenção antineoplásica. A farmacomiografia possui o potencial de aumentar a eficácia terapêutica e anular os efeitos colaterais, através da manipulação de interações quimioterápicohospedeiro-microbiota e para personalização de regimes quimioterápicos baseados na avaliação do microbiota de um indivíduo. Uma maior compreensão da interação complexa entre a microbiota intestinal e o sistema imunitário também pode gerar novas abordagens quimioterapêuticas. OBJETIVO: Investigar a influência positiva da microbiota intestinal no tratamento do câncer. METODOLOGIA: Trata-se de uma revisão de literatura. O processo de seleção dos artigos (em inglês, espanhol e português) incluiu a busca no banco de dados Scielo, Lilacs e PubMed. Foram selecionados os trabalhos que apresentavam abordagem sobre a influência da microbiota intestinal no tratamento de pessoas com câncer. Dentre os artigos pesquisados, doze atenderam aos critérios de inclusão (publicação entre 2010 e 2018, textos completos e estreita relação com o tema). RESULTADOS: Há evidências crescentes de que a microbiota intestinal modula a resposta do hospedeiro aos quimioterápicos, com três principais desfechos clínicos: facilitação da eficácia do medicamento, revogação e comprometimento dos efeitos anticancerígenos e mediação de toxicidade. A microbiota intestinal é crítica para o desenvolvimento de estratégias personalizadas de tratamento do câncer e, portanto, uma maior compreensão do co-metabolismo procariótico de drogas quimioterápicas é necessária. Estudos in vitro mostraram que bactérias intestinais estão intimamente ligadas aos efeitos farmacológicos das quimioterapias (5-fluorouracil, ciclofosfamida, oxaliplatina, metotrexato) e novas imunoterapias direcionadas, tais como as terapias antiPD-L1 e anti-CLTA-4. CONCLUSÃO: Durante a terapia do câncer, a microbiota intestinal é uma estrutura dinâmica, influenciada por interações complexas entre múltiplos fatores, como imunidade do hospedeiro, quimioterápicos, medicações concomitantes, ambiente e dieta. A manipulação da microbiota intestinal para alcançar um equilíbrio perfeito entre a eficácia quimioterápica e a redução dos efeitos colaterais representa um desafio significativo. Portanto, o potencial da farmacovigilância pode proporcionar uma nova era de tratamento do câncer, melhorando a eficácia e a tolerabilidade.

Palavras-chave: Antineoplasia, Câncer, Microbiota. 


\section{Referências}

ALEXANDER, James L. e tal. Modulação da microbiota intestinal da eficácia e toxicidade da quimioterapia. Nature Reviews Gastroenterology \& Hepatology, v.14, n.6, p. 356, 2017.

YANG, Yongzhi et al. Integrated microbiome and metabolome analysis reveals a novel interplay between commensal bactéria and metabolites in colorectal cancer. Theranostics, v.9, n.14, p.4101, 2019. 


\section{PERFIL EPIDEMIOLÓGICO DO CÂNCER INFANTO-JUVENIL NO ESTADO DO PIAUÍ}

Laís Neiva Rego Siqueira1; Isadora Soares Marques²; Karen Lima Barradas²; Ana Valéria de Carvalho²; Augusto César Maia Rio Lima Silveira ${ }^{2}$; João Luiz Vieira Ribeiro ${ }^{3}$

${ }^{1}$ Acadêmica do curso de medicina no Centro Universitário Uninovafapi, Teresina- PI, Brasil;

${ }^{2}$ Acadêmicos do curso de medicina no Centro Universitário Uninovafapi, Teresina- PI, Brasil;

${ }^{3}$ Médico pneumologista, docente do curso de medicina no Centro Universitário Uninovafapi, Teresina-PI, Brasil

Autor para correspondência: Haylane Nunes da Conceição / lanenunes_@hotmail.com / 99982599435

INTRODUÇÃO: O percentual dos tumores infanto-juvenis brasileiros é de 3\%, assim, espera-se que ocorram 12.500 casos novos de câncer em crianças e adolescentes até os 19 anos a cada ano no Brasil, sendo as regiões sudeste e nordeste as que apresentam os maiores números de casos. OBJETIVO: Descrever o perfil epidemiológico dos cânceres infanto-juvenis no estado do Piauí, observando a sua distribuição nos últimos 10 anos. MÉTODOS: Estudo ecológico e descritivo, com base nos dados do Sistema de Informação Hospitalar (SIH/SUS) e do Instituto Nacional do Câncer (INCA), no período de janeiro de 2008 a dezembro de 2018, associado à revisão de literatura na base de dados LILACS.Após a coleta, os dados foram transferidos para o programa Windows Excel versão 2013, no qual os gráficos e tabelas foram construídos e, em seguida, analisados. RESULTADOS: Observando-se o levantamento no Sistema de Informação Hospitalar (SIH/SUS), pode-se observar que as neoplasias do tecido linfo-hematopoiético representam aproximadamente $54 \%(\mathrm{n}=4889)$ das neoplasias infanto-juvenis no estado do Piauí no período de 2008 a 2018. Neste tecido, as leucemias representam 48,8\% (n= 4460) e o linfoma não-hodgkin 4,09\% $(n=374)$. Enquanto que os índices de incidência de câncer de próstata, mama e órgãos reprodutivos femininos não apresentaram relevância epidemiológica. Detendo-se à observação na faixa de 0-14 anos, há a predominância de leucemias - 42,99\%, neoplasias do sistema osteoarticular - 10,33\%, neoplasias do trato genitourinário - 8,56\%. Estendendo-se a observação até os 19 anos, a predominância continua a mesma, porém com um aumento considerável das neoplasias malignas de pele. CONCLUSÃO: Conlui-se que distribuição epidemiológica do câncer infanto-juvenil (0-19 anos) no Piauí corresponde à distribuição brasileira, porém com menor percentual de neoplasias de sistema nervoso central do que o estipulado.

Palavras-chave: Câncer, Crianças, Adolescentes, Piauí

\section{Referências}

INSTITUTO NACIONAL DE CÂNCER. MINISTÉRIO DA SAÚDE. Câncer infanto juvenil. 21. maio. 2019. Disponívelem:www.inca.gov.br/tipos-de-cancer/cancer-infanto juvenil.Acessoem18.junho.2019.

MUTTI, Cintia Flôres et al. Perfil clínico-epidemiológico de crianças e adolescentes com câncer em um serviço de oncologia. Revista Brasileira de Cancerologia, v.64, n.3, p.293-300, 2018. 
ZOUAIN-FIGUEIREDO, Gláucia Perini, et al. Perfil epidemiológico dos casos novos de câncer infanto-juvenil em hospital de referência no Espírito Santo, Brasil, de 1986 a 2010. Revista Brasileira de Pesquisa em Saúde, v.17, n.4, p.109-120, 2016.

SANTOS, B. P. M.et al. Epidemiologia do câncer infanto-juvenil do hospital Nossa Senhora da Glória nos anos de 2010 a 2015. Revista Esfera Acadêmica de Saúde, v.1, n.2, 2016.

FRIESTINO, Jane Kelly Oliveira $e$ tal .Panorama do câncer em crianças e adolescentes sob a perspectiva da saúde coletiva. Revista Baiana de saúde pública, v.40, n.2, 2017. Disponível em: http://doi.org/10.22278/2318-2660.Acesso em18. junho.2019.

OLIVEIRA SANTOS, Marceli de. Incidência, mortalidade e morbidade hospitalar por câncer em crianças, adolescentes e adultos jovens no Brasil: informações dos registros de câncer e do sistema de mortalidade. Revista Brasileira de Cancerologia, v.64, n.3,p. 439-440, 2018. 


\title{
PROMOÇÃO A SAÚDE DE PACIENTES ONCOLOGICOS: RELATO DE EXPERIÊNCIA
}

\author{
Haylane Nunes da Conceição ${ }^{1}$; Hayla Nunes da Conceição²
}

${ }^{1}$ Acadêmica de fisioterapia, UniFacema, Caxias, Maranhão, Brasil;

${ }^{2}$ Graduada em Enfermagem pela UEMA; Mestranda em Saúde e Comunidade-UFPI, Caxias, Maranhão, Brasil

Autor para correspondência: Haylane Nunes da Conceição / lanenunes_@ hotmail.com / 99982599435

INTRODUÇÃO: A incidência de câncer tem crescido no Brasil, assim como em todo mundo, acompanhando a mudança do perfil etário da população. Assim, visualiza-se a necessidade da criação de grupos para possibilitar a promoção da saúde e apoio aos pacientes oncológicos. Os grupos de apoio têm apresentado uma demanda crescente no contexto nacional e internacional e vêm se consolidando como uma modalidade de cuidado eficaz. Os participantes de buscam obterem informações, orientações, opiniões, encorajamento, compartilhamento de experiências e apoio psicológico. OBJETIVO: Relatar a experiência do desenvolvimento de atividades de acolhimento e promoção à saúde a pacientes oncológicos. MÉTODOS: A abordagem metodológica do projeto consiste na excursão de atividades de extensão com o objetivo de promover a saúde de paciente com câncer, no município de Caxias - MA. O projeto foi desenvolvido na "ONG ANLUCC-Amigos na Luta Contra o Câncer”, que atende pacientes de todo o Estado do Maranhão. A execução no grupo foi por meio do desenvolvimento de atividades lúdicas, de lazer e descontração, por meio da: musicoterapia, momento de reflexões e oração . RELATO DA EXPERIÊNCIA: Através do desenvolvimento das atividades foi possível promover a melhora da qualidade de vida dos pacientes, bem como possibilitou o intercâmbio de experiência e informações sobre o câncer, mecanismos de enfretamento da doenças e direito dos pacientes oncológicos. Ainda oportunizou momento de lazer e religiosidade. CONSIDERAÇÕES FINAIS: O desenvolvimento do projeto possibilitou uma atenção mais humanizada aos pacientes com câncer, bem como permitiu promover a saúde dos pacientes com câncer e auxiliando do tratamento da doença por meio do apoio e inserindo-os na lutas pelos seus direitos.

Palavras-chave: Promoção da saúde, Câncer, Saúde.

\section{Referências}

MOSCHETA, Murilo dos Santos et al. Grupos de apoio para homens com câncer de próstata revisão integrativa da literatura. Ciência \& Saúde Coletiva, v.17, n.5, p.12251233,2012 


\section{APRESENTAÇÃO ATÍPICA DE CARCINOMA EPIDERMOIDE ESOFÁGICO DE BAIXO GRAU}

Sousa Neto, A. M. ${ }^{1}$; Normando, S.R.C. ${ }^{2}$.

1. Especialista em Clínica Médica, Universidade Estadual do Piauí, Teresina, Piauí, Brasil;

2. Especialista em Oncologia Clínica, Faculdade de Medicina do ABC, São Paulo, Brasil

Autor para correspondência: Antonio Moreira de Sousa Neto / antonionetomed@gmail.com

INTRODUÇÃO: No Brasil, o câncer de esôfago é o sexto mais prevalente, sendo a histologia carcinoma epidermoide diagnosticado em $96 \%$ dos casos. O principal método diagnóstico é a endoscopia digestiva alta e o estadiamento é complementado com tomografias de tórax e abdome. A maioria dos pacientes são diagnosticados em estado avançado da doença, sendo relacionado sobretudo a tumores de alto grau. Dessa forma é incomum tumores de baixo grau de diferenciação apresentarem rápida progressão e metástases a distância. Neste estudo relatamos um caso de carcinoma de esôfago inferior bem diferenciado com invasão extensa do mediastino anterior e médio, comprometimento miocárdico associado a trombo intracavitário e metástases ósseas. RELATO DE CASO: C.A.R., 60 anos, sexo masculino, coronariopata, paraparético, com história perda ponderal, disfagia e dor óssea há 3 mês do diagnóstico. Realizou-se esofagoscopia que identificou uma lesão vegetante, obstrutiva, em esôfago inferior. Realizou-se exame histopatológico, evidenciando um carcinoma espinocelular bem diferenciado de esôfago confirmado por estudo imunohistoquímico. Ao estadiamento clínico, evidenciou-se em tomografia de tórax extensa massa esofagiana infiltrativa $(12,0 \mathrm{~cm})$ com íntimo contato com grandes vasos e coração. Complementou-se a investigação com ressonância cardíaca, que demonstrou disfunção sistólica biventricular associada a massa ocupando $50 \%$ do ventrículo direito, trombo aderido e sinais sugerindo tamponamento cardíaco. Evidenciou-se, ainda, metástases ósseas em arcos costais, osso ilíaco, acetábulo e ramo isquiopúbico direito. Devido perda de performance status do paciente, optou-se por suporte paliativo exclusivo, tendo o mesmo evoluído a óbito após 2 meses do diagnóstico. CONSIDERAÇÕES FINAIS: É incomum que tumores bem diferenciados de esôfago se apresentem com invasão extensa e agressiva ao diagnóstico, sobretudo relacionados a metástases, como no miocárdio. Dessa forma é imprescindível a confirmação histológica complementar por imunohistoquímica, a fim de estabelecer a melhor estratégia terapêutica. O paciente do estudo apresentava alto risco de morte súbita podendo apresentar laceração miocárdica espontânea, tromboembolismo maciço ou choque obstrutivo, devido a metástase miocárdica diagnosticada.

Palavras-chave: Metástases cardíacas; Carcinoma epidermóide; Neoplasias esofágicas.

\section{Referências}

Brasil. Ministério da Saúde. Instituto Nacional de Câncer, 2018.

Diretrizes Diagnóstica e Terapêuticas do Carcinoma de Esôfago. Secretaria de Atenção à Saúde. Ministério da Saúde, 2014. 
Jemal A, Bray F, Center MM, Ferlay J, Ward E, Forman D. Global cancer statistics. CA Cancer J Clin. 2011;61(2):69-90.

Allum WH, Blazeby JM, Griffin SM, Cunningham D, Jankowski JA, Wong R. Guidelines for the management of oesophagealandgastric cancer. Gut. 2011;60(11):1449-72.

Yang S, Wu S, Huang Y, Shao Y, Chen XY, Xian L, et al. Screening for oesophageal cancer. Cochrane Database Syst Rev. 2012. 


\section{EXPOSIÇÃO A AGROTÓXICOS E OS RISCOS DE DESENVOLVIMENTO DO LINFOMA NÃO-HODGKIN (LNH)}

Layza Karyne Farias Mendes ${ }^{1}$; Dheyson Sousa Dutra ${ }^{2}$; Renata Martins Costa ${ }^{2}$; Aldaisa Pereira Lopes ${ }^{2}$; Ma. Ana Cibele Pereira Sousa ${ }^{3}$.

${ }^{1}$ Discente, Universidade Federal do Piauí , Picos, PI, Brasil;

2 Discente, Universidade Federal do Piauí, Picos, PI, Brasil;

${ }^{3}$ Docente, Universidade Federal do Piauí, Picos, PI, Brasil.

Autor para correspondência: Dheyson Sousa Dutra / dheysonsousa97@bol.com.br / 89 999350563

INTRODUÇÃO: Os agrotóxicos são produtos de origem química e biológica (fungicidas, herbicidas, inseticidas e pesticidas) usados como defensivos agrícolas no controle de pragas. Ao longo dos anos, os padrões de Ingredientes Ativos (Ias) de agrotóxicos modificaram-se, em especial, nos países em desenvolvimento, devido ao avanço da produção agrícola, expondo assim, cada vez mais a população a esses ativos. Alguns desses IAs apresentam associações para a indução de carcinomas, como é o caso do Linfoma não-Hodgkin, um tipo de câncer de origem nas células do sistema linfático que faz parte do sistema imunológico. OBJETIVO: Com esse estudo, buscou-se analisar os fatores de riscos associados a população expostas a agrotóxicos e o desenvolvimento do linfoma não-Hodgkin. MÉTODOS: Realizou-se uma pesquisa na base de dado SciELO, sem demarcação temporal, em língua inglesa e portuguesa, utilizando os descritores agrotóxicos, Câncer, linfoma não-Hodgkin. Foram encontrados um total de 08 artigos, usando como critério de exclusão apenas artigos relacionando os IAs e câncer, foram selecionados 03 artigos para o presente estudo. RESULTADOS: Os herbicidas (2,4-D e glifosato) e os inseticidas (diazinona e malationa) atuam através de vários mecanismos de carcinogenicidade relevantes como a capacidade de atuar na morte celular, alterar o reparo do DNA, alterações epigenéticas, estresse oxidativo. Os IAs têm a capacidade de dano genotóxico por translocação cromossômica causada pelo rearranjo de partes entre cromossomos não-homólogos. Vale destacar também os resultados de imunossupressão para 2,4-D e da diazinona em ensaios in vitro com células humanas, e para o 2,4-D em humanos, também associado ao LNH. CONCLUSÃO: Os achados nesse estudo apresentam uma associação positiva de alguns ingredientes ativos dos agrotóxicos e a indução de neoplasias. Não obstante, estudos sobre o uso de agrotóxicos é um tema de suma relevância para o controle e a prevenção do câncer. Diante essa situação de estrema vulnerabilidade da população a doenças ocasionadas por agrotóxicos, condutas regulatórias e legislações mais restritivas são imprescindíveis.

Palavras-chave: Agrotóxicos, Câncer, Linfoma não-Hodgkin

\section{Referências}

CURVO, Hélen Rosane Meinke. Morbimortalidade por câncer infantojuvenil associada ao uso agrícola de agrotóxicos no Estado de Mato Grosso, Brasil. Cadernos Saúde Coletiva, Rio de Janeiro, 2013. Disponível em: SciELO. Acesso em: 12 jun. 2019.

COSTA, Vanessa Indio do Brasil. Exposição ambiental e ocupacional a agrotóxicos e o linfoma não Hodgkin. Saúde em Debate, Rio de Janeiro, 2017. Disponível em: SciELO. Acesso em: 14 jun. 2019. 
MAGALHÃES, Andrea Franco Amoras. Exposição ocupacional e envenenamento por produtos químicos no Distrito Federal. Revista Brasileira de Enfermagem, Brasília, 2019. Disponível em: SciELO. Acesso em: 15 jun. 2019. 


\section{AVALIAÇÃO DA ATIVIDADE ANTITUMORAL E QUIMIOPROTETORA DO INDOL-3-CARBINOL, UM FITONUTRIENTE ENCONTRADO NO BRÓCOLIS}

Najarah Caracas Cedro; Maria Janiele de Morais Silva; Antonio Thailson de Resende Abreu; Cleiton Nadson Aquino Barreto; Thais Ferreira Santos; João Marcelo de Castro e Sousa.

Autor para correspondência: Najarah Caracas Cedro / nahcaracas@gmail.com / 89 999327280

INTRODUÇÃO: A suplementação com fitoquímicos tem sido alvo de estudos para avaliar a atividade antitumoral e/ou a capacidade protetora durante o tratamento quimioterápico, já que a terapia não apresenta seletividade a células neoplásicas danificando as células normais e tornando o tratamento mais prejudicial ao paciente. Assim, o objetivo deste trabalho foi realizar uma busca na literatura e avaliar os possíveis efeitos modulatórios e protetores do Indol-3-carbinol (I3C), um fitonutriente encontrado em vegetais crucíferos, como o brócolis, que apresenta propriedades anticancerígenas, diante dos danos causados por quimioterápicos. METODOLOGIA: Foi realizada uma revisão sistemática nos bancos de dados Science Direct, PubMed, medline e Scielo durante o período de janeiro a março de 2019. As palavras-chaves utilizadas na identificação dos artigos foram associadas da seguinte forma: indol-3-carbinol e câncer; indol-3-carbinol e tratamento quimioterápico; indol-3-carbinol e quimioproteção. Os critérios de inclusão para a seleção dos artigos foram: artigos originais de pesquisa sobre I3C nos últimos 10 anos, publicados em português e/ou inglês que tivessem um dos descritores no título ou nas palavras-chave.. Os critérios de exclusão foram: trabalhos que não envolvessem fatores antitumorais e quimioprotetores do composto ou não disponibilizados na íntegra. RESULTADOS: O total de artigos identificados nas bases de dados citadas foram 326. Após a aplicação dos critérios de inclusão e exclusão foram selecionados, no total, 50 artigos. DISCUSSÃO: Os estudos avaliados confirmam os efeitos anticancerígenos do I3C, que pode agir inibindo os radicais livres diminuindo, assim, o estresse oxidativo em células normais causados pelos antineoplásicos, além de interferir na divisão celular tumoral e suprimir a migração de células tumorais, agindo como antimetastático. Ademais, em estudos in vivo, o I3C se mostrou um potente inibidor de adenocarcinoma pulmonar, quando administrado durante a fase inicial da tumorigênese ou após o desenvolvimento de tumores, indicando o potencial do composto não apenas para prevenir o câncer de pulmão, mas também para terapia. Pesquisas com exposição gestacional ao Bisfenol A (BPA), composto químico potencialmente cancerígeno para próstata, suplementado com I3C,mostrou que o fitonutriente tem efeito protetor em animais adultos expostos ao BPA durante a gestação reduzindo os efeitos do imprinting estrogênico gestacional sobre a próstata. CONCLUSÃO: o indol-3-carbinol mostrou-se ser um composto potencialmente antitumoral e capaz de ser utilizado como estratégia de suplementação no tratamento oncológico.

\section{Referências}

Qian, X., Melkamu, T., Upadhyaya, P., \& Kassie, F. (2011). Indole-3-carbinol inhibited tobacco smoke carcinogen -induced lung adenocarcinoma in $\mathrm{A} / \mathrm{J}$ mice when administered 
during the post-initiation or progression phase of lung tumorigenesis. Cancer letters, 311(1), 57-65. doi:10.1016/j.canlet.2011.06.023.

BRANDT, Joyce Zalotti. Exposição in uteroao desregulador endócrino bisfenol A e ao agente quimiopreventivoindol-3-carbinol: efeitos sobra a morfogênese e a suscetibilidade à carcinogênese prostática. Disponível em: repositorio.unesp.br.2013.

DE FELIPPE JUNIOR, José. Indol-3-Carbinol e Câncer: antiproliferativo, apoptótico e antiangiogênico. Disponível em:www.medicinaintegrativa.com.br.2011

KIM, Young S.; MILNER, J. A. Targets for indole-3-carbinol in cancer prevention. The Journal of nutritional biochemistry, v. 16, n. 2, p. 65-73, 2005. 


\section{MEDIDAS NÃO FARMACOLÓGICAS QUE AJUDAM A MINIMIZAR OS ENJOOS CAUSADOS PELO TRATAMENTO ONCOLÓGICO}

Najarah Caracas Cedro; Maria Janiele de Morais Silva; Antonio Thailson de Resende Abreu; Cleiton Nadson Aquino Barreto; Thais Ferreira Santos; João Marcelo de Castro e Sousa.

Autor para correspondência: Najarah Caracas Cedro / nahcaracas@gmail.com / 89 999327280

INTRODUÇÃO: É comum ocorrer toxicidade gastrointestinal, em decorrência de quimioterápicos, que por sua vez afetam o estado nutricional de pacientes, em virtude de náusea, vômitos e anorexia, fatores que comumente aceleram a perda de peso, além da disgeusia, dor, constipação e diarreia, outros sintomas comumente relatados pelos pacientes. Assim, é fundamental compreender e estudar formas de tratamento coadjuvante e medidas não farmacológicas que contribuam para a manutenção do estado nutricional do paciente oncológico reduzindo os efeitos colaterais adversos. OBJETIVO: buscar na literatura meios não farmacológicos que minimizem as náuseas e vômitos em pacientes oncológicos. MÉTODOS: realizou-se uma busca nas bases científicas PubMed, Lilacs e Medline, com as palavras chave "nutrição", "câncer" e "náuseas", "nutrição", "câncer" e "efeitos colaterais", em português e inglês e utilizando o conectivo quando necessário. Os critérios de inclusão foram: trabalhos originais, dos últimos 10 anos, que abordassem o tema, publicados em português e/ou inglês. Os de exclusão foram: trabalhos que não abordassem medidas não farmacológicas no tratamento oncológico. RESULTADOS: O total de artigos encontrados nas bases de dados citadas foram 238, 9 e 97, respectivamente. Após a aplicação dos critérios de inclusão e exclusão, foram selecionados 69 artigos. DISCUSSÃO: Os estudos avaliados mostraram que modificações na refeição, como evitar alimentos condimentados e doces, beber líquidos gelados, consumir alimentos secos e fracionar as refeições, são estratégias eficazes para evitar o aumento de enjoos. Comer devagar, evitar deitar-se e/ou fazer esforço após as refeições e não usar roupas apertadas são estratégias de comportamento alimentar que também podem auxiliar no tratamento quimioterápico. Pesquisas com alimentos específicos apontaram que o aumento da ingestão de frutas e vegetais pode reduzir a frequência e a severidade dos efeitos colaterais induzidos pela radioterapia no tratamento de câncer de cabeça e pescoço. Fitoquímicos, presentes em frutas, vegetais, grãos e outros alimentos vegetais, podem diminuir os efeitos colaterais da radioterapia e aumentar as taxas de sobrevida dos pacientes. CONCLUSÃO: estratégias não farmacológicas para a melhora dos efeitos colaterais do tratamento oncológico são possíveis de serem realizadas e eficazes, podendo ajudar numa melhora de efeitos negativos e no estado nutricional do paciente em tratamento oncológico.

\section{Referências}

MARX, Wolfgang et al. Chemotherapy-induced nausea and vomiting: a narrative review to inform dietetics practice. Journal of the Academy of Nutrition and Dietetics, v. 116, n. 5, p. 819-827, 2016.

MOLASSIOTIS, Alexander et al. A prospective observational study of chemotherapyrelated nausea and vomiting in routine practice in a UK cancer centre. Supportive Care in Cancer, v. 16, n. 2, p. 201-208, 2008. 
DE OLIVEIRA GOZZO, Thais et al. Ocorrência e manejo de náusea e vômito no tratamento quimioterápico em mulheres com câncer de mama. Revista Gaúcha de Enfermagem, v. 35, n. 3, p. 117-123, 2014.

BRATEIBACH, Valdecir et al. Sintomas de pacientes em tratamento oncológico. Revista Ciência \& Saúde, v. 6, n. 2, p. 102-9, 2013. 


\section{CAPACIDADE FUNCIONAL DE PACIENTES COM RADIODERMATITE}

Thallys Denneyson Andrelino Silva ${ }^{1}$; Daniel de Macêdo Rocha²; Aline Costa de Oliveira $^{2}$; Lídya Tolstenko Nogueira ${ }^{3}$.

${ }^{1}$ Bacharel em Enfermagem, Universidade Federal do Piauí, Teresina-PI, Brasil;

${ }^{2}$ Mestre em Enfermagem, Universidade Federal do Piauí, Teresina-PI, Brasil;

${ }^{3}$ Doutora em Enfermagem, Universidade Federal do Piauí, Teresina-PI, Brasil.

Autor para correspondência: Thallys Denneyson Andrelino Silva / 86994823345 / thallys-andrelino@hotmail.com

Introdução: A radiodermatite é definida como um conjunto de lesões cutâneas decorrente da exposição intensa a radiação e considerada problema de saúde por apresentar elevada incidência, assim como por comprometer a Qualidade de Vida e a capacidade funcional dos pacientes, gerando custos elevados para os serviços de saúde e requerendo esforços substanciais para prevenção, controle e tratamento. Nessa perspectiva, faz-se necessária a elaboração de estratégias e planos de cuidado voltados para minimizar os impactos relacionados à lesão e a prevenção de incapacidades. Objetivo: Avaliar a capacidade funcional de pacientes com radiodermatite. Método: Estudo observacional, transversal e analítico, com 133 pessoas que desenvolveram reações cutâneas como evento adverso ao tratamento radioterápico. Para coleta de dados, foi utilizado um formulário para caracterização e avaliação clínica e o instrumento European Organization for Research and Treatment of Cancer Quality of Life Questionnaire-Core30 para mensuração da capacidade funcional. Para análise dos dados e comparação entre variáveis, medidas de tendência central e de variabilidade, bem como os testes Mann-Whitney, Kruskal-Wallis e ANOVA, considerando diferença estatisticamente significativa para $p<0,05$. O estudo foi aprovado pelo Comitê de Ética em Pesquisa da Universidade Federal do Piauí e o parecer favorável foi emitido por meio do processo número 2.379.708. Resultados: Foi observado que o estado civil apresentou associação significativa com os domínios Função Física $(\mathrm{p}<0,001)$, Função Cognitiva $(\mathrm{p}<0,001)$, situação laboral e Renda familiar foram associadas com significância aos domínios Função Física $(p<0,001)(p=0,002)$, Função Cognitiva $(p<0,001)(p=0,027)$. As variáveis sexo e procedência não apresentaram associação significativa com nenhum dos domínios da Escala Funcional. Conclusão: A presença da radiodermatite impactou negativamente na capacidade funcional dos pacientes, levando a comprometimentos físicos, cognitivos e emocionais.

Palavras-chave: Radiodermatite, Radioterapia, Câncer, Neoplasias

\section{Referências}

Schneider F,Danski MTR, Vayego SA. Usage of Calendula of ficinalis in the prevention and treatment of radiodermatitis: a randomized double-blind controlled clinical trial. Rev Esc Enferm USP.2015; 49(2): 221-8.

Melo A M, Alves D S, Pereira A, Lacerda E C. A new perspective in the treatment of radiodermatitis. Indian J Cancer. 2015;52(4):544-5.

Rollmann D C, Novotny P J, Petersen I A,Garces Y I, Bauer H J, Yan E S, et al.Doubleblind, placebo-controlled pilot study of processed ultra meu oil versus placebo in the prevention of radiation dermatitis.Int J Radiat Oncol Biol Phys.2015;92(3):650-8. 


\section{DIAGNÓSTICO E TRATAMENTO PRECOCE DA LEUCEMIA LINFOIDE AGUDA EM PACIENTES ONCOLÓGICOS PEDIÁTRICOS: REVISÃO DE LITERATURA}

Dhyôvanna Carine Cardoso Beirão ${ }^{1}$, Carla Aparecida Sousa da Silva ${ }^{2}$; Fernanda Menezes Guimarães 2; Késsia Louhanna da Silva Sousa 2; Marcilene Carvalho Gomes 2; Delmerson de Sousa Monteiro Veras ${ }^{3}$.

${ }^{1}$ Graduada em Ciências Biológicas pela Universidade Estadual do Maranhão-UEMA, Colinas, Maranhão, Brasil;

${ }^{2}$ Graduanda de Enfermagem da Universidade Estadual do Maranhão-UEMA, Colinas, Maranhão, Brasil;

${ }^{3}$ Especialista e Docente do Instituto de Ensino Kairós de Oeiras-Piauí Brasil

Autor para correspondência: Dhyôvanna Carine Cardoso Beirão / 89999713793 / dhyovanna.k@hotmail.com

INTRODUÇÃO: A Leucemia Linfoide Aguda (LLA) é um dos tipos de câncer mais frequente na infância. A LLA apresenta uma proliferação desordenada de glóbulos brancos imaturos, que impedem a produção das plaquetas e glóbulos vermelhos. $\mathrm{O}$ diagnóstico laboratorial é realizado a partir do mielograma, com demonstração de mais de $20 \%$ de linfoblastos na medula e imunofenotipagem. Um dos tratamentos é a quimioterapia, e é realizada de acordo com as condições clínicas (imunológica, citogenéticas) do paciente. Alguns trabalhos relatam a importância do tratamento e diagnóstico precoce da leucemia em crianças isoladamente, no entanto, a literatura não aborda esses temas correlacionados. OBJETIVO: Compreender a importância do diagnóstico e tratamento precoce de crianças com leucemia linfoide aguda. MÉTODOS: O presente artigo se trata de uma revisão da literatura realizada através de pesquisas de artigos de língua inglesa e/ou portuguesa completos publicados entre 2008 e 2017 em plataformas científicas como: SCIELO, PubMed, LILACS, através dos descritores "leucemia linfoide aguda", "câncer infantil", "tratamento oncológico", "diagnóstico precoce". RESULTADOS: Inicialmente foram encontrados 30 artigos para análise, destes apenas 5 foram utilizados para a composição final da pesquisa. Alguns estudos apontam que os avanços tecnológicos no diagnóstico baseados nas características individuais de cada criança, tem contribuído para um melhor prognóstico e tratamento. Com relação aos tratamentos atualmente realizados estão transplante de medula óssea, quimioterapia, imunoterapia, radioterapia ou associação de diferentes tratamentos. No entanto, no Brasil os pacientes ainda sofrem com dificuldades na rapidez e acesso aos tratamentos pelo Sistema Único de Saúde, onde muitas vezes só é possível ser realizado nas cidades que possuem centros de saúde mais desenvolvidos, outro fator é a baixa renda dos pais, sem falar nas complicações do quadro clínico de cada paciente que dificultam o avanço/início do tratamento. Em um estudo realizado na Alemanha e Noruega, foi observado que o diagnóstico precoce e o tratamento eficaz, aumenta as chances de remissão da leucemia linfoide aguda em até $90 \%$ dos casos. Sendo assim inquestionável a relevância e necessidade da utilização de exames que apresentem um maior grau de sensibilidade e especificidade e também de uma maior acessibilidade aos tratamentos. CONCLUSÃO: Conclui-se então, que os pais e profissionais da saúde devem ficar atentos aos sinais da doença, principalmente sabendo da inespecificidade sintomatológica da doença, e que uma rápida atuação referente ao diagnóstico precoce e o tratamento 
imediato desse câncer infantil podem influenciar positivamente no prognóstico, contribuindo assim para uma maior taxa de sobrevivência dessas crianças.

Palavras-chave: câncer infantil, leucemia linfoide aguda, tratamento oncológico, diagnóstico precoce, revisão de literatura.

\section{Referências}

CAVALCANTE, M. S; ROSA, I. S. S; TORRES, F. Leucemia linfoide aguda e seus principais conceitos. Revista Científica da Faculdade de Educação e Meio Ambiente. Ariquemes: FAEMA, v.8,n.2,jul./dez.,2017.

DANTAS, G. K. S; SILVA, L. T. A; PASSOS, X. S, CARNEIRO C. C. Diagnóstico diferencial da leucemia linfoide aguda em pacientes infanto juvenis. Ver Universidade Vale do Rio Verde [Internet].2015.Acesso em:05/06/2019.

ROCHA, B. C. Leucemia linfoide aguda: relato de um caso e revisão de literatura. São Paulo, 2012. Acesso em: 05/06/2019. 


\title{
FATORES ASSOCIADOS À SÍNDROME DE BURNOUT EM PROFISSIONAIS DE ENFERMAGEM ONCOLÓGICA: UMA REVISÃO DA LITERATURA
}

\author{
Marcilene Carvalho Gomes ${ }^{1}$, Carla Aparecida Sousa da Silva ${ }^{1}$; Fernanda Menezes \\ Guimarães ${ }^{1}$; Késsia Louhanna da Silva Sousa ${ }^{1}$; Dhyôvanna Carine Cardoso Beirão². \\ ${ }^{1}$ Graduanda em Enfermagem, Universidade Estadual do Maranhão-UEMA, Colinas, \\ Maranhão, Brasil; \\ ${ }^{2}$ Mestra Docente da Universidade Estadual do Maranhão-UEMA, Colinas, Maranhão, \\ Brasil.
}

Autor para correspondência: Dhyôvanna Carine Cardoso Beirão / 89999713793 / dhyovanna.k@hotmail.com

INTRODUÇÃO: Os profissionais de saúde em especial os da área oncológica lidam diariamente com emoções que contêm incertezas e angústias fruto da fragilidade humana. A equipe de enfermagem oncológica é então, altamente vulnerável à Síndrome de Burnout, uma síndrome que surge como resposta aos estresses interpessoais ocorridos na situação de trabalho. Estudos sobre esgotamento emocional são correlacionados com os mecanismos chaves do desenvolvimento de burnout, porém pouco se sabe sobre a relação da Síndrome de Burnout com a atividade da equipe de enfermagem oncológica. OBJETIVO: Analisar a relação da síndrome de Burnout com a equipe de enfermagem oncológica, bem como os fatores de risco associados a equipe profissional e aos pacientes oncológicos. MÉTODOS: Trata-se de uma revisão integrativa realizada a partir do levantamento de produção científica através de base de dados LILACS/Ibecs, SciELO, BDENF, todas pelo portal BVS e MedLine via PubMed, utilizando-se como critérios de inclusão, artigos com textos completos, publicados em 2009 à 2018, em língua portuguesa, inglesa e espanhola e que retratem a temática proposta. RESULTADOS: Foram encontrados 97 artigos para análise e destes foram selecionados 5 para amostra final. Através deste estudo constatou-se que no ambiente hospitalar o setor de oncologia é o local que gera uma maior carga de estresse, onde principalmente os enfermeiros que estão em contato direto com o paciente, são mais susceptíveis a desenvolverem a Síndrome de Burnout. Além disso, foi observado que a carga de trabalho e a natureza exigente do trabalho oncológico são fatores identificados como uma das principais causas de estresse. A prática de trabalho da equipe de enfermagem oncológica expõe o profissional ao contato estreito com situações de dor, finitude e morte, além de mutilações, desesperança e expectativas de cura da doença. A questão do sofrimento psíquico vivenciados pelos profissionais, compromete tanto os profissionais como a qualidade da assistência prestada, colocando em risco os pacientes, com má qualidade dos cuidados e falhas para reconhecer o sofrimento do paciente. CONCLUSÃO: Durante a pesquisa, ficou evidente que o sofrimento da equipe de enfermagem está relacionado à morte e ao sofrimento do paciente. Assim, é importante que as instituições hospitalares atentem para o cuidado da saúde mental dos seus profissionais, principalmente da equipe de enfermagem, pois estes estão presentes durante todo o tratamento do paciente e estão susceptíveis à Síndrome de Burnout. 
Palavras-chave: enfermagem oncológica, Síndrome de Burnout, esgotamento profissional; oncologia; saúde mental.

\section{Referências}

Alacacioglu A, Yavuzsen T, Dirioz M, Oztop I, Y1lmaz U. Burnout in nurses and physicians working at na oncology department. Psychooncology 2009;18:543.

KLUSER, Sinara Raskopf et al. Vivência de uma equipe de enfermagem acerca do cuidado aos pacientes com câncer. Rev. Rene. v. 12, n. 1, p. 166 -172, 2011. Disponível em: <http://periodicos.ufc.br/rene/article/view/4179>. Acesso em: 20 de Jun. de 2018.

Marôco, J., Marôco, A., Leite, E., Bastos, C., Vazão, M., \& Campos, J. (2016). Burnout em profissionais de saúde portugueses: Uma análise a nível nacional. Revista Cientifica da Ordem dos Médicos, 29 (1) 24-3. 


\section{A IMPORTÂNCIA DA ATENÇÃO BÁSICA NO MANEJO DE PACIENTES ONCOLÓGICOS}

Gabriela Ribeiro Moreira ${ }^{1}$; David de Sousa Carvalho ${ }^{1}$; Renata Kelly dos Santos e Silva ${ }^{1}$; Ivanildo Gonçalves Costa Júnior ${ }^{1}$; Isabel Mariana Ferreira da Silva ${ }^{1}$; João Marcelo de Castro e Sousa ${ }^{2}$

${ }^{1}$ Discentes, Universidade Federal do Piauí - UFPI, Picos, Piauí, Brasil;

${ }^{2}$ Docente (Programa de Pós-Graduação em Ciências Farmacêuticas e Biotecnologia), Universidade Federal do Piauí - UFPI, Picos, Piauí, Brasil;

Autor para correspondência: Gabriela Ribeiro Moreira / grmoreira19@gmail.com / 86 988520848

INTRODUÇÃO: A atenção Primária à Saúde (APS) faz parte de uma organização estrutural em níveis de atenção à saúde para melhor atender a população. Os cuidados aos pacientes oncológicos desde o diagnóstico até a redução de danos são iniciados na Atenção Básica, uma vez que é a porta de entrada do serviço de Saúde no Brasil. Ela dispõe de um conjunto de ferramentas pautadas em manusear os clientes acometidos por neoplasias, visando ao seu acompanhamento diário. OBJETIVO: Evidenciar através da literatura científica, a importância da Atenção Primária à Saúde na assistência ao paciente oncológico. METODOLOGIA: Tratou-se de uma revisão integrativa da literatura, com coleta nas seguintes bases de dados e bibliotecas: Biblioteca Virtual de Saúde (BVS), PubMed, Biblioteca Eletrônica Científica Online (Scielo) e Literatura Latino-Americana e do Caribe em Ciências da Saúde (LILACS), durante o período de maio e junho de 2019. Foram utilizados os seguintes descritores em ciências da Saúde (DECS) em português e seus correspondentes em inglês: Atenção Primária a Saúde/ Primary Health Care, Oncologia/Oncology e Cuidado de Enfermagem/ Nursing Care. Foram Aplicados os seguintes critérios de inclusão: artigos; texto completo disponível; em Português, Inglês e Espanhol; publicados em revistas científicas nos últimos 5 anos. Foram excluídas teses, estudos repetidos e que não correspondessem ao objetivo da pesquisa. A busca baseada nos critérios de inclusão estabelecidos consolidou 20 artigos, dos quais apenas 18 estavam de acordo com os critérios de inclusão. RESULTADOS: Os estudos demonstraram a grande relevância e importância da Atenção Primária à Saúde no cuidado direto aos pacientes oncológicos, pois é através desta porta de entrada inicial e basilar, que há a criação de um cenário estruturante para o desenvolvimento de várias ações de controle das neoplasias, destacando-se como ações principais: promoção da saúde, diagnóstico precoce e referenciamento dos pacientes, isto ocorre devido o seu modelo de contato direto da Estratégia de Saúde da Família (ESF), com a população assistida, onde ocorre a criação do vínculo, integralidade e longitudinalidade, que possibilita um acompanhamento imprescindível e essencial antes, durante e depois do processo de diagnóstico. CONCLUSÃO: Diante das considerações apresentadas, torna-se claro, a relevância e importância da Atenção Primária à Saúde, pois é por meio desta, que há uma efetiva prestação da assistência à saúde, por meios de intervenções multiprofissionais que visem à promoção da saúde, somando a redução dos danos aos pacientes acometidos pela doença.

Palavras-chave: Atenção Primária à Saúde; Oncologia; Cuidado de Enfermagem; 


\section{Referências}

GIOVANELLA, L. Atenção Básica ou Atenção Primária à Saúde? Cad. SaúdePública 2018.

SILVA, K. F.et al. Construindo a linha de cuidado do Paciente Oncológico Paliativo em um município do sul do Brasil: Relato de Experiência. Rev. APS. 2018 jul/set; 21(3):470477.

SOUZA M. M. et al. Atributos derivados da Atenção Primáriana Assistência ao Paciente Oncológico. Rer enferm UFPE online.Recife, 10(8):3004-10,ago.2016. 


\title{
ÉTICA DA EQUIPE DE ENFERMAGEM NO CUIDADO À PACIENTES COM CÂNCER: UMA REVISÃO INTEGRATIVA
}

\author{
Marcilene Carvalho Gomes ${ }^{1}$, Carla Aparecida Sousa da Silva ${ }^{1}$; Fernanda Menezes \\ Guimarães ${ }^{1}$; Késsia Louhanna da Silva Sousa ${ }^{1}$; Dhyôvanna Carine Cardoso Beirão \\ 1. Graduanda em Enfermagem da Universidade Estadual do Maranhão-UEMA, Colinas, \\ Maranhão, Brasil; \\ 2. Mestra e Docente da Universidade Estadual do Maranhão-UEMA, Colinas, \\ Maranhão, Brasil
}

Autor para correspondência: Marcilene Carvalho Gomes / 99981334639 / marcilene10sjp@gmail.com

INTRODUÇÃO: A ética exige reflexão sobre os valores morais e considera a razão como base para definir as regras as quais são necessárias para a vida em harmonia dentro de um grupo. A oncologia é locus de constantes problemas éticos, os quais são vivenciados a partir de situações já consideradas como parte do cotidiano profissional. Somado a isso, há uma importância na postura do profissional de Enfermagem, pois esta deve ser nitidamente ética na prestação de cuidados à pacientes oncológicos, no entanto estudos tem apontado alguns desvios de conduta profissional que podem dificultar a assistência à pacientes com câncer. OBJETIVOS: Analisar a ética do cuidado em enfermagem, especificamente no tratamento de pacientes oncológicos. METODOLOGIA: O método utilizado para a realização desse estudo foi uma revisão integrativa da literatura, nos bancos de dados eletrônicos LILACS/Ibecs, SciELO e PubMed, por meio dos descritores: cuidados de enfermagem, oncologia, ética em oncologia e cuidados paliativos. Os artigos com texto completo, publicados em 2005 à 2018 em língua portuguesa e inglesa foram incluídos no estudo, e os artigos que não atendiam aos critérios de pertinência e consistência do conteúdo foram excluídos do estudo. RESULTADOS: Foram encontrados 112 artigos, dos quais apenas 8 foram selecionados para a pesquisa. Neste estudo de revisão de literatura, foi identificado alguns fatos referentes a conduta ética de enfermeiros oncológicos que podem comprometer a assistência terapêutica ao paciente. Observou-se em um determinado estudo uma falha ética grave, prontuários com pouca ou nenhuma informação relacionada aos procedimentos realizados nos pacientes oncológicos. Em uma pesquisa realizada em Unidades de Terapia Intensivas foi demonstrado que profissionais evitam registrar algumas condutas, por receio de punição pelo código de ética e/ou penal. Outra questão é em relação a comunicação com o paciente e referente aos cuidados paliativos, pois muitas vezes os enfermeiros têm dificuldades de falar e/ou de desenvolver um cuidado a um paciente em fase avançada pois se sentem angustiados e desmotivados. Infelizmente a ausência de uma legislação clara a respeito do assunto contribui para esse tipo de falha profissional, potencializando os problemas éticos nos cuidados a pacientes oncológicos. CONCLUSÃ̃: Ao final desse estudo foi possível perceber que quando se trata de cuidados direcionados a pacientes oncológicos os enfermeiros enfrentam constantemente problemas éticos os quais podem dificultar a prestação de uma assistência adequada aos pacientes e aos familiares.

Palavras-chave: conduta ética, ética em oncologia, enfermagem oncológica; cuidados da enfermagem. 


\section{Referências}

Carvalho KK, Lunardi VL. Therapeutic futility as an ethical issue: intensive care unit nurses. Rev. LatinoAm. Enfermagem. 2009 Jun;17(3):308-13.

LUZ KR, VARGAS MAO, SCHMIDTT PH, BARLEM ELD, TOMASCHEWSKIBARLEM JG, ROSA LM. Problemas éticos vivenciados por enfermeiros oncológicos. Rev. Latino-Am. Enfermagem nov.-dez. 2015;23(6):1187-94.

Waldow VR, Borges RF. Caring and humanization: relationships and meanings. Acta Paul Enferm[Internet]. 2011[cited 2015 Apr 10];24(3):414-18. Available from: http://www.scielo.br/pdf/ape/v24n3/en_17. 


\title{
INTERVENÇÕES NÃO INVASIVAS QUE INFLUENCIAM NA QUALIDADE DE VIDA DE PACIENTES COM CÂNCER AVANÇADO
}

\author{
Dhyôvanna Carine Cardoso Beirão ${ }^{1}$, Carla Aparecida Sousa da Silva²; Fernanda Menezes \\ Guimarães 2; Késsia Louhanna da Silva Sousa 2; Marcilene Carvalho Gomes 2; Delmerson \\ de Sousa Monteiro Veras ${ }^{3}$ \\ ${ }^{1}$ Graduada em Ciências Biológicas pela Universidade Estadual do Maranhão-UEMA, \\ Colinas, Maranhão, Brasil; \\ ${ }^{2}$ Graduanda de Enfermagem da Universidade Estadual do Maranhão-UEMA, Colinas, \\ Maranhão, Brasil; \\ ${ }^{3}$ Especialista e Docente do Instituto de Ensino Kairós de Oeiras-Piauí Brasil.
}

Autor para correspondência: Marcilene Carvalho Gomes / 99981334639 / marcilene10sjp@gmail.com

INTRODUÇÃO: Devido ao grande número de pacientes oncológicos sem disponibilidade de tratamento curativo, as intervenções não invasivas são de extrema importância para o atendimento integrado destes pacientes. Essas intervenções têm sido apontadas como alternativas na melhora da qualidade de vida de pacientes com câncer. Em contrapartida, estudos envolvendo essa temática ainda são escassos, por isso, se faz necessário abordar essa temática e demonstrar a relevância desses tipos de cuidados frente a pacientes com câncer avançado. OBJETIVO: Investigar as intervenções não invasivas que são utilizadas na melhora da qualidade de vida, no alívio a dor e que minimizam o sofrimento dos pacientes oncológicos em estágio terminal. MÉTODOS: Foi realizado uma revisão integrativa da literatura nas bases de dados: BVS, LILACS, SciELO e PubMed, através dos seguintes descritores: "intervenções" e "cuidados paliativos", "métodos não invasivos" e "intervenções não invasivas". Para a inclusão dos artigos no estudo foi considerado: artigos completos publicados em português e inglês que abordam a temática, de 2006 até de 2018, cujos textos completos tinham disponibilidade pública. Os artigos que estavam fora do tema da pesquisa ou que estavam em outros idiomas, foram excluídos. RESULTADOS: Foram encontrados 45 artigos para análise, no qual após a seleção apenas 5 foram utilizados. Sabe-se que o câncer, pode influenciar drasticamente em vários aspectos da qualidade de vida do paciente, bem como o seu tratamento, atingindo tanto o físico, como o psicológico e social. Alguns estudos buscando compreender os tipos de intervenções relacionadas a melhora de pacientes oncológicos observaram que a atividade física, dieta, modalidades mente-corpo, acupuntura, massagem terapêutica, tratamento espiritual entre outros, estão sendo utilizadas para amenizar os seus efeitos. Como o câncer pode levar ao óbito, os programas de cuidados paliativos têm sido reconhecidos como estratégias fundamentais para minimizar o sofrimento das pessoas doentes. Além disso, observou-se que nessas intervenções a abordagem é centrada no indivíduo e na família, com a finalidade de controlar e aliviar o sofrimento físico, psicossocial e espiritual, a fim de se alcançar um cuidado ideal e lhes proporcionar uma melhor qualidade de vida. CONCLUSÃ̃ O: Conclui-se que ainda há um vasto campo a ser estudado a respeito das medidas de intervenções integrativas na oncologia, devido as demandas desencadeadas por doenças que acompanham o perfil epidemiológico da população no Brasil. Dessa forma, se faz necessário planejamento nas ações em saúde a fim de fornecer subsídios que permitam viabilizar a introdução dessas práticas nos serviços de saúde. 
Palavras-chave: pacientes oncológicos, intervenções integrativas, cuidados paliativos, câncer, qualidade de vida.

\section{Referências}

Salehi A, Marzban M, Zadeh A. Acupuntura para tratamento de ondas de calor em pacientes com câncer de mama: uma meta-análise atualizada. Cuidados de Suporte em Câncer. 2016;

Silva RCF, Hortale VA. Cuidados paliativos oncológicos: elementos para o debate de diretrizes nesta área. Cad Saúde Pública.2006;22(10):2055-66. 


\section{O CONSUMO ALIMENTAR DE PACIENTES ONCOLÓGICOS: UMA REVISÃO DE LITERATURA}

Nathalia Andrade Pereira ${ }^{1}$; Joseane Alves Fernades ${ }^{2} ;{ }^{3}$ Amanda Cristine Ferreira dos Santos

${ }^{1}$ Acadêmico, Estácio, Teresina, Piauí, Brasil;

${ }^{2}$ Acadêmico, Estácio, Teresina, Piauí, Brasil;

${ }^{3}$ Mestre, Estácio, Teresina, Piauí, Brasil.

Autor para correspondência: Nathalia Andrade Pereira / 86 9431-4535 / nathalyaandrade643@gmail.com

INTRODUÇÃO: O câncer pode ser definido como uma enfermidade multicausal crônica, caracterizada pelo crescimento descontrolado de células. Seu desenvolvimento envolve alterações do DNA celular, que se acumulam com o tempo. Quando essas células lesadas escapam dos mecanismos envolvidos na proteção do organismo contra o crescimento e a disseminação de tais células, é estabelecida uma neoplasia. OBJETIVO: analisar o consumo alimentar de pacientes oncológicos. METODOLOGIA: Trata-se de uma revisão integrativa realizada nas bases de dados Google acadêmico, Scielo, Lilacs no período de junho de 2019, sendo utilizados os descritores: câncer, nutrição, consumo de alimentos. Os critérios de inclusão foram artigos disponíveis na íntegra, cuja data de publicação era entre 2015 a 2019, que abordassem a temática do estudo e escritos na língua portuguesa. RESULTADOS E DISCURSÃO: Resultados encontrados mostraram alguns hábitos alimentares considerados de risco para o desenvolvimento do câncer. Observou-se inadequação quanto ao consumo alimentar de frutas, legumes, verduras, cereais e tubérculos, mostrando abaixo do recomendado, embora as evidências científicas a respeito do assunto ainda sejam muito variadas, diversas pesquisas demonstram forte correlação entre a adequação alimentar e a incidência de alguns tipos de câncer. CONCLUSÃ O: concluiu-se que o consumo alimentar dos pacientes se mostrou inadequado; os hábitos alimentares têm influência determinante no processo de carcinogêneas.

Palavras chaves: câncer, nutrição, consumo de alimentos.

Referências

BRITO, D. A. ,\& DA COSTA MAYNARD, D. (2019). Avaliação da relação entre nutrição e câncer: Uma visão dó impacto no estado nutricional e qualidade de vida de pacientes oncológicos. Nutrición clínicay dietética hospitalaria, 39(1),169-175.

SCHEIBLER,J.,SILVA,F.M.,MOREIRA,T.R.,\&ADAMI,F.S.(2016).Qualidade de vida, estado nutricional e consumo alimentar de mulheres com câncer de mama em tratamento quimioterápico. Revista Brasileira em Promoção da Saúde,29(4),544-553.

SOUZA,R.G.,LOPES,T.V.,PEREIRA,S.S.,SOARES,L.P.,\&PENA,G.D.G.(2017).Avali ação do estado nutricional, consumo alimentar e capacidade funcional em pacientes oncológicos. Braz J Oncol,13(44),1-11.

PEREIRA,P.L.,NUNES,A.L.S.,\&DUARTE,S.F.P.(2015).Qualidade de vida e consumo alimentar de pacientes oncológicos. Rev Bras Cancerol,61(3),243-51. 
ALMEIDA,F.S.B.,DOSSANTOS,L.V.,MOZER,L.S.,DOSSANTOS,M.L.,\&MACHAD O,P.P.A.(2019).Correlação entre indicadores de qualidade em terapia nutricional e estado nutricional.Mostra de Trabalhos do Curso de Nutrição do Univag,4. 


\title{
CURCUMINA: UM POTENTE POLIFENOL DA CÚRCUMA LONGA NA PREVENÇÃO DO CÂNCER GÁSTRICO
}

\author{
Renata Martins Costa 1; Aldaisa Pereira Lopes 2; Dheyson Sousa Dutra 2; Layza Karyne \\ Farias Mendes ${ }^{2}$; Ma. Ana Cibele Pereira Sousa ${ }^{3}$ \\ ${ }^{1}$ Discente, Universidade Federal do Piauí , Picos, PI, Brasil; \\ 2 Discente, Universidade Federal do Piaú, Picos, PI, Brasil; \\ ${ }^{3}$ Docente, Universidade Federal do Piauí, Picos, PI, Brasil.
}

Autor para Correspondência: Renata Martins Costa / natinhacosta-s2@ hotmail.com / 89 999281779

INTRODUÇÃO: O câncer gástrico primário (PGC) é o quarto câncer maligno mais comum e a segunda maior causam de morte no mundo. A curcumina é o principal polifenol isolado da cúrcuma, que apresenta atividades anti-inflamatória, antioxidante, antiapoptótica, antitumoral e antimetastática. As evidências existentes indicam que a curcumina pode exercer uma ampla gama de propriedades pleiotrópicas benéficas no trato gastrointestinal, podendo inibir o crescimento celular e induzir apoptose no carcinoma gástrico. OBJETIVO: Com este estudo buscou-se descrever e analisar as evidências dos mecanismos de ação da curcumina no tratamento do câncer de estomago. MÉTODOS: Realizou-se uma pesquisa na base de dado PubMed, entre os anos de 2018 a 2019, em língua inglesa, utilizando os descritores cúrcuma longa, câncer gástrico e polifenol. Foram encontrados um total de 90 artigos, usando como critério de exclusão apenas artigos relacionando o composto com o câncer, foram selecionados 06 artigos para o presente estudo. RESULTADOS: Os resultados demonstraram que a curcumina inibiu o crescimento das células AGS e induziu a apoptose através da ativação da via de sinalização Ras / ERK e da cascata de caspases a jusante, podendo ser um alvo potencial para o tratamento do carcinoma gástrico, além disso os resultados de ensaio de citometria de fluxo indicaram que a curcumina induziu a apoptose das células gástricas induzindo autofagia nas células ativando a via de sinalização do P53 e inibiu a via de sinalização PI3K regulando positivamente o P53 e o P21, que também inibiram a via PI3K através da regulação negativa PI3K, p-Akt e p-mTOR. CONCLUSÂO:. A evidência de que este derivado de cúrcuma inibe a invasão e proliferação de células de câncer gástrico é encorajadora e merece mais estudos experimentais e clínicos com novas formulações para apoiar a inclusão da curcumina em regimes de terapia contra o câncer.

Palavras-chave: Cúrcuma longa, Câncer gástrico e Polifenol.

\section{Referências}

U M, Cao. Curcumin induces apoptosis in human gastric carcinoma AGS cells and colon carcinoma HT-29 cells through mitochondrial dysfunction and endoplasmic reticulum stress. .Pub Med, China, 2019. Disponível em: https://www.ncbi.nlm.nih.gov/pubmed/23881281.Acessoem:19jun.2019.

G U, Xixi. Curcumin inhibits liver metastasis of gastric câncer by reducing circulating tumor cells. .Pub Med, China, 2019. Disponível em: https://www.ncbi.nlm.nih.gov/pmc/articles/PMC6428112/. Acesso em:19jun.2019. 


\title{
SUCCINATO DE ALFA-TOCOFERIL ( $\alpha$-TOS) E SEU PAPEL NA INDUÇÃO À APOPTOSE DE CÉLULAS CANCERÍGENAS
}

\author{
Layza Karyne Farias Mendes ${ }^{1}$; Dheyson Sousa Dutra ${ }^{2}$; Renata Martins Costa ${ }^{2}$; Aldaisa \\ Pereira Lopes ${ }^{2}$; Ma. Ana Cibele Pereira Sousa ${ }^{3}$. \\ ${ }^{1}$ Discente, Universidade Federal do Piauí, Picos, PI, Brasil; \\ 2 Discente, Universidade Federal do Piauí, Picos, \\ PI, Brasil; \\ ${ }^{3}$ Docente, Universidade Federal do Piauí, Picos, PI, Brasil.
}

Autor para correspondência: Dheyson Sousa Dutra , e-mail: dheysonsousa97@bol.com.br

INTRODUÇÃO: Nos últimos anos, os esforços para melhorar a terapia do câncer se concentraram principalmente no desenvolvimento de novos agentes antineoplásicos. Entre estes agentes incluem-se os análogos da vitamina E, onde o succinato de alfatocoferil ( $\alpha$-TOS) é a forma mais eficaz que suprimem o cancro, com isso induzindo a apoptose. É de interesse como ocorrem os vários mecanismos moleculares subjacentes à morte celular induzida por $\alpha$-TOS e o uso potencial de combinação de drogas direcionadas no tratamento do câncer. OBJETIVO: Com este estudo buscou-se descrever e analisar as evidências do mecanismo de ação do succinato de alfa-tocoferil ( $\alpha$-TOS) no tratamento de câncer. MÉTODOS: Realizou-se uma pesquisa na base de dado PubMed, entre os anos de 2003 e 2019, em língua inglesa e portuguesa utilizando os descritores vitamina E Câncer, câncer de próstata. Foram encontrados 90 artigos, utilizando critério de inclusão apenas artigos relacionando o $\alpha$-TOS com a apoptose, foram selecionados 05 artigos para este trabalho. RESULTADOS: Estudos in vitro e in vivo demonstraram que o $\alpha$-TOS atacam seletivamente células tumorais com pouco ou nenhum efeito sobre as células normais. Os tocoferóis (TOH) são antioxidantes lipofílicos que requerem o grupo $\mathrm{OH}$ fenólico para sua atividade redox. Em contraste, os ésteres ativos não-redox de $\alpha$-TOH com succinato ( $\alpha$-TOS) mostraram possuir atividade próapoptótica nas células cancerígenas. Foi sugerido que esta atividade é mediada via inibição mitocondrial com posterior produção de $\mathrm{O} 2$ (-) desencadeando apoptose e que a modificação do linker entre o succinato e o cromossomo lipofílico pode modular esta atividade. $O$ tratamento com $\alpha$-TOS é uma grande promessa para futuras aplicações clínicas, pois causa a morte celular, pelo menos em parte, induzindo seletivamente a apoptose pela desestabilização mitocondrial. Esta revisão apresenta uma visão geral das perspectivas sobre $\alpha$-TOS e os usos potenciais tratamento do câncer de modo geral, e outras aplicações clínicas. CONCLUSÃO: A evidência de que o $\alpha$-TOS mata seletivamente as células tumorais do câncer é promissora, entretanto são necessários mais estudos experimentais e clínicos com novas formulações para apoiar sua introdução nos tratamentos de câncer.

PALAVRAS-CHAVE: Vitamina E, Câncer de próstata, Apoptose.

\section{Referências}

KANEKO, S. Combination Effect of Bowman-Birk Inhibitor and $\alpha$-Tocopheryl Succinate on Prostate Cancer Stem-Like Cells. Journal of nutritional science and vitaminology, Tokio, 2019. Disponível em: Pub med. Acesso em:18maio 2019. 
TOMASETTI, Marco. Alpha-Tocopheryl Succinate Inhibits Autophagic Survival of Prostate Cancer Cells Induced by Vitamin K3 and Ascorbateto Trigger Cell Death. Plos One, [S.1.],2012. Disponível em: Pub med. Acesso em:18maio2019.

NEUZIL, J. Vitamin E succinate and câncer treatment: a vitamin E prototype for selective antitumour activity. British Journal of Cancer, [S.1.],11nov.2003. Disponível em: Pub med. Acesso em:18maio2019.

GRUBER, Julia. Tocopheramine succinate and Tocopheryl succinate: mechanism of mitochondrial inhibition and production of superoxide radical. Bioorganic \& Medicinal Chemistry,[S.1.],2014. Disponível em: Pub med. Acesso em:18maio2019.

ANGULOMOLINA, Aracely. The role of Alpha-tocopheryl succinate ( $\alpha$-TOS) as a potential anticancer agent. Routledge, [S.1.],30jan.2014. Disponível em: Pub med. Acesso em:18maio2019. 


\section{CÂNCER DE CABEÇA E PESCOÇO: POLIMORFISMOS GENÉTICOS E O METABOLISMO DO FOLATO}

Layza Karyne Farias Mendes ${ }^{1}$; Aldaisa Pereira Lopes ${ }^{2}$; Dheyson Sousa Dutra ${ }^{3}$; Renata Martins Costa; ${ }^{4}$ Ma. Ana Cibele Pereira Sousa

${ }^{1}$ Discente, Universidade Federal do Piauí, Picos, PI, Brasil;

2 Discente, Universidade Federal do Piauí, Picos, PI, Brasil;

${ }^{3}$ Discente, Universidade Federal do Piauí, Picos, PI, Brasil;

${ }^{4}$ Docente, Universidade Federal do Piauí, Picos, PI, Brasil

Autor para correspondência: Layza Karyne Farias Mendes / karyne-layza@hotmail.com

INTRODUÇÃO: O ácido fólico é uma vitamina hidrossolúvel é encontrado naturalmente nas plantas, principalmente os de folhagem verde escuros, mas pode ser produzida sinteticamente gerando suplementos enriquecidos. Os cânceres de cabeça e pescoço é o nome que se dá ao conjunto de tumores que se manifestam, na boca, na faringe, laringe, entre outros e correspondem a 3\% de todos os tipos de câncer. Pesquisas realizadas mostram evidências epidemiológicas que sugerem, variantes genéticas que codificam enzimas envolvidas no metabolismo do folato que podem modular o risco de câncer de cabeça e pescoço. OBJETIVO: Com esse estudo buscou-se analisar como os polimorfismos genéticos afetam o metabolismo do folato e como isso pode influenciar no desenvolvimento do câncer de cabeça e pescoço. MÉTODOS: Realizou-se uma pesquisa na base de dado SciELO, sem demarcação temporal, em língua inglesa e portuguesa, utilizando os descritores câncer de cabeça, câncer de pescoço, polimorfismos, folato. Foram encontrados um total de 10 artigos, usando como critério de inclusão apenas artigos relacionando os cânceres com a deficiência do folato, foram selecionados 03 artigos para o presente estudo. RESULTADOS: Alterações nos níveis de folato devido a polimorfismos genéticos envolvidos em sua via metabólica estão associadas com mudanças na metilação, síntese e reparo do DNA e na estabilidade genômica, pois níveis adequados de folato são essenciais para a biossíntese de purinas e pirimidinas, necessárias para esses processos biológicos. Existem três mecanismos pelos quais as alterações no metabolismo do folato podem contribuir com a carcinogênese: (1) hipometilação de DNA e subsequente ativação dos proto-oncogenes; (2) erro de incorporação da uracila durante a síntese de DNA que leva à instabilidade genômica; e (3) aumento na desaminação de citosina nos sítios de metilação de DNA. Estudos revelam que os polimorfismos MTHFR C677T e MTHFR A1298C, foram analisados in vitro e foi detectado que eles diminuem a atividade enzimática, já o MTHFR C677T, MTHFR A1298C, MTR A2756G, MTRR A66G e RFC1 A80G parecem modular o risco de câncer de cabeça e pescoço. CONCLUSÃO: Diante do exposto pode-se concluir que a deficiência de folato no organismo, está associada aos polimorfismos genéticos, causando assim, um aumento considerável nos riscos de desenvolvimento do câncer de cabeça e pescoço.

Palavras-chave: Câncer de cabeça, Câncer de pescoço, Polimorfismo, Folato.

\section{Referências}

YANG, J. Cisplatin and paclitaxel co-delivered by folate-decorated lipid carriers for the treatment of head and neck cancer. Drug Delivery, [S. 1.], 2016. Disponível em: Pubmed. Acesso em: 18 maio 2019. 
NEJATINAMINI, S. Head and Neck Cancer Patients Do Not Meet Recommended Intakes of Micronutrients without Consuming Fortified Products. Nutrition and Cancer, [S. 1.], 2018. Disponível em: Pubmed. Acesso em: 18 maio 2019.

GALBIATTI, A.l. Head and neck cancer: genetic polymorphisms and folate metabolism. Brazilian Journal of Otorhinolaryngology, [S. 1.], 2012. Disponível em: Pubmed. Acesso em: 18 maio 2019. 


\section{O USO DO RESVERATROL NO TRATAMENTO DO CÂNCER DE MAMA}

Aldaisa Pereira Lopes ${ }^{1}$; Layza Karyne Farias Mendes ${ }^{2}$; Dheyson Sousa Dutra ${ }^{3}$; Renata Martins Costa 3; Maria Eduarda De Sousa Brito 3; Ma. Ana Cibele Pereira Sousa ${ }^{4}$

${ }^{1}$ Discente, Universidade Federal do Piauí , Picos, PI, Brasil;

2 Discente, Universidade Federal do Piauí, Picos, PI, Brasil;

${ }^{3}$ Discente, Universidade Federal do Piauí, Picos, PI, Brasil;

${ }^{4}$ Docente, Universidade Federal do Piauí, Picos, PI, Brasil.

Autor para correspondência: Aldaisa Pereira Lopes / aldaisa_pl@ hotmail.com

INTRODUÇÃO: As doenças cancerígenas estão na liderança da mortalidade humana nos dias atuais. O Resveratrol é um polifenol que pode ser encontrado principalmente em sementes e peles de uvas, vinho tinto, cacau e amendoins. Esse composto tem mostrado importantes efeitos antitumorais contra alguns tipos de câncer, como o de mama, patologia essa causada pela multiplicação desordenada de células mamárias. É o terceiro carcinoma com maior incidência no mundo e o primeiro com maior frequência em mulheres. OBJETIVO: Com este estudo buscou-se descrever e analisar as evidências dos mecanismos de ação do Resveratrol no tratamento do câncer de mama. MÉTODOS: Realizou-se uma pesquisa na base de dado PubMed, entre os anos de 2015 a 2019, em língua inglesa e portuguesa, utilizando os descritores Resveratrol, Câncer de mama. Foram encontrados um total de 50 artigos, usando como critério de exclusão apenas artigos relacionando o composto com o câncer, foram selecionados 06 artigos para o presente estudo. RESULTADOS: O Resveratrol altera o metabolismo celular, afetando o armazenamento de energia, sinalização celular, progressão e proliferação do câncer. Um dos principais mecanismos de ação atribuído ao composto, foi a sua capacidade de modulação de quinases dependentes de ciclinas, resultando assim na parada do ciclo celular no ponto de checagem G0/G1, embora exista também achados mostrando parada no ciclo celular nos pontos de checagem $\mathrm{G} 2 / \mathrm{M}$ e S. A ingestão oral por dieta com uma dose de $5 \mathrm{mg}$ a $50 \mathrm{mg}$ resultou em significativas diminuição do peso, do volume e crescimento do tumor mamário com a diminuição da angiogênese, metástase e da metilação do RASSF-1 $\alpha$, um supressor de tumor. CONCLUSÃ̃O: Diante do exposto, nota-se que esse polifenol tem propriedades anticancerígenas que merecem estudos mais aprofundados, pois apesar de alguns estudos pré-clínicos demostram que o resveratrol tem apresentado efeitos promissores na inibição da proliferação e progressão do câncer de mama verifica-se que muitos dos estudos ainda são poucos conclusivos quanto aos resultados clínicos associados a administração desse composto em pacientes com neoplasia mamária.

Palavras-chave: Resveratrol, Câncer de mama, Doenças cancerígenas.

\section{Referências}

ITURRI, J. Resveratrol-Induced Temporal Variation in the Mechanical Properties of MCF-7 Breast Cancer Cells Investigated by Atomic Force Microscopy. Int J Mol Sci, [S.l.],2019.PubMed.

SUN, Y. Resveratrol Inhibits the Migration and Metastasis of MDA-MB-231 Human Breast Cancerby Reversing TGF- $\beta 1$-Induced Epithelial-Mesenchymal Transition. Molecules,[S.l.],2019. 


\section{USO CRÔNICO DE ÁLCOOL E SUA RELAÇÃO COM O CÂNCER}

Gabriele Cristina Schröder ${ }^{1}$; Antonio Martins de Mesquita Neto ${ }^{2}$; Bruna Aguiar de Negreiros²; Edmilson Alves de Carvalho Neto²; Raissa Fernanda Maciel Gomes²; José Lopes Pereira Júnior ${ }^{3}$

1. Discente do curso de Medicina pelo Instituto Educacional do Vale do Parnaíba IESVAP, Parnaíba-PI, Brasil;

2. Discente do curso de Medicina do Instituto Educacional do Vale do Parnaíba IESVAP, Parnaíba-PI, Brasil;

3. Docente do curso de Medicina do Instituto Educacional do Vale do Parnaíba IESVAP, Parnaíba-PI, Brasil.

Autor para correspondência: Gabriele Cristina Schroder / gabi.f.schroder@ hotmail.com / 89999205855

INTRODUÇÃO: Os tumores malignos, assim como a maioria das doenças não transmissíveis, são potencialmente evitáveis, pois estão associados a exposições ambientais e a fatores relacionados aos hábitos de vida dos indivíduos, destacando-se tabagismo, dieta e consumo de bebidas alcoólicas. OBJETIVO: Analisar o etilismo como fator de risco para o desenvolvimento de câncer. MÉTODOS: Trata-se de uma revisão da literatura na qual utilizou-se os descritores em Ciências da Saúde (DECS): "Câncer", "Álcool", "Neoplasia", "Alcoolismo", "Uso crônico", nas bases de dados SciELO, Bireme e PubMed, nos idiomas português e inglês considerando-se os trabalhos publicados nos últimos 10 anos. RESULTADOS: A literatura evidenciou o uso excessivo de álcool como fator de risco para o desenvolvimento de neoplasias, destacando-se o câncer hepático, cabeça e pescoço, além de tumores de cavidade oral, faringe, laringe, esôfago, colorretal e mama. Estudos indicam que o consumo de álcool seja responsável por $1,7 \%$ das mortes por câncer nos homens e 5,2\% nas mulheres de todo o mundo. Dentre os casos, a prevalência do consumo abusivo de álcool (13,7\% da população adulta brasileira), prevalece 3,3 vezes mais entre os homens $(21,6 \%)$ quando comparado com as mulheres $(6,6 \%)$, o que explica aumento da taxa de mortalidade, por exemplo, do câncer hepático no sexo masculino com 28,8\%, enquanto no sexo feminino apenas $5,5 \%$. Portanto, há uma maior prevalência de neoplasias no gênero masculino, tendo como fator de risco o uso crônico de álcool. Porém, nos últimos anos, a incidência de câncer entre as mulheres vem aumentando gradativamente devido mudanças de hábitos, sendo o câncer de mama a neoplasia mais comum (60\% dos casos). Quanto aos mecanismos de carcinogenicidade não há consenso por parte da literatura, porém, relatos evidenciam que o uso crônico do álcool levaria a um desequilíbrio na capacidade antioxidante do organismo com instalação de estresse oxidativo, além de haver um comprometimento na genética do indivíduo com superexpressão de oncogenes e subexpressão de genes supressores de tumor. Estudos americanos relatam que o uso do álcool acarreta ao homem diminuição no sistema imunológico, além de lesionar células, fatores estes que potencializariam o desenvolvimento de neoplasias. CONCLUSÃO: Conclui-se que o consumo exacerbado de álcool é sem dúvidas fator predisponente ao desenvolvimento de inúmeras neoplasias, apesar de ainda não se ter mecanismos carcinogênicos elucidados. O alcoolismo deve ser considerado problema de saúde público nas redes de atenção à saúde, sendo necessárias estratégias para cessar ou diminuir o hábito de consumo.

Palavras-chave: Câncer, Álcool, Neoplasia, Alcoolismo, Uso crônico. 


\section{Referências}

KFOURI, Suely Aparecida et al. Fração de câncer de cabeça e pescoço atribuível ao tabaco e ao álcool em cidades de três regiões brasileiras. Revista Brasileira de Epidemiologia [online]. 2018, v.21 [Acessado6Agosto2019], e180005.Disponível em:<https://doi.org/10.1590/1980-549720180005>.Epub02Ago2018.ISSN19805497.https://doi.org/10.1590/1980-549720180005.

LLEWELLYN, C. D.; et al. An Analysis of Risk Factors for Oral Cancer in Young People: a Case-control Study. Oral Oncology, 2004; 40: 304-313.

WÜNSCH FILHO, V. Consumo de bebidas alcoólicas e risco de câncer. Revista USP, n.96, p.37-46, 28 fev. 2013. 


\section{APLICAÇÃO DA BIÓPSIA LÍQUIDA EM ONCOLOGIA: UMA REVISÃO ACERCA DE SUAS VANTAGENS E DESVANTAGENS NA DETECÇÃO DE BIOMARCADORES TUMORAIS}

Klayane Milena de Castro Carvalho ${ }^{1}$; Antonia Luzia Lima do Nascimento²; Bruna Letícia Lima Carvalho²; Maria Ester Oliveira Sales²; Valentina Rémily de Melo Vasconcelos²; Thiago Nobre Gomes ${ }^{3}$.

${ }^{1}$ Acadêmica, Universidade Federal do Piauí, Parnaíba, Piauí, Brasil;

${ }^{2}$ Acadêmica, Universidade Federal do Piauí, Parnaíba, Piauí, Brasil

${ }^{3}$ Mestre, Universidade Federal do Piauí, Parnaíba, Piauí, Brasil

Autor para correspondência: Klayane Milena de Castro Carvalho / klayanemilena@hotmail.com / 86998269281

INTRODUÇÃO: A biópsia é um método primário muito comum na prática médica para o diagnóstico do câncer e orientação da terapia, porém é um procedimento invasivo que possui limitações. Nos últimos anos, pesquisas no campo da oncologia têm focado em biomarcadores tumorais que circulam no sangue. Nesse contexto, a biópsia líquida surgiu como uma excelente ferramenta, pelo fato de ser obtida por coleta sanguínea padrão minimamente invasiva. OBJETIVO: Analisar a literatura científica reunindo informações disponíveis sobre a aplicação da biópsia líquida na área oncológica, enfatizando vantagens e desvantagens sobre sua utilização. MÉTODOS: Trata-se de um estudo retrospectivo, com revisão literária a partir de publicações indexadas nas bases de dados PubMed, SciELO e Google Acadêmico. Utilizou-se como descritores de busca os termos "Biópsia Líquida", "Câncer", e "Biomarcadores tumorais". Como critérios de inclusão, foram consideradas as pesquisas publicadas entre os anos de 2015 a 2019, abordando a referida temática. RESULTADOS: Após leituras dos trabalhos encontrados inicialmente e exclusão daqueles que não se enquadravam aos critérios propostos, foram selecionados 22 artigos científicos. Observou-se que o DNA tumoral circulante (ctDNA) e Exossomas (EXOs) são excelentes biomarcadores candidatos para realização de biópsias líquidas em muitos tipos de câncer. Algumas das vantagens do ctDNA é que seu isolamento ocorre de forma simples, e que seus níveis aumentam ou diminuem em resposta ao grau de carga tumoral, facilitando assim o monitoramento da doença. Uma desvantagem do ctDNA é que para ele servir como uma ferramenta clinicamente viável, são necessários métodos de detecção altamente sensíveis e específicos. Os EXOs também se mostram ótimos biomarcadores tumorais, pois seu conteúdo molecular reflete a composição da célula de origem. Porém, EXOs podem ser liberados por qualquer célula do corpo em condições fisiológicas e patológicas. Outro grande desafio é que o método padrão-ouro e um dos mais utilizados para o isolamento de EXOs requer grande quantidade de material de partida e não fornece análise individual de partículas, não sendo adequado para ensaios de alto rendimento. CONLUSÃO: Conforme observado, o principal obstáculo para que a biópsia líquida seja eficaz como ferramenta de diagnóstico do câncer, prognóstico e monitoramento da terapia é a sensibilidade. Desta forma, apesar desta variedade de biópsia se mostrar como promissora, muitos desafios ainda precisam ser superados antes da mesma ser implementada na rotina clínica em oncologia.

Palavras-chave: Biópsia Líquida; Câncer; Líquidos Corporais; Biomarcadores tumorais.

\section{Referências}


MINCIACCHI, V. R. et al. Extracellular vesicles for liquid biopsy in prostate cancer: where are we and where are we headed. Prostate Cancer Prostatic Dis. September,2017. Palmirotta, R. et al. Liquid biopsy of cancer: a multimodal diagnostic tool in clinical oncology. Ther Adv Med Oncol. August,2018.

COSTA, J. L. SCHMITT, F. C. Liquid biopsy: A New too in oncology. Acta Cytologica. June, 2019. 


\section{AUDITORIA DE PROCEDIMENTOS CLÍNICOS EM ONCOLOGIA CONFORME PRODUÇÃO AMBULATORIAL DO SISTEMA ÚNICO DE SAÚDE EM TERESINA-PI}

Grace Kelly Lima da Fonseca ${ }^{1}$; Ludymila Freitas de Amorim²; Walber de Vasconcelos Brito Júnior ${ }^{2}$; Izonete Pereira da Silva Melo²; Dean Douglas Ferreira de Olivindo ${ }^{3}$

1. Graduanda em Enfermagem, Centro Universitário Santo Agostinho - UNIFSA, Teresina, PI, Brasil;

2. Graduandos em Enfermagem, Centro Universitário Santo Agostinho - UNIFSA, Teresina, PI, Brasil;

3. Docente de Enfermagem, Centro Universitário Santo Agostinho - UNIFSA, Teresina, PI, Brasil.

Autor para correspondência: Grace Kelly Lima da Fonseca / gracekelly.adm8@gmail.com / (86) 988860872

INTRODUÇÃO: A supervisão do câncer abrange um agrupamento de ações em diversas áreas. Uma dessas áreas é a terapêutica oncológica, que, devido ao emprego de tecnologias de alta complexidade e custos, requerem expressivos recursos do Sistema Único de Saúde (SUS). A auditoria dos procedimentos clínicos em oncologia é um instrumento influente na qualificação da rede de atenção no intuito de aprimorar e controlar a prestação dos procedimentos clínicos. OBJETIVO: Analisar os registros ambulatoriais dos procedimentos clínicos em oncologia com o propósito de fornecer instrumentos de apoio ao planejamento e gestão de políticas de terapêutica e controle do câncer. METODOLOGIA: Realizou-se uma pesquisa documental, de caráter descritivo e retrospectivo. A coleta de dados foi realizada no Sistema de Informação Ambulatorial (SIA/SUS), disponíveis no Departamento de Informática do Sistema Único de Saúde (DATASUS) e processados no Microsoft Excel. As variáveis analisadas foram: valores aprovados conforme caráter do atendimento, complexidade, natureza jurídica, financiamento, forma organização, compreendidos no espaço temporal de janeiro de 2009 a abril de 2019. A complementação de dados bibliográficos foi realizada por meio de consulta a Biblioteca Virtual em Saúde (BVS) com os descritores "Sistemas de Informação em Atendimento Ambulatorial" e "oncologia". RESULTADOS: No período estudado o valor aprovado por local de atendimento para produção ambulatorial do SUS para tratamento em oncologia foi de $\mathrm{R} \$ 282.287 .422,10$, demonstrou-se um aumento progressivo no decorrer dos anos, sendo o ano de 2018 com os maiores gastos. Nessa perspectiva se faz necessária auditorias permanentes nos serviços de assistência oncológica, treinamento e educação dos funcionários, controle da produção realizada, vislumbrando o declínio dos gastos excessivos e monitoramento das intervenções realizadas. $\mathrm{O}$ caráter de atendimento predominante foi o eletivo, visto que, terapêutica oncológica é de alta complexidade e programada. No que concerne a natureza jurídica aponta-se associação privada. No tocante ao financiamento evidencia-se a Média e Alta Complexidade- MAC (96,3\%) e Fundo de Ações Estratégicas e Compensações - FAEC $(3,7 \%)$. Quanto a forma de terapêutica se destaca a Quimioterapia paliativa - adulto, com $29,8 \%$ dos gastos, seguida pela Radioterapia (20,7\%), ressalta-se também a Quimioterapia prévia (neoadjuvante/citorredutora)- adulto (10,9\%), Quimioterapia adjuvante (profilática) - adulto $(10,6 \%)$ e Quimioterapia de tumores de criança e adolescente (9,3\%). CONCLUSÃO: Pretende-se com este estudo, contribuir para a 
explanação de estratégias de avaliação dos registros de produção, sendo útil para auxiliar os gestores das unidades prestadoras de serviço, fornecendo instrumentos de apoio ao planejamento e gestão de políticas de terapêutica e controle do câncer.

Palavras-chave: Sistemas de Informação em Atendimento Ambulatorial, Oncologia, Saúde Pública.

\section{Referências}

BRASIL. MINISTÉRIO DA SAÚDE. Informações de Saúde (TABNET) Assistência à saúde- $\quad$ Brasil 2019.2 Disponível em:<http://tabnet.datasus.gov.br/cgi/deftohtm.exe?sia/cnv/qapi.def $>$.Acesso em: jun. 2019.

GOMES JR, S. C. S. ; ALMEIDA, R. T. Comparação do registro da produção ambulatorial em oncologia no Sistema Único de Saúde. Cadernos de Saúde Pública, v.22, p.141-150, 2006. 


\section{MORTALIDADE FEMININA POR NEOPLASIA MALÍGNA DO OVÁRIO NO NORDESTE BRASILEIRO}

Ludymila Freitas de Amorim ${ }^{1}$; Maria Juliêta Reis Barros²; Maria Nillane da Silva²; Gisele Lopes Cavalcante ${ }^{3}$

${ }^{1}$ Graduanda em Enfermagem, Centro Universitário Santo Agostinho - UNIFSA, Teresina, PI, Brasil;

${ }^{2}$ Graduandos em Enfermagem, Centro Universitário Santo Agostinho - UNIFSA, Teresina, PI, Brasil;

${ }^{3}$ Mestranda em Ciências Farmacêuticas pela Universidade Federal do Piauí - UFPI, Teresina, PI, Brasil.

Autor para correspondência: Ludymila Freitas de Amorim / ludymilaamorim22@gmail.com / (89) 994154267

INTRODUÇÃO: A neoplasia maligna do ovário é uma das mais incidentes e possui grande impacto na taxa de mortalidade por neoplasias ginecológicas no mundo. A dificuldade na detecção precoce da patologia dificulta o tratamento, tornando-a a quinta principal causa de morte por câncer em mulheres. OBJETIVO: Avaliar a mortalidade feminina por neoplasia maligna do ovário no Nordeste brasileiro. MÉTODOS: Constituise de um estudo documental, retrospectivo e de série temporal, baseado em dados coletados por meio do Sistema de Informações sobre Mortalidade (SIM) do Departamento de Informática do Sistema Único de Saúde (DATASUS). Analisou- se a tendência de não completude segundo ano do óbito, região, faixa etária, raça/cor e escolaridade no período de 2010 a 2017 no Nordeste do Brasil. RESULTADOS: Os resultados demonstraram um total cumulativo de 5.813 óbitos no período estudado com a identificação de um significativo crescimento das taxas de óbito ano a ano, sendo o ano de 2017 o de maior incidência com 14,91\% ( $\mathrm{n}=867)$ do total de óbitos. No tocante aos estados estudados a maior taxa de óbito foi encontrada na Bahia com 24,26\% ( $\mathrm{n}=1.410)$ do total de óbitos, seguida do Pernambuco com 22,26\% ( $n=1.294)$ e do Ceará com 18,2\% (1.058) dos óbitos. No que concerne a faixa etária, teve- se que o grupo etário de maior incidência foi o de 60 a 69 anos com 23,43\% (1.362) do total de óbitos. Em relação à raça/cor das mulheres a raça parda foi a declarada com $54,26 \%(n=3.154)$ do número total de óbitos. Um significativo achado diz respeito à escolaridade, já que a maior taxa de óbitos $(21,49 \%)$ está relacionada com as mulheres que possuíam somente 1 a 3 anos de estudo, com o total de 1.249 óbitos. CONCLUSÃO: A ausência de rastreamento e a escassez de sintomas tornam o diagnóstico precoce mais difícil fazendo com que grande parte das pacientes já se apresente com disseminação peritoneal e ascite no momento do diagnóstico. Sendo assim, é de extrema importância encaminhar a paciente ao especialista precocemente sempre que houver suspeita dessa patologia após a análise clínica e exame físico detalhado, e assim garantindo melhor expectativa e qualidade de vida.

Palavras- Chave: Câncer, Neoplasia, Ovário.

\section{Referências}

BRASIL. Ministério da saúde. DATASUS. Disponível em <http://www2.datasus.gov.br/DATASUS/index.php?area=02>.Acesso em 06082019. 


\section{MORBIDADE HOSPITALAR POR NEOPLASIAS EM MULHERES PIAUIENSES: ANÁLISE DE UMA DÉCADA}

Ludymila Freitas de Amorim¹; Maria Juliêta Reis Barros²; Maria Camila Leal de Moura²; Grace Kelly Lima da Fonseca ${ }^{2}$; Izonete Pereira da Silva Melo²; Gisele Lopes Cavalcante ${ }^{3}$

${ }^{1}$ Graduanda em Enfermagem, Centro Universitário Santo Agostinho - UNIFSA, Teresina, PI, Brasil;

${ }^{2}$ Graduandos em Enfermagem, Centro Universitário Santo Agostinho - UNIFSA, Teresina, PI, Brasil;

${ }^{3}$ Mestranda em Ciências Farmacêuticas pela Universidade Federal do Piauí - UFPI, Teresina, PI, Brasil..

Autor para correspondência: Ludymila Freitas de Amorim / ludymilaamorim22@gmail.com / (89) 994154267

INTRODUÇÃO: Atualmente, estimativas do Instituto Nacional do Câncer (INCA) apontam a incidência de 282.450 casos de neoplasias em mulheres brasileiras. Convém destacar que as maiores taxas de mortalidade afetam principalmente as regiões com maior vulnerabilidade socioeconômica, estando o Piauí inserido nesse contexto. OBJETIVO: Avaliar o perfil de morbidade hospitalar por neoplasias em mulheres no estado do Piauí a fim de corroborar na compreensão da incidência desse agravo de saúde pública. MÉTODOS: Constitui-se de uma pesquisa documental, retrospectiva e de série temporal baseada em dados coletados por meio Morbidade Hospitalar do SUS (SIH/SUS) do Departamento de Informática do Sistema Único de Saúde (DATASUS). Analisou-se a tendência de não completude segundo ano, município, faixa etária, raça/cor, morbidade e valores dos serviços hospitalares no recorte temporal de Janeiro de 2009 a Dezembro de 2018 em consonância com a 10 ${ }^{\mathrm{a}}$ revisão da versão brasileira da Classificação Internacional de Doenças (CID BR-10). RESULTADOS: Demonstrou-se que dentre os achados das neoplasias destacaram-se o leiomioma intramural do útero, as neoplasias in situ benignas e de comportamento incerto e desconhecido, a neoplasia maligna da mama e a neoplasia maligna do colo do útero. Nessa perspectiva, compreende-se a necessidade de uma intensa intervenção a nível estadual nos programas públicos voltados a atenção e integralidade da saúde feminina. Observou-se que o triênio 2016-2018 contemplou a maior taxa de ocorrência com 31,87\% $(n=19.762)$ dos casos. No que concerne aos municípios, Teresina, capital do estado, ocupou o primeiro lugar com 39,38\% dos casos $(n=24.413)$, seguida de Parnaíba com 6,62\% ( $n=4103)$ e Picos com 2,24\% ( $n=1390)$ respectivamente. No tocante ao grupo etário, evidenciou-se que as mulheres piauienses mais acometidas por neoplasias foram as pertencentes a faixa etária de 40 a 59 anos com $48,87 \%(\mathrm{n}=30302)$. No que diz respeito a raça/cor evidenciou-se maior incidência na parda com $71,91 \%(n=44581)$. No que se refere aos valores provenientes dos serviços hospitalares para atendimento dos casos, têm-se uma ascensão onde em 2009 tinha-se um gasto de $\mathrm{R} \$ 3858169,844$ passando para $\mathrm{R} \$ 9735604,84$ em 2018. CONCLUSÃO: Portanto, infere-se que a morbidade hospitalar de mulheres piauienses pelo câncer no Piauí constitui-se como um agravo de saúde a ser enfrentado. Espera-se que as análises das variáveis do estudo possam corroborar no planejamento de intervenções adequadas e na implementação de políticas locais de saúde vislumbrando a minimização da problemática e consequente melhoria da saúde da mulher piauiense.

Palavras-chave: Câncer. Sistema de informação. Saúde da mulher. Saúde pública. 


\section{Referências}

INSTITUTO NACIONAL DE CÂNCER (Brasil). Estimativas nacionais de Câncer. Rio de Janeiro, 2018. 


\section{REFLEXO DAS NEOPLASIAS NO BRASIL: MORTALIDADE E MORBIDADE HOSPITALAR ENTRE 2010-2017}

Grace Kelly Lima da Fonseca ${ }^{1}$; Ludymila Freitas de Amorim²; Daniela Francine de Alencar Sousa Soares ${ }^{2}$; Izonete Pereira da Silva Melo²; Francisco Samuel A. de A. Campelo²; Dean Douglas Ferreira de Olivindo ${ }^{3}$

${ }^{1}$ Graduanda em Enfermagem, Centro Universitário Santo Agostinho - UNIFSA, Teresina, PI, Brasil;

${ }^{2}$ Graduandos em Enfermagem, Centro Universitário Santo Agostinho - UNIFSA, Teresina, PI, Brasil;

${ }^{3}$ Docente de Enfermagem, Centro Universitário Santo Agostinho - UNIFSA, Teresina, PI, Brasil.

Autor para correspondência: Grace Kelly Lima da Fonseca / gracekelly.adm8@gmail.com / (86) 988860872

INTRODUÇÃO: Nas últimas décadas o Brasil tem passado por profundas mudanças em seu perfil epidemiológico e demográfico, determinando alterações nos padrões de saúdedoença, evidenciada pela transição no perfil de mortalidade, com declínio da taxa de doenças infecciosas e evolução simultânea da taxa de doenças crônico-degenerativas, em particular doenças cardiovasculares e o câncer. Estas transformações têm se verificado com padrões e intensidades inerentes entre as regiões do país. OBJETIVO: Retratar o perfil de mortalidade e de morbidade hospitalar por neoplasias no Brasil no período de 2010 à 2017. METODOLOGIA: Realizou-se uma pesquisa documental, de caráter descritivo e retrospectivo. A coleta de dados foi realizada no Sistema de Informações sobre Mortalidade - SIM e Sistema de Informações Hospitalares do SUS (SIH/SUS), disponíveis no Departamento de Informática do Sistema Único de Saúde (DATASUS) e processados no Microsoft Excel. As variáveis analisadas foram: mortalidade por neoplasias, sexo, internações, valor médio de internação, tempo de internação, no recorte temporal de 2010 a 2017. A complementação de dados bibliográficos foi realizada por meio de consulta a Biblioteca Virtual em Saúde (BVS). RESULTADOS: No período estudado, ocorreram 1.600.691 óbitos por neoplasias no Brasil. Cerca de 48,32\% destes óbitos ocorreram na região Sudeste e $21,36 \%$ na região Nordeste. A taxa de mortalidade no Brasil foi de 100 por 100 mil habitantes. Pode-se observar que o câncer de maior mortalidade entre as mulheres foi o de mama, com 116.545 óbitos, seguido pelo câncer de brônquios e dos pulmões $(n=79.980)$ e colo do útero $(n=44.247)$. Já entre os homens, a neoplasia mais evidente foi a de brônquios e dos pulmões, representando 13,9\% dos óbitos masculinos, seguido pelo câncer de próstata (13,2\%). Dentre as neoplasias, as internações por Neoplasia maligna da bexiga foram as que apresentaram maior valor médio por internação e o maior gasto total $(\mathrm{R} \$ 1.783,76)$. Neoplasia maligna do lábio, cavidade oral e faringe foram as neoplasias malignas que mais internações ocasionaram. Neoplasia benigna do encéfalo e outras partes do sistema nervoso central, foi a que requereu maior tempo de internação, aproximadamente 12 dias, seguida por Neoplasia maligna do encéfalo $(11,2)$ e Neoplasia maligna de outras partes do sistema nervoso central (11.1). CONCLUSÃO: A verificação da carga da doença é imprescindível para serem debatidas as estratégias de prevenção, diagnóstico precoce, tratamento e atenção paliativa ao câncer. Pretende-se com este estudo, contribuir para o fornecimento de instrumentos de apoio ao planejamento e gestão de políticas de terapêutica e controle das neoplasias. 
Palavras-chave: Neoplasias, Mortalidade, Morbidade, Saúde Pública.

\section{Referências}

Barroso MF, Gomes KRO, Andrade JX. Frequência da colpocitologia oncótica em jovens com antecedentes obstétricos em Teresina, Piauí, Brasil. Ver Panam Salud Publica. 2011 mar; 29 (3): 162-8.

Brasil, Ministério da Saúde. Instituto Nacional de Câncer. Coordenação Geral de Ações Estratégicas. Divisão de Apoio à Rede de Atenção Oncológica. Diretrizes brasileiras para o rastreamento do câncer do colo do útero. Rio de Janeiro: Instituto Nacional de Câncer; 2011.

Ministério da Saúde (BR). Instituto Nacional de Câncer José de Alencar Gomes da Silva. Coordenação de Prevenção e Vigilância. Monitoramento das ações de controle dos cânceres do colo do útero e de mama. Inf Detecção Precoce. 2014 jan-abr; 5(1):1-8.

Brasil, Ministério da Saúde. Instituto Nacional do Câncer José de Alencar Gomes da Silva. Estimativa 2018: incidência de câncer no Brasil. Rio de Janeiro: Instituto Nacional do Câncer; 2017. 


\title{
AVALIAÇÃO CITOPATOLÓGICA EM MULHERES NO CLIMATÉRIO EM CENTRO DE REFERÊNCIA DE OEIRAS-PIAUÍ
}

\author{
Gideon Batista Viana Júnior1; Maria Clara Leal Cortez²; Lucas Bezerra Pinheiro³; \\ Jefferson Tôrres Nunes ${ }^{4}$ \\ ${ }^{1}$ Acadêmico de Medicina, Universidade Estadual do Piauí, Teresina, Piauí, Brasil; \\ ${ }^{2}$ Acadêmica de Medicina, Centro Universitário UNINOVAFAPI, Teresina, Piauí, \\ Brasil; \\ ${ }^{3}$ Acadêmico de Medicina, Faculdade Integral Diferencial, Teresina, Piauí, Brasil; \\ ${ }^{4}$ Médico Ginecologista, Faculdade integral Diferencial, Teresina, Piauí, Brasil
}

Autor para correspondência: Gideon Batista Viana Júnior / (86) 99911-9398 / gideon.viana.jr@gmail.com

INTRODUÇÃO: O período do climatério é uma fase biológica do ciclo vital feminino que tem início normalmente por volta dos 40 anos de idade, podendo se estender até os 65. Embora seja uma patologia prevalente no menacme, o câncer do colo do útero não perde sua importância no climatério já que corresponde, aproximadamente, a $15 \%$ de todos os cânceres que ocorrem no gênero feminino. É rastreado através do exame citopatológico, conhecido como Papanicolaou que embora tenha sido introduzido no Brasil desde a década de 50, o câncer de colo do útero ainda continua sendo um problema de saúde pública. OBJETIVOS: Identificar os principais diagnósticos citopatológicos e o perfil epidemiológico de mulheres no climatério atendidas na Clínica Nossa Senhora da Conceição em Oeiras - Piauí, no intervalo de tempo de dezembro de 2018 a fevereiro de 2019. MÉTODOS: Trata-se de um estudo prospectivo com abordagem quantitativa, a coleta de dados foi realizada através da aplicação direta de um questionário e verificação do laudo citopatológico. RESULTADOS: Foram analisadas 85 mulheres entre 40 a 81 anos, que já apresentaram a menopausa, a idade média da menopausa encontrada foi de 48 anos; a maioria era natural de Oeiras (65\%); apresentava o intervalo de tempo da última coleta de papanicolaou até a atual de 1 a 2 anos (45\%); tinham dor pélvica (15\%) como queixa principal. A citopatologia foi positiva em 5\%, apresentando lesões precursoras de câncer de colo uterino como ASC-US, ASC-H e LSIL e a Gardnerella associada à atrofia foi o microorganismo mais identificado. DISCUSSÃO: A prevalência de aproximadamente 5\% de anormalidades citológicas nos exames está de acordo com as frequências aproximadas de $2 \%$ a $9 \%$, bem como o microorganismo identificado (Gardnerella) que é prevalente na maioria dos estudos nacionais. A idade média da menopausa corresponde à tendência encontrada nas últimas décadas no Brasil, que evidencia uma queda de 51,2 para 48,8 anos. CONCLUSÃO: Através do estudo, foi possível obter conhecimento sobre o perfil das mulheres no climatério atendidas em Centro de Referência na cidade de Oeiras, bem como os principais diagnósticos citopatológicos, constituindo assim um estudo pioneiro na cidade que fortalece políticas de rastreio de câncer do colo uterino.

Palavras-chave: Neoplasias do Colo do Útero, Teste de Papanicolaou, Rastreamento de Células

\section{Referências}

Brasil. Ministério da Saúde. Instituto Nacional do Câncer. Coordenação de prevenção e vigilância. 2010. 
Silva AG, Giranelli VR, Gamarra CI, Bastonaite-Teixrira MT. Cervical Cancer Mortality Trends in Brasil, 1981-2006. Cad Saude Publica. 2010 Dec, 26 (12): 2399-2407. 


\title{
INFLUÊNCIA DO ÍNDICE E CARGA GLICÊMICA DA DIETA SOBRE O CRESCIMENTO DO TUMOR MALIGNO DE MAMA
}

\author{
Patrícia Barbosa Pereira $^{1}$; Gilmara Péres Rodrigues ${ }^{2}$ \\ 1. Graduanda, Universidade Federal do Piauí, Teresina, Piauí, Brasil. \\ 2. Doutoranda, Universidade Federal do Piauí, Teresina, Piauí, Brasil.
}

Autor para correspondência: Patrícia Barbosa Pereira / patybarbosa0@ hotmail.com / (89)994547985

INTRODUÇÃO: O câncer de mama é a principal causa de morbimortalidade em mulheres brasileiras de 40 a 69 anos. De etiologia indefinida, destaca-se a interação entre fatores genéticos e ambientais no aumento ou diminuição do risco carcinogênico no tecido mamário. Atualmente, sabe-se que dietas com baixo índice e carga glicêmica aumentam os níveis circulantes de insulina, favorecendo a expressão gênica do fator de crescimento semelhante à insulina tipo 1 (IGF-1), capaz de estimular a proliferação celular. OBJETIVO: Avaliar as evidências disponíveis e discutir a influência do índice e carga glicêmica da dieta sobre o crescimento do tumor maligno de mama. MÉTODOS: Realizou-se uma revisão integrativa da literatura científica, nas bases de dados SciELO e PUBMED. Os descritores utilizados foram "carcinoma mamário humano", "carcinogênese", "crescimento", "nutrição", "índice glicêmico", "carga glicêmica" e "IGF-1". Foram selecionados artigos publicados em texto completo, em português, nos últimos dez anos, que respondessem ao problema de pesquisa. Para extração dos dados, utilizou-se formulário validado, de metodologia descritiva. RESULTADOS: Foram recuperados 36 artigos, dos quais 20 foram incluídos para análise crítica. Do total de 20 artigos originais, 18 demonstraram influência positiva do índice e carga glicêmica da dieta sobre o crescimento de tumores mamários. A explicação destes achados está relacionada à superexpressão de IGF-1 decorrente do consumo habitual de alimentos de alto índice e carga glicêmica. Em níveis elevados, o IGF-1 inibe a expressão de E-caderina, via $\mathrm{PI} 3 \mathrm{~K} / \mathrm{AKt} / \mathrm{mTOR} 7$, reduzindo a adesão intercelular e favorecendo a expansão tumoral. Além disso, o IGF-1 superexpresso estimula a secreção do fator de crescimento endotelial vascular, essencial à vascularização e crescimento tumoral. CONCLUSÃO: As evidências disponíveis permitem concluir que padrões alimentares de elevado índice e carga glicêmica podem favorecer a proliferação e crescimento tumoral na neoplasia mamária. Entretanto, mais estudos são necessários para avaliar a contribuição glicêmica da dieta na gênese, progressão e terapia nutricional dos diferentes tipos de câncer.

Palavras-chave: Carcinoma mamário humano, Carcinogênese, Índice glicêmico, Carga glicêmica, IGF-1.

\section{Referências}

BELLO, G. B; SILVA, F. M; DIER, C; SCHNEIDER, A. P. Associação entre o índice glicêmico e a carga glicêmica da dieta de frequentadores de clínicas estéticas privadas de Porto Alegre- RS e indicadores de adiposidade corporal. Nutrire. 2015 Apr; 40(1): 2128. Disponível em: http://dx.doi.org/10.4322/2316-7874.043714. Acesso em 29 de junho de 2019. 
MOTTER, A .F. Avaliação do hábito de consumo de fibras alimentares e gorduras da dieta antes do diagnóstico de câncer de mama em pacientes Da cidade de pelotas-rs. Revista Brasileira de Obesidade, Nutrição e Emagrecimento, São Paulo. v.10. n.58. p.171-179.2016. Disponível em: http://oaji.net/pdf.html?n=2016/811-1473014646.pdf. Acesso em 1 de julho de 2019.

PRASAD C.P et al. Expression analysis of E-cadherin, Slug and GSK3beta in invasive ductal carcinoma of breast. BMC Cancer. 2009;9:325. Disponível em: https://www.ncbi.nlm.nih.gov/pubmed/19751508. Acesso em 04 de julho de 2019. 


\section{EFEITOS DA TERAPIA MEDICAMENTOSA COM TAMOXIFENO NO CÂNCER DE MAMA: UMA REVISÃO INTEGRATIVA}

Hyan Ribeiro da Silva ${ }^{1}$; Rayssa Hellen Ferreira Costa ${ }^{1}$; Mateus Henrique de Almeida da Costa $^{1}$; Daniella Nobre Leal ${ }^{1}$;Nanielle Silva Barbosa ${ }^{1}$;Francilene Viera da Silva ${ }^{1}$

${ }^{1}$ Acadêmicos de farmácia pela Faculdade Integral Diferencial - FACIDIWYDEN

${ }^{2}$ Orientadora , Professora da Faculdade Mauricio de Nassau

Autor para correspondência: Hyan Ribeiro da Silva / hyanribeiro16@outlook.com / 9898719-8000

INTRODUÇÃO: O Tamoxifeno é um agente antiestrogênico não esteroidal que é frequentemente utilizado para o tratamento de pacientes portadoras de câncer de mama com receptor estrógeno positivo. É a terapia adjuvante sistêmica que dá continuidade ao tratamento cirúrgico ou quimioterápico. O câncer de mama representa a neoplasia maligna mais frequente que acomete as mulheres (excetuando-se o câncer de pele não melanoma) em todo o mundo. No Brasil representa também o principal tipo de câncer na população feminina. OBJETIVO: Avaliar os efeitos da terapia medicamentosa com tamoxifeno em mulheres com câncer de mama. MÉTODOS: Trata-se de uma revisão integrativa da literatura realizada através de publicações dos últimos dez anos, indexadas nos bancos de dados da BVS, BDENF, IBECS, MEDLINE e SCIELO. Foram utilizados os seguintes descritores: "Câncer de Mama", "Tamoxifeno", "Terapia Medicamentosa", sendo encontrados 71 artigos dos quais apenas 7 fazem parte da amostra final do resultado. Foram inclusos artigos disponíveis, online e gratuitos e exclusos os não gratuitos e indisponíveis. RESULTADOS: Constatou-se que o tamoxifeno é o medicamento mais utilizado pela população estudada, seus efeitos se constituem na redução da dor, do tumor e aumento da sobrevida. Porém apresenta riscos de desenvolvimento de câncer endometrial. Foi possível identificar sua relação com o sobrepeso e obesidade. Apresentando também redução da resposta imunológica quando na presença de estresse. Quando comparado ao anastrozol o tamoxifeno apresentou uma menor expectativa de vida para as mulheres em tratamento. CONCLUSÃO: Pode-se concluir que o tamoxifeno é o medicamento mais indicado para o tratamento e alívio dos sintomas em mulheres com câncer de mama na pós-menopausa, apresentando resultados bastante positivos e contribuindo para a sobrevida dessa população. No entanto, por mais de IV década o tamoxifeno foi prescrito com sucesso no cenário adjuvante e metastático. No entanto, podemos afirmar que, tem que ser desenvolvidas mas pesquisas.

Palavras-chave: Câncer de Mama, Tamoxifeno, Terapia Medicamentosa.

\section{Referências}

LAGARES, E. B. et al. Excesso de Peso em Mulheres com Diagnóstico de Câncer de Mama em Hormonioterapia com Tamoxifeno. Revista Brasileira de Cancerologia. 2013; 59 (2): 201-210.

FONSECA1, M; ARAÚJO, G. T. B; .SAAD, E.D. cost-effectiveness of anastrozole, in comparison with tamoxifen, in the adjuvant treatment of early breast câncer in brazil. Ver Assoc Med Bras 2009; 55 (4): 410-5. 
BARRA, A. A. et al. Avaliação endometrial em pacientes usuárias de tamoxifeno. FEMINA| janeiro /fevereiro 2013| vol41 $\mid \mathrm{n}^{\circ} 1$.

OLYMPIO, P. C. A. P; AMORIM, M. H. C; LIMA, E. F. A. Estresse e resposta imunológica em mulheres mastectomizadas durante o tratamento com tamoxifeno. Rev. enferm. UERJ, Rio de Janeiro, 2012 jan/mar; 20(1):15-20.

GAMBOA, O; DÍAZ, S; CHICAÍZA, L; GARCÍA, M. Análisis de costo-efectividad en Colombia de anastrazol Vs. Tamoxifeno como terapia inicial em mujeres com câncer temprano de mama y receptor hormonal positivo. Biomédica 2010; 30: 46-55. 


\section{CARCINOMA OCULTO DE MAMA COM METÁSTASE CUTÂNEA: RELATO DE CASO}

Augusto Cesar Maia Rio Lima Silveira ${ }^{1}$; Paula Shelda Fonseca Fernandes ${ }^{2}$; Igor Gabriel de Brito Liberato ${ }^{3}$; Luiza Ivete Vieira Batista ${ }^{4}$; Cristiane Amaral dos Reis ${ }^{5}$

${ }^{1}$ Acadêmica do curso de medicina no Centro Universitário Uninovafapi, Teresina- PI, Brasil;

${ }^{2}$ Acadêmica do curso de medicina no Centro Universitário Uninovafapi, Teresina- PI, Brasil

${ }^{3}$ Acadêmico de Medicina da Universidade Federal do Piauí, Teresina-PI, Brasil.

${ }^{4}$ Médica Pediatra, Teresina-PI, Brasil.

${ }^{5}$ Médica Oncologista Geneticista, Teresina-PI, Brasil

Autor para Correspondência: Augusto Cesar Maia Rio Lima Silveira / gutoc14@ hotmail.com/ (86) 98104-1006

INTRODUÇÃO: O câncer de mama é, o segundo tipo de câncer mais comum entre as mulheres no mundo. No Brasil, o percentual é de $29 \%$ dos novos casos a cada ano e, em 2018, foram estimados cerca de 59.700 casos, sendo destes 600 casos no estado do Piauí. Dentre os principais fatores de risco estão idade e histórico familiar. Metástase é a capacidade de o câncer sair do seu local de origem e invadir novos tecidos. Nesse caso falaremos da metástase cutânea, um tipo de metástase que não é tão comum quando comparada à frequência de outros tipos. Essa proliferação cutânea pode acontecer junto a outros tipos de metástases, sendo ela o primeiro indicativo para a presença de uma neoplasia maligna subjacente ou oculta. $\mathrm{O}$ presente estudo relata um caso de um carcinoma com sítio primário oculto a exames de imagem. RELATO DE CASO: Paciente mulher, 70 anos, hipertensa, nega etilismo, e tabagismo passivo no trabalho. Relatou perceber, em 2017, aparecimento lento e progressivo de nódulo em região posterior esquerda do pescoço, trazendo Mamografia de Julho de 2018 BIRADS 3 e imagem nodular QSE mama esquerda. Em agosto de 2018 o nódulo foi submetido a biopsia incisional resultando em carcinoma, e Imunohistoquímica sugestiva de sítio primário em mama. Optou-se pela realização de Ressonância Magnética com resultado BIRADS 2, não sendo identificado nódulo mamário para biópsia. Em novembro de 2018 durante o exame físico foi verificado área espessada em torno de $2,3 \times 2,4 \mathrm{~cm}$ em região lateral mama esquerda e duas próximas ao local, 1 em ombro a direita e outra nas costas. Submetida a biópsia excisional de lesão cutânea em parede lateral do tórax, tendo como achado fragmento de tecido fibromuscular com infiltrado celular padrão epitelioide. Realizado Imunoistoquímica em dezembro de 2018 com resultados que favoreceu Mama como sítio primário de Carcinoma Infiltrativo de Derme e Subcutâneo. Teve como conduta controle por exames de imagem e tratamento com anastrozol. CONSIDERAÇÕES FINAIS: A metástase cutânea - descrita na literatura em casos isolados e raros - tem como importância a contribuição para o reconhecimento do sítio primário oculto. Estudo retrospectivo mostrou em 45 anos casos de metástase a partir de carcinomas internos tendo a mama como principal responsável pelos surgimentos de metástase cutâneas em mulheres. Ressalta-se, que, mesmo com diversos anos de amostragem o surgimento foi de 209 casos nesse tempo. Portanto, em função da baixa incidência, o relato reforça a importância da análise do caso.

Palavras-chave: Neoplasias da Mama; Metástase Neoplásica; Carcinoma; 


\section{Referências:}

HOSSNE, R. S. Relato de Caso e Revisão da Literatura. Diagn Tratamento, n. 4, p. 217 , 2008 .

HU, S. C.-S. et al. Cutaneous metastases from different internal malignancies: a clinical and prognostic appraisal. Journal of the European Academy of Dermatology and Venereology: JEADV, v. 22, n. 6, p. 735-40, jun. 2008.

INSTITUTO NACIONAL DE CÂNCER. MINISTÉRIO DA SAÚDE. Câncer de Mama.Junho,2019. Disponível em <https://www.inca.gov.br/tipos-de-cancer/cancer-demama>.

SAURE SARRIA, Víctor Manuel; CARDOSO HERNANDEZ, Jorge; HERNANDEZ HERRERA, Leonardo. Cáncer oculto de mama: presentación de caso. AMC, Camagüey ,v. 14,n. 5,oct.2010 . Disponível em $<$ http://scielo.sld.cu/scielo.php?script=sci_arttext\&pid=S102502552010000500011\&lng=es\&nrm=iso>.

SITTART, Jose Alexandre de Souza; SENISE, Monica. Cutaneous metastasis from internal carcinomas: a review of 45 years. An. Bras. Dermatol. Rio de Janeiro ,v. 88,n. 4,p. 541-544,Aug.2013.

VARADARAJAN, R. et al. Prognosis of occult breast carcinoma presenting as isolated axillary nodal metastasis. Oncology, v. 71, n. 5-6, p. 456-9, 2006. 


\title{
INTERRUPÇÃO DO CRESCIMENTO DE CÉLULAS CANCERÍGENEAS MEDIADA PELA VITAMINA D: UMA REVISÃO DE LITERATURA
}

\author{
Maria Alíssia Costa Carvalho ${ }^{1}$; Raniella Borges da Silva ${ }^{1}$; Erica Isabel de Abreu Freire ${ }^{2}$; \\ Heverson Dias de Araújo $^{2}$; Ellienai Erika Pereira de Sousa ${ }^{2}$; Lidiane Pereira de \\ Albuquerque $^{3}$ \\ ${ }^{1}$ Graduanda em Nutrição, Universidade Federal do Piauí, Teresina, Piauí. \\ ${ }^{2}$ Graduando em Enfermagem, Faculdade Integral Diferencial - FACID Wyden, \\ Teresina, Piauí. \\ ${ }^{3}$ Docente, Depto de Bioquímica e Farmacologia, Universidade Federal do Piauí, \\ Teresina, Piauí
}

Autor para correspondência: Maria Alíssia Costa Carvalho / mariaalissia@ gmail.com / 86995773993

INTRODUÇÃO: Inúmeras pesquisas têm demonstrado que a vitamina D interfere positivamente na proliferação, na diferenciação e na apoptose em células normal e maligna, contribuindo para inovação de intervenções que aproveitem o potencial anticancerígeno deste nutriente, dentre os quais, o incentivo à exposição solar, a suplementação ou a síntese farmacológica de compostos análogos da vitamina D para prevenção ou tratamento de patologias. OBJETIVO: Investigar o mecanismo de interrupção do crescimento de células cancerígenas através de compostos contendo vitamina D. METODOLOGIA: Trata-se de uma revisão narrativa de literatura. $O$ processo de seleção de artigos (em inglês e português) incluiu uma busca no banco de dados Scielo, PubMed e Google Acadêmico. Priorizaram-se trabalhos que abordavam os mecanismos biológicos dos compostos de vitamina D como medida terapêutica em pacientes oncológicos. Dentre os artigos pesquisados e analisados, dez atenderam aos critérios de inclusão (publicações entre 2010 e 2017, textos completos e estreita relação com o tema). RESULTADOS: A forma ativa da vitamina D $(1,25-$ dihidroxicholecalciferol) estimula a diferenciação celular e, assim, consegue inibir o crescimento de muitas células cancerígenas, resultando em um fenótipo com características pouco malignas. Além disso, pode provocar a interrupção do ciclo celular nas fases $\mathrm{G} 0 / \mathrm{G} 1$, fazendo com que as células não atinjam a fase $\mathrm{S}$, na qual iria ocorrer a autorreplicação das moléculas de DNA. Nesse contexto, estudos experimentais têm mostrado que em culturas de células da mama, cólon, próstata, pele, pulmão, expostas à forma ativa da vitamina $\mathrm{D}$, sofrem uma notável inibição do crescimento e indução da diferenciação terminal. Logo, quanto mais diferenciadas forem essas células, menor sua capacidade de invasão e metástase. CONCLUSÃO: A vitamina D demonstra efeitos positivos tanto para prevenção quanto para o tratamento do câncer. Conforme tem evidenciado a atuação dessa vitamina nos processos e mecanismos de ação anticancerígenos em pacientes oncológicos e seus efeitos positivos nestes, é evidente que sua suplementação pode se apresentar como um novo alvo na terapia oncológica.

Palavras-chave: Oncologia, vitamina D, anticancerígeno. 


\section{Referências:}

CARVALHO, J.P. Papel da vitamina D na oncogênese e sobre o risco de câncer. In: A importância da vitamina D na saúde da mulher. São Paulo: Federação Brasileira das Associações de Ginecologia e Obstetrícia, 2017.

FELDMAN, D. et al. O papel do vitamina D na redução do risco de câncer e progressão. Nat Rev Cancer, 2014.

SILVA, J. et al. Vitamina D e cancro: dos mecanismos biológicos à utilidade terapêutica. Associação Portuguesa de Nutriçãa. Monte de Caparica, 2017. 


\title{
MECANISMO DE AÇÃO DO ISOTIOCIANATO DE ALILA NA PREVENÇÃO DO CÂNCER DE BEXIGA: UMA REVISÃO DE LITERATURA
}

\author{
Maria Alíssia C. Carvalho ${ }^{1}$; Raniella B. da Silva ${ }^{1}$; Erica Isabel de A. Freire ${ }^{1}$; Heverson \\ D. de Araújo ${ }^{2}$; Ellienai Erika P. de Sousa ${ }^{1}$; Lidiane P. de Albuquerque ${ }^{3}$ \\ ${ }^{1}$ Graduanda em Nutrição, Universidade Federal do Piauí, Teresina, Piauí. \\ ${ }^{2}$ Graduando em Enfermagem, Faculdade integral diferencial - FACID Wyden, \\ Teresina, Piauí. \\ ${ }^{3}$ Docente, Depto de Bioquímica e Farmacologia, Universidade Federal do Piauí, \\ Teresina, Piauí.
}

Autor para correspondência: Maria Alíssia Costa Carvalho / mariaalissia@gmail.com / 86995773993

INTRODUÇÃO: O isotiocianato de alila (ATIC) é uma substância oleosa incolor presente principalmente na semente de mostarda, rábano e wasabi (raiz-forte), relacionado com diversos efeitos benéficos à saúde humana abrangendo elevado potencial antiogiogênico, anti-inflamatório, neuroprotetor e anticarcinogênico. Devido a isso, diversos estudos experimentais têm demonstrado sua aplicabilidade anticancerígena em câncer de bexiga, devido sua excreção ser majoritariamente urinária, sendo exposto por mais tempo a esse órgão. OBETIVO: Analisar o mecanismo de ação anticancerígeno do isotiocianato de alila (ATIC) em câncer de bexiga, a fim de promovê-lo como medida terapêutica. METODOLOGIA: Trata-se de uma revisão narrativa de literatura. O processo de seleção de artigos (em inglês e português) incluiu uma busca no banco de dados Scielo, Pubmed e Google Acadêmico. Priorizaram-se os trabalhos que abordavam os mecanismos anticarcinogênico do ATIC, bem como estudos que demonstrem evidências de suas propriedades benéficas para o câncer de bexiga. Entre os artigos pesquisados e analisados, oito atenderam aos critérios de inclusão (publicações entre 2010 e 2018, textos completos e estreita relação com o tema). RESULTADOS: Estudos demonstraram que o ATIC quando submetido a diferentes linhagens celulares de câncer de bexiga foi possível verificar que a substância produz uma interrupção do ciclo celular em mitose, que ocorre devido à degradação da $\alpha$ e $\beta$-tubulinas, além de induzir apoptose mediada por $\mathrm{Bcl}-2$, citocromo $\mathrm{C}$ e ativação das caspases 9 e 3, mecanismos estes relacionados com a proliferação e desenvolvimento de células malignas. Em outros ensaios verificaram que o uso de ATIC inibiu a proliferação de células de carcinoma de bexiga in vitro, com valor de IC50 de 2,7-3,3 mM, o qual foi associado à parada do ciclo celular na fase G2/M e à apoptose, sendo consideravelmente menos tóxico para células epiteliais normais da bexiga (IC50 de 69,4 mM), efeitos estes que demonstram o potencial anticarcinogênico desse composto. CONCLUSÃO: Com isso, conforme tem sido evidenciado a ação do ATIC sobre o ciclo celular e apoptose de células tumorais é necessário que seja oferecido métodos terapêuticos que ofereçam o uso da substância de maneira eficaz ou que auxiliem no tratamento de pacientes com câncer de bexiga. Além da atuação desse composto para prevenção dessa patologia.

Palavras-chave: Oncologia, câncer de bexiga, anticancerígeno. 


\section{Referências:}

BATISTA, M. S. H. O papel dos fitoquímicos na quimioprevenção do cancro. Monografia (Graduação em Ciências da Nutrição) - Faculdade de Ciências da Nutrição e Alimentação da Universidade do Porto. Porto, 2010.

DIAS, J. V. M. Potencial de formulações para solucionar problemas da administração oral do isotiocianato de alilo (aitc). Monografia (Graduação em Farmácia) - Escola de Farmácia, Universidade Federal de Ouro Preto, Ouro Preto, 2018.

SÁVIO, A. L. V. Efeitos toxicogenéticos e toxicogenômicos do Isotiocianato de Alila (óleo de mostarda) em linhagens celulares de carcinoma de bexiga. Dissertação (mestrado) - Universidade Estadual Paulista Júlio de Mesquita Filho, Faculdade de Medicina de Botucatu, 2014. 


\section{ANÁliSE DE PLANTAS MEDICINAIS COMO POTENTE AGENTE NEOPLÁSICO}

Hyan Ribeiro da Silva ${ }^{1}$ Rayssa Hellen Ferreira Costa ${ }^{1}$; Mateus Henrique de Almeida da Costa $^{\mathbf{1}}$; Carlos Antonio Alves de Macedo Júnior ${ }^{\mathbf{1}}$; José Chagas Pinheiro Neto; Francilene Viera da Silva ${ }^{2}$

${ }^{1}$ Acadêmicos de farmácia pela Faculdade Integral Diferencial - FACIDIWYDEN

${ }^{2}$ Orientadora, Professora da Faculdade Integral Diferencial - FACIDIWYDEN

Autor para correspondência: Hyan Ribeiro da Silva / hyanribeiro16@ outlook.com / 98 987198000

INTRODUÇÃO: O câncer é uma doença que decorre de múltiplos fatores, sendo caracterizado pela maneira desorganizada e incontrolada das células, devido a mutações decorrentes de agentes químicos, físicos e ou biológicos. A quimioterapia é o preferido e mais comum tratamento para o câncer na prática clínica. Porém um aumento do número de pesquisadores em todo o mundo estão se concentrando em medicamentos naturais para encontrar novos medicamentos antitumorais. OBJETIVO: Demonstrar as principais plantas medicinais utilizadas no desenvolvimento de anticancerígenos. MÉTODOS: Foram utilizados 10 artigos publicados entre os anos de 2009 a 2019, em português ou inglês, disponíveis nos bancos de dados da BVS e Medline, através dos seguintes descritores: Plantas medicinais, Oncologia, Anticancerígenos. Foram exclusos artigos disponíveis em outros idiomas que não fossem português e inglês. Após a análise os artigos foram comparados e discutidos de acordo com a literatura. RESULTADOS: O câncer com a proliferação desordena de algumas células que invade órgão e tecidos no corpo humano tem crescido cada vez mais no decorre dos anos. No entanto, algumas pesquisas relata que o uso de plantas utilizadas para desenvolver novos fármacos. Dentre as principais plantas medicinas utilizadas para o desenvolvimento de anticancerígenos e agentes quimioterápicos destaca-se a Taxus brevifolia Nutt. (Taxaceae), Taxus baccata L. (Taxaceae), Catharanthus roseus (L.) G. Don. (Apocynaceae), Camptotheca acuminata Decne. (Cornaceae), Podophyllum peltatum L. (Berberidaceae), Piper tuberculatum Jacq. (Piperaceae) e Capraria biflora L, um dos estudos destacou o uso da Camellia nitidissima (C. nitidissima). Constatou-se tambem o uso da Ganoderma que inclui cerca de 80 espécies de cogumelos, além da Phyllanthus amarus. CONCLUSÃO: Conclui-se que várias plantas já vêm sendo utilizadas para o tratamento de vários tipos de câncer, onde os mesmos apresentam resultados satisfatórios, contudo constata-se que são necessários mais estudos para assegurar a utilização de tais medicamentos desenvolvidos das plantas medicinas ao câncer.

Palavras-chave: Anticancerígenos, Oncologia, Plantas medicinais.

\section{Referências:}

FREIRE, L. H. M. dos S; ALVES, F. Ação de extratos naturais sobre o câncer. Belo Horizonte, MG, v.04, n.08, $\begin{array}{lll}\text { Dez. } & \text { de } & \end{array}$ OLIVEIRA, L.A.R; MACHADO, R.D; RODRIGUES, A.J.L. Levantamento sobre o uso de plantas medicinais com a terapêutica anticâncer por pacientes da Unidade Oncológica 
de Anápolis. Rev. Bras. Pl. Med., Campinas, v.16, n.1, p.3240, 2014.

HOU et al: The antitumor activity screening of chemical constituents from Camellia nitidissima Chi. International Journal of Molecular Medicine 41: 2793-2801, 2018.

LIN, et al. Natural Compounds from Herbs that can Potentially Execute as Autophagy Inducers for Cancer Therapy. Int. J. Mol. Sci. 18, 1412. 2017

VAN, T. N; JENNETTE, A. S; CHRISTOPHER, J. S. Physicochemical Properties, Antioxidant and Cytotoxic Activities of Crude Extracts and Fractions from Phyllanthus amarus. Medicines, 4, 42. 2017 


\title{
$1^{\circ}$ CURSO MULTIPROFISSIONAL EM ONCOLOGIA: EDUCAÇÃO EM SAÚDE PARA CAPACITAÇÃO PROFISSIONAL
}

\author{
Gabriela Ribeiro Moreira1; David de Sousa Carvalho ${ }^{1}$; Renata Kelly dos Santos e Silva ${ }^{1}$, \\ Ivanildo Gonçalves Costa Júnior ${ }^{1}$; Isabel Mariana Ferreira da Silva ${ }^{1}$; João Marcelo de \\ Castro e Sousa ${ }^{2}$ \\ ${ }^{1}$ Discentes, Universidade Federal do Piauí - UFPI, Picos, Piauí, Brasil; \\ ${ }^{2}$ Docente (Programa de Pós-Graduação em Ciências Farmacêuticas e Biotecnologia), \\ Universidade Federal do Piauí - UFPI, Picos, Piauí, Brasil;
}

Autor para correspondência: Gabriela Ribeiro Moreira / grmoreira19@gmail.com / 86 988520848

INTRODUÇÃO: Segundo o Instituto Nacional de Câncer José Alencar Gomes da Silva (INCA), entre os anos de 2018 e 2019 ocorrerão cerca de 600 mil novos casos de câncer no Brasil. Atualmente, o câncer é um problema de saúde pública, sendo a segunda maior causa de mortes no mundo. Pelo menos um terço dos casos novos de câncer que ocorre anualmente poderia ser prevenido. Uma das maneiras mais eficazes de prevenir o câncer, é o conhecimento. OBJETIVOS: Realizar a capacitação e atualização de estudantes e profissionais de saúde de Picos e macrorregião através de uma abordagem multidisciplinar em oncologia. MÉTODOS: Trabalho descritivo, tipo relato de experiência, que trata sobre a realização de um Curso Multidisciplinar em Oncologia realizado durante 06 sábados entre maio e junho de 2019. O evento foi organizado pela Liga Acadêmica de Oncologia e Histologia (LAOH) e pelo Núcleo de Pesquisa em Genética Toxicológica e Avaliação Antitumoral (Toxgen). As aulas foram ministradas por médicos oncologistas, nutricionistas, biomédico, farmacêutico e uma enfermeira, e trataram dos temas: genética oncológica e ciclo celular; biomarcadores inflamatórios; farmacologia e cirurgia para o tratamento oncológico; nutrigenômica; e cuidados de enfermagem ao paciente oncológico paliativo. Os conteúdos foram ministrados utilizando recursos que instigassem a participação do público, incluindo a resolução de casos clínicos. RESULTADOS: Participaram do curso acadêmicos de enfermagem, medicina, nutrição, biologia professores do ensino superior e profissionais de saúde. A partir do feedback dos participantes, o evento trouxe informações de extrema relevância para compreender melhor a dinâmica do câncer e prestar uma assistência adequada ao paciente oncológico. A vinda de palestrantes de outras regiões do Brasil para darem aula permitiu um enriquecimento através da partilha transcultural de saberes científicos especialmente dentre as áreas de pesquisa e clínica. CONCLUSÃO: O evento conferiu aos participantes, capacitação para lidar com o paciente oncológico a partir de uma abordagem multidisciplinar, compreendendo o complexo englobado, por exemplo, entre a dieta prescrita pelo nutricionista e executada pela equipe de enfermagem, interação com a farmacologia do tratamento e os biomarcadores inflamatórios que sinalizam o sucesso da terapia escolhida. A atividade propiciou notável contribuição para os acadêmicos da área da saúde a partir de temas não trabalhados durante a graduação, forneceu empoderamento dos profissionais de saúde e abriu caminho para novas pesquisas em oncologia a partir da atualização de conteúdo fornecida.

Palavras-chave: Educação em Saúde, Oncologia, Capacitação Profissional. 


\section{Referências:}

MINISTÉRIO DA SAÚDE. Instituto Nacional de Câncer José Alencar Gomes da Silva (INCA). ABC do câncer. Rio de Janeiro, RJ 2017.

MINISTÉRIO DA SAÚDE. Instituto nacional de câncer josé alencar gomes da silva. Estimativa 2016: Incidência de Câncer no Brasil. Rio de Janeiro, 2016. Disponível em: <http://www.inca.gov.br/wcm/dncc/2015/index.asp>. Acesso em: 21 jun. 2019.

OPAS. Organização Pan Americana de Saúde. Folha Informativa - Câncer. 2018. Disponível em: $<$ https://www.paho.org/bra/index.php?option=com_content\&view=article\&id=5588:fol ha-informativa-ca ncer\&Itemid=1094>. Acesso em: 21 jun. 2019. 